Aus der Abteilung Neuropathologie

(Prof. Dr. med. W. Brück)

im Zentrum Pathologie und Rechtsmedizin

der Medizinischen Fakultät der Universität Göttingen

\title{
Charakterisierung der myopathologischen \\ Veränderungen bei der Kamptokormie des Morbus Parkinson
}

\author{
INAUGURAL - DISSERTATION \\ zur Erlangung des Doktorgrades \\ der Medizinischen Fakultät \\ der Georg-August-Universität zu Göttingen \\ vorgelegt von \\ Arne Wrede \\ aus \\ Göttingen
}

Göttingen 2011 
Dekan: Prof. Dr. med. C. Frömmel

I. Berichterstatter: Priv.-Doz. Dr. med. W. J. Schulz-Schaeffer

II. Berichterstatter/in: Priv.-Doz. Dr. med. J. Schmidt

III. Berichterstatter/in: Prof. Dr. med., Dr. rer. nat. T. Crozier

Tag der mündlichen Prüfung: 29. Februar 2012 


\section{Inhaltsverzeichnis}

$\begin{array}{ll}\text { 1. Einleitung } & 01\end{array}$

$\begin{array}{ll}\text { 1.1 Neurodegenerative Erkrankungen } & 01\end{array}$

1.2 Proteinaggregation als Prinzip einer Krankheit 02

$\begin{array}{ll}1.3 \text { Morbus Parkinson } & 03\end{array}$

1.3.1 Epidemiologie des M. Parkinson 05

1.3.2 Name der Erkrankung 06

1.3.3 Klinik des M. Parkinson 06

$\begin{array}{ll}\text { 1.3.4 Klinische Diagnosekriterien des M. Parkinson } & 07\end{array}$

$\begin{array}{ll}\text { 1.3.5 Zur Pathophysiologie des M. Parkinson } & 09\end{array}$

1.3.6 These: Synaptische $\alpha$-Synukleinaggregate führen zur Neurodegeneration 11

1.3.7 Synuklein als neuronales Protein 12

$\begin{array}{ll}\text { 1.3.8 Eigenschaften des Proteins } \alpha \text {-Synuklein } & 12\end{array}$

1.4 Kamptokormie 13

$\begin{array}{ll}\text { 1.4.1 Geschichte des Begriffs } & 13\end{array}$

1.4.2 Inzidenz, Prävalenz und Assoziation mit anderen Erkrankungen 14

$\begin{array}{ll}1.4 .3 \text { Klinik } & 18\end{array}$

1.4.4 Beurteilung und Bewertung einer Kamptokormie 19

$\begin{array}{ll}\text { 1.4.5 Pathophysiologie } & 20\end{array}$

$\begin{array}{ll}\text { 1.4.6 Risikofaktoren } & 21\end{array}$

$\begin{array}{ll}\text { 1.4.7 Therapie } & 21\end{array}$

1.4.8 Morphologische Beschreibungen 23

1.5 Zielsetzung dieser Arbeit 23

2. Material und Methoden 25

2.1 Muskelbiopsien 25

$\begin{array}{ll}2.2 \text { Kontrollen } & 27\end{array}$

2.3 Enzymfärbungen / Histochemische Färbungen 30

2.4 Allgemeine Rezepte 35

2.5 Immunhistochemie 36

2.6 Elektronenmikroskopie $\quad 40$

2.7 PET-blot 42

2.7.1 Einleitung zur Methode $\quad 42$

2.7.2 Protokoll PET-blot 42 
2.7.3 PET-blot zum Demenzstaging 43

2.7.4 PET-blot an Muskelgewebe zur Suche nach aggregiertem $\alpha$-Synuklein $\quad 45$

2.8 Tissueblot als Zwischenstufe zwischen PET-blot und Histoblot 45

2.9 Die Auswertung der Proben 46

2.9.1 Enzymfärbungen 46

2.9.2 Wert der einzelnen histochemischen Färbung 47

2.9.3 Semidünnschnittpräparate 53

2.9.4 Elektronenmikroskopie $\quad 54$

3. Ergebnisse 55

3.1 Lichtmikroskopischer Befund der Kamptokormiefälle 55

3.2 Lichtmikroskopischer Befund der Kontrollfälle $\quad 61$

3.3 Immunhistochemischer Befund der Kamptokormiefälle 67

3.4 Immunhistochemischer Befund der Kontrollfälle 70

3.5 Befunde der Semidünnschnittpräparate $\quad 71$

$\begin{array}{ll}\text { 3.5.1 Befunde der Kamptokormiefälle } & 71\end{array}$

$\begin{array}{ll}\text { 3.5.2 Befunde der Kontrollfälle } & 72\end{array}$

$\begin{array}{ll}3.6 \text { Befunde der Elektronenmikroskopie } & 73\end{array}$

3.6.1 Befunde der Kamptokormiefälle 73

$\begin{array}{ll}\text { 3.6.2 Befunde der Kontrollfälle } & 74\end{array}$

3.7 PET-blot- und Tissue-blot-Analyse des Gewebes 75

3.7.1 Untersuchungen am Paraffinmaterial 75

3.7.2 Untersuchungen am Gefriermaterial mittels „Tissueblot“-Technik 75

3.8 Neurodegenerationsstaging mittels PET-blot 78

4. Diskussion $\quad 80$

4.1 Eignung postmortaler Gewebeproben als Kontrollgewebe $\quad 80$

4.2 Die Befunde stehen in einer Reihe mit denen einiger anderer Gruppen $\quad 80$

4.3 Andere Gruppen wiederum kommen zu anderer Einschätzung des Bildes $\quad 81$

4.4 Eine immer wiederkehrende Diskussion: Was ist die Kamptokormie? 81

4.5 Kamptokormie findet sich als Spätsymptom des M. Parkinson 83

4.6 Entspricht das Bild einer „Exercise myopathy“? 83

4.7 Helfen die Therapieansätze bei der Einordnung des Krankheitsbildes? 84

4.8 Welche Rückschlüsse erlauben die neuropathologischen Befunde? 84

4.8.1 Vermehrte Aktivität der sauren Phosphatase $\quad 84$

4.8.2 Strukturläsionen - nicht spezifisch, aber recht charakteristisch 85 
4.8.3 Prädominanz des Fasertyps I durch Atrophie des Fasertyps II 85

4.8.4 Schwache Zeichnung der Fasern für Glycogen und Fett 87

4.9 Kamptokormie - Eine Mitochondriopathie der paraspinalen Muskulatur? $\quad 88$

4.10 Die Frage nach der entzündlichen Genese der Kamptokormie 89

4.11 Minderversorgung mit Blut - Ein möglicher Auslöser? 89

4.12 Kamptokormie - Erkrankung oder Symptom? 90

4.13 Kamptokormie - (K)ein Fall für $\alpha$-Synuklein? 91

5. Zusammenfassung 93

6. Tabellenverzeichnis 99

7. Abbildungsverzeichnis 99

8. Literaturverzeichnis 100 


\section{Abkürzungsverzeichnis:}

AD Alzheimer`s Disease; M. Alzheimer

AEC 3-Amino-9-Ethylcarbazol (Chromogen)

ALS Amyotrophe Lateralsklerose

AML Akute myeloische Leukämie

AMP Adenosin-5-monophosphat-Dinatriumsalz

AP Alkalische Phosphatase

Aqua bidest. Doppelt destilliertes Wasser

Aqua dest. Aqua destillata; destilliertes Wasser

ARDS Acute / Adult respiratory distress syndrome; akutes progressives

Lungenversagen

ATP Adenosintriphosphat

AWMF Arbeitsgemeinschaft der Wissenschaftlichen Medizinischen Fachgesellschaften

BP „Backpack“-Therapie

BCIP Brom-4-chlor-3-indoxylphosphat

BCSG1 Breast cancer specific gene 1

Ca. Carcinoma; Karzinom

CAA Cerebral amyloid angiopathy; zerebrale Amyloidangiopathie

CBD Corticobasal degeneration; Kortikobasale Degeneration

CD Cluster of Differentiation; Systematik der Antikörpererfassung, orientiert an Oberflächenmarkern der Zellen

CERAD Consortium to Establish a Registry for Alzheimer's Disease

CIDP Chronisch inflammatorische demyelinisierende Polyneuropathie

CJK Creutzfeldt-Jakob-Krankheit; im Englischen CJD = Creutzfeldt-Jakob-Disease

COX Cytochrom-C-Oxidase

CT Computertomographie

DAB Diaminobenzidin (Chromogen)

DBS Deep brain stimulation; Tiefenhirnstimulation

Dh. "Dropped head"

DLB Dementia with lewy bodies; Demenz mit Lewy-Körperchen

DM Dystrophia myotonica; Myotone Dystrophie (Curshman Steinert)

DMF Dimethylformamid

E. Einwohner 
EMG Elektromyogramm

EvG Elastica van Gieson (Färbung)

FHL-1 Four and a half LIM domains protein; Protein, das bei bestimmten

Muskeldystrophien betroffen ist

FSHD Fazioskapulohumerale Dystrophie

GdnSCN Guanidinthiocyanat

GPi Globus pallidus internus

GvHD Graft versus host disease; Transplantat-Wirt-Reaktion

HE Hämatoxylin-Eosin (Färbung)

HIER Heat induced epitope retrieval; hitzeinduzierte Epitopdemaskierung

HOPS Hirnorganisches Psychosyndrom

HPF High power field; Gesichtsfeld bei 400-facher Vergrößerung

HRP Horseradishperoxidase; Meerrettichperoxidase

IBM Inclusion body myositis; Einschlusskörpermyositis

IVIg Intravenöse Gabe von Immunglobulinen

Kk. Kamptokormie

LAMP Lysosome associated membrane protein; Lysosomales Membranprotein

LB Lewy body; Lewy-Körperchen

LGMD Limb girdle muscular dystrophy; Gliedergürteldystrophie

LIM Strukturdomäne in Proteinen (Akronym nach den ersten drei Proteinen, bei denen eine solche Domäne beschrieben wurde)

LMNA Lamin A/C

LPF $\quad$ Low power field; Gesichtsfeld bei100-facher Vergrößerung

Lsg. $\quad$ Lösung

M. Morbus

M. Musculus

MAD Myoadenylatdeaminase

MAG Menadione-linked alpha-Glycerophosphatase

MFM Myofibrilläre Myopathie

MHC-I Major histocompatibility complex I

MI Myokardinfarkt

mk monoklonal

Mm. $\quad$ Musculi; Muskeln

MPF Medium power field; Gesichtsfeld bei 200-facher Vergrößerung 
MRT; MRI Magnetresonanztomografie; Kernspintomografie

MSA Multisystematrophie

MW in Laborprotokollen: Mikrowelle; statistisch: Mittelwert

NAC-P Non-A beta component of AD amyloid precursor; Vorläuferprotein der nichtBetaamyloidkomponente des M. Alzheimer; später $\alpha$-Synuklein

NADH Nicotinamid-Adenin-Dinucleotid-Dehydrogenase

NADH-TR Nicotinamid-Adenin-Dinucleotid-Dehydrogenase Tetrazoliumreduktase

n.b. nicht beurteilbar

NB Normalbefund

NBT Nitroblautetrazoliumchlorid

NCL Neuronal ceroid lipofuscinoses, Neuronale Zeroidlipofuszinose

NclST Nucleus subthalamicus

NMJ Neuromuskuläre Junktion

NTM Puffer aus Natriumchlorid, Tris-HCl und Magnesiumchlorid

n.v. nicht verfügbar

ORO Oil red O; Färbung für Neutralfette, Ölrotfärbung

PAS Periodic acid Schiff; Perjodsäure Schiffbase, Glycogenanfärbung

PBS Phosphate buffered saline; Phosphatpuffer

PD Parkinson's disease, Parkinsonerkrankung

PDD Parkinson's disease with dementia; Parkinsonerkrankungen mit

Demenzkomponente

PET Paraffin embedded tissue; in Paraffin eingebettetes Gewebe

PF Power field; Gesichtsfeld (in der Mikroskopie)

PFA Paraformaldehyd

pk polyklonal

PK Proteinase K

PSP Progressive supranuclear palsy; Progressive supranukleäre Blickparese

RRF Ragged-red fibres; ,ragged red“-Fasern

RT Raumtemperatur

SCA Spinozerebelläre Ataxie

SDH Succinatdehydrogenase

SEPN1 Gen des Selenoprotein N

SERCA Sarcoendoplasmic calcium ATPase; Sarkoendoplasmatische Retikulum-

Kalzium-ATPase 
SM Skelettmuskulatur

SP Saure Phosphatase

SSPE Subakut sklerosierende Panenzephalitis

SUMO Short ubiquitin-like modifier

TBS Tris buffered saline; Trispuffer

TBST Trispuffer mit Zusatz von Tween 20

TEM Transmissionselektronenmikroskop

TIA Transitorisch ischämische Attacke

TR Tumorresektion

UPDRS Unified Parkinson disease rating scale; Schema zur klinischen Erfassung des Parkinsonismus

XMPMA X-linked myopathy with postural muscle atrophy; spezielle Form der Myopathie

ZASP Z-band alternatively spliced PDZ-motif protein; Z-Banden-assoziiertes Protein, akkumuliert bei einer Form der myofibrillären Myopathie

ZNS Zentrales Nervensystem

ZNT9 Zinktransporter 9; Protein 



\section{Einleitung}

\subsection{Neurodegenerative Erkrankungen}

Neurodegenerative Erkrankungen sind Erkrankungen des zentralen Nervensystems, bei denen es zu einem zunehmenden Verlust der normalerweise vorhandenen Hirnleistungen kommt. Dem zugrunde liegt eine Schädigung von Nervenzellen und / oder eine Schädigung der Stützzellen (Astrozyten, Oligodendrozyten; möglicherweise auch Mikrogliazellen; Ependymzellen werden in diesem Zusammenhang bisher eher theoretisch diskutiert (Danik et al. 1999)) mit daraus resultierender eingeschränkter Funktion der Nervenzellen. Diese Erkrankungen betreffen in der Regel zumindest primär nicht alle Nervenzellen, sondern eine Selektion von Nervenzellen (Sandmann-Keil und Braak 2005). Daraus ergibt sich eine Symptomatik, die sich aus der normalen Funktion der primär betroffenen Strukturen herleiten lässt. So sind beispielsweise beim Morbus Alzheimer primär die Neurone des Hippokampus betroffen und es resultiert eine sukzessiv zunehmende Störung der mnestischen Funktionen. Bei der amyotrophen Lateralsklerose (ALS) sind demgegenüber die Motorneurone des motorischen Kortex bzw. der Vorderhörner im Rückenmark betroffen, so dass es zu einem zunehmenden Ausfall der Innervation der Skelettmuskulatur kommt. Beim Morbus Parkinson sind hingegen primär die Neurone der Substantia nigra des Mittelhirns betroffen. In der Folge kommt es zu einer hypertonen hypokinetischen Bewegungseinschränkung, die meist von einer vegetativen Störung begleitet wird. Viele neurodegenerative Erkrankungen zeigen in ihrem Verlauf schließlich eine mehr oder minder weitgehende Ausbreitung in weitere Strukturen oder Funktionssysteme, sodass teilweise in späten Stadien zusätzliche Symptome hinzukommen. Beim M. Parkinson finden sich zum Beispiel Fälle, die im späten Stadium eine Demenz entwickeln, die sich nicht durch die Schädigung des Mittelhirns erklären lässt. Morphologisch kennzeichnen sich neurodegenerative Erkrankungen häufig durch charakteristische Einschlüsse in Nervenzellen der betroffenen Region (Tangles beim M. Alzheimer, Lewy-Körperchen beim M. Parkinson, Bunina-Körperchen bei der ALS, PickBodies beim M. Pick) oder eine Vakuolisierung der Neurone, wie bei der Creutzfeldt-JakobKrankheit (CJK). Nicht selten finden sich in den betroffenen Arealen auch extrazelluläre Ablagerungen, wie Plaques beim M. Alzheimer oder bestimmten Formen der CJK. Mit Fortschreiten der jeweiligen Erkrankung findet sich ein zunehmender Verlust der Nervenzellen in den betroffenen Arealen, der von einer reaktiven Schwellung der Astrozyten, einer so genannten Gliose, begleitet wird. Häufig ist dieser Nervenzellverlust aber erst in den späten Stadien der Erkrankung histologisch nachvollziehbar, sodass wahrscheinlich nicht der 
Zelltod von Neuronen primär für die Entstehung der Symptomatik verantwortlich, sondern eher Ausdruck des Abbaus bei Funktionsverlust der betroffenen Zellen ist. Zu denken ist beispielsweise an die Schädigung der Synapsen, einen gestörter Substratmetabolismus oder die Behinderung des axonalen Transports, die einem Funktionsverlust der betroffenen Nervenzellen entspricht. Die daraus resultierende Signalverarmung oder die Behinderung der physiologischen Zellabläufe führt dann in der Konsequenz zum Zelltod der betroffenen Nervenzellen. Vielen neurodegenerativen Erkrankungen liegt eine Proteinaggregation zugrunde oder kann in diesem Zusammenhang nachgewiesen werden. Diese ist bei entsprechenden Nachweismethoden geeignet, um frühe Stadien der Erkrankung bereits nachzuweisen (Methoden sind hierbei auf Antigen-Antikörperreaktion basierende Nachweismethoden, wie die Immunhistochemie (Braak et al. 2006a; Alafuzoff et al. 2009), der PET-blot (Schulz-Schaeffer et al. 2000) und der Western-blot (z.B. Thomzig et al. 2007).

\subsection{Proteinaggregation als Prinzip einer Erkrankung}

Proteine sind neben Fetten und Kohlenstoffverbindungen entscheidende Komponenten von Organismen. Man findet sie als lösliche Komponenten in Zellen bzw. flüssigen Kompartimenten eines Organismus oder aber als membrangebundene Strukturbestandteile. Dabei können Proteine in unterschiedlicher Form als einzelne Moleküle oder in Komplexen aus mehreren Proteinen vorliegen. Es kann sich dabei um Komplexe eines Proteins oder mehrerer unterschiedlicher Proteine handeln. Wenn gleiche Proteine sich zusammenlagern, spricht man je nach Größe der Gebilde von Oligomeren, Polymeren oder Aggregaten. Viele Faktoren bestimmen das Vorkommen dieser Zustandsformen im physiologischen oder im pathologischen Geschehen. Die Ladung der Proteine, ihre Struktur, Van-der-Waals-Kräfte, Disulfidbrücken, Glycosylierung, Phosphatierung, Membrananker, pH-Wert der Umgebung, Konzentrationen, Konzentrationsgradienten zwischen Kompartimenten und vieles mehr beeinflussen diese Zustandsformen. Proteinaggregation findet sich offensichtlich auch unter Bedingungen, die als nicht krankheitsassoziiert angesehen werden (z.B. Hiranokörperchen). Es könnte sich um einen Mechanismus handeln, mit dem anfallende Proteine, die nicht (mehr) benötigt werden und nicht (sofort) „,recycled“ werden können, in eine Form gebracht werden, in der sie möglichst wenig negative Effekte haben. In bestimmten Fällen, wie beim Prionprotein handelt es sich aber offensichtlich um das primäre Problem der Erkrankung, da die Einbringung der pathologischen Proteinform (veränderte Sekundärstruktur, $\beta$ Faltblattstrukturen ersetzen Teile der $\alpha$-helikalen Strukturen) dazu führt, dass die 
physiologische Form des Proteins im betroffenen Organismus in die pathologische überführt wird und aggregiert.

Zelleigene Mechanismen, die der Proteinaggregation entgegen wirken, sind die normalen Synthese- und Abbauvorgänge mit ihrer jeweiligen Steuerung. Somit wird die Proteinsynthese in der Regel über Signalkaskaden gesteuert, die entsprechend dem jeweiligen Bedarf die Biosynthese starten, heraufregulieren, drosseln oder unterbinden. Die Proteindegradation in der Zelle erfolgt beispielsweise über den Ubiquitin-Proteasom Pathway. Die abzubauenden Proteine werden mit Ubiquitin, SUMO-1 oder anderen Proteinen verbunden (markiert) und dann dem Abbau zugeführt (Cuervo et al. 2010; Wilkinson und Henley 2010). Proteinaggregate bieten in der Diagnostik die Möglichkeit, sie als kompakte Strukturen bereits in der HE-Färbung zu erkennen. Sie lassen sich außerdem mit bestimmten Farbstoffen nachweisen, die sich in diese Aggregate einlagern, und sich aus diesen sehr viel schlechter als aus dem normalen Gewebe wieder auswaschen lassen (Kongorot, Thioflavin T oder S, Kresylviolett), wobei der methodische Hintergrund hierzu in Übersichtsarbeiten u.a. von Hawe et al. (Hawe et al. 2008) zu finden ist. Aus dem üblichen Abbauweg folgt, dass Aggregate häufig ubiquitinyliert sind und sich dann durch gegen Ubiquitin gerichtete Antikörper nachweisen lassen. Somit stellt die immunhistochemische Detektion mittels Ubiquitin häufig gewissermaßen eine Suchreaktion dar. In der Immunhistochemie und im PET-blot-Verfahren lassen sich aggregierte Proteine von nicht aggregierten Formen durch einen enzymatischen Verdau unterscheiden (in der Regel Verdau durch eine Protease). Hierbei werden beispielsweise Verdauschritte mit Proteinase K, Protease, Trypsin, Collagenase, Thermolysin, Papain oder Pepsin angewendet. Lassen sich nach einem solchen Verdauschritt noch Strukturen mit Hilfe des jeweiligen gegen das gesuchte Protein gerichteten Antikörpers nachweisen, handelt es sich nach derzeitigem Verständnis um aggregierte Formen des Proteins. Eine gewisse Schwierigkeit ergibt sich an dieser Stelle daraus, dass jeweils zu definieren ist, wie lange und mit welcher Stärke ein solcher Verdau stattzufinden hat. Auch die Definition der physikalisch-chemischen Bedingungen, unter denen der Verdau ausgeführt wird, spielt eine wichtige Rolle (Wemheuer et al. 2009).

\subsection{Morbus Parkinson}

Morbus Parkinson ist eine neurodegenerative Erkrankung, die in der Literatur vielfach unter dem Oberbegriff einer „Synucleinopathie“ geführt wird. Bei diesem Begriff handelt es sich um einen historisch begründeten Begriff. Dieser Oberbegriff ist sicherlich insofern problematisch, als hier ein einzelnes Protein als pathologisches Agens und somit als 
Namensgeber einer Erkrankungsgruppe definiert wird, ohne dass seine Rolle bisher wirklich schlüssig geklärt wäre. Besser wäre sicherlich, von einer mit „, $\alpha$-Synuklein assoziierten Proteinaggregationserkrankung“ zu sprechen. Eine solche Namensgebung verdeutlicht einerseits, dass dem Protein $\alpha$-Synuklein bei Erkrankungen dieser Gruppe eine besondere Rolle zuteil wird. Andererseits wird klar, dass der zugrunde liegende Pathomechanismus eine Proteinaggregation ist. Diese Proteinaggregation wird derzeit mit dem Nachweis von $\alpha$ Synuklein detektiert. Daraus folgt aber nicht zwangläufig, dass $\alpha$-Synuklein auch das pathogenetisch entscheidende Protein bzw. der auslösende Faktor bei den Erkrankungen ist. Historisch gesehen wurde als mit dem Morbus Parkinson assoziiert eine Ablagerung von Lewy-Körperchen in den Neuronen der Substantia nigra des Mittelhirns als zentraler Befund der pathologisch anatomischen Untersuchungen erkannt (Lewy 1912 und 1913). Dieser wird begleitet von einem fortschreitenden Verlust der Neurone der Substantia nigra. Dieser Verlust führt schließlich zur bereits makroskopisch erkennbaren Abblassung der anatomischen Struktur, im Endstadium auch zur völligen Depigmentierung der Substantia nigra. Im Rahmen der in den 1940er Jahren aufkommenden, verstärkt ab den 1980er Jahren und bis heute weiterentwickelten Techniken des Nachweises von Epitopen mit Hilfe von Antikörpern (Coons et al. 1950; Takeda et al. 1998), insbesondere mithilfe der Immunhistochemie, wurde a-Synuklein als Bestandteil der Lewy-Körperchen 1997 von Spillantini et al. (Spillantini et al. 1997) nachgewiesen und fortan für die Diagnostik genutzt. In die Gruppe der mit $\alpha$-Synuklein assoziierten Erkrankungen ordnet man derzeit neben dem Morbus Parkinson auch die Demenz mit Lewy-Körperchen (Dementia with Lewy Bodies, DLB) und die Multi-System-Atrophie (MSA) ein (Spillantini et al. 1998a; Spillantini et al. 1998b). Eine Besonderheit stellt die DLB dar, die von einigen Autoren als Sonderform eines M. Parkinson angesehen wird. Gemäß den Kriterien von McKeith (McKeith 2006) tritt bei der DLB eine Demenz als führendes Symptom früh in der Erkrankung auf und schreitet damit dem Parkinsonismus voraus. Ein Überblick zum Thema der mit Ablagerungen von $\alpha$-Synuklein verbundenen Erkrankungen, die klinisch ein Parkinsonbild präsentieren, sowie ein neuropathologisches Staging werden von Braak et al. präsentiert; (Braak et al. 2006a und b). Wichtig ist überdies, dass sich eine teilweise nennenswerte Ablagerung aggregierten $\alpha$-Synukleins auch im Rahmen anderer neurodegenerativer Erkrankungen, wie dem M. Alzheimer, nachweisen lässt. Dieser Umstand kann in einzelnen Fällen zu Schwierigkeiten bei der neuropathologischen Einordnung der Befunde und der abschließenden Diagnosefindung führen (Hansen et al. 1990). 


\subsubsection{Epidemiologie des Morbus Parkinson}

Morbus Parkinson ist eine der häufigsten neurodegenerativen Erkrankungen mit weltweitem Auftreten. Die Prävalenz beträgt weltweit etwa $0,3 \%$ der Gesamtbevölkerung, aber bereits 3\% in der Gruppe der über 65 jährigen Einwohner (Lang und Lozano 1998). Unter den betroffenen Patienten finden sich 5 bis 10 \% Personen, die einen Beginn der Symptome vor dem 40. Lebensjahr zeigen und daher als ,young onset Parkinson's patients“ bezeichnet werden (Lang und Lozano 1998). Bezogen auf ethnische Gruppen findet sich eine Bevorzugung der weißen Bevölkerung, wobei Afrikaner und Asiaten seltener betroffen sind (Lang und Lozano 1998). Je nach Studie werden unterschiedliche Daten referiert. Es finden sich in der Literatur Angaben, wonach sich die höchste Prävalenz innerhalb der weißen (100600/100.000E.; Errea et al. 1999), eine mittlere Prävalenz in der asiatischen (146/100.000 E.; Yamawaki et al. 2009) und die niedrigste Prävalenz in der schwarzen Bevölkerung findet (67/100.000 E.). Als besonders hervorstechend ist Australien anzusehen, wo die Prävalenz mit bis zu 414/100.000 E. beschrieben wird (McCann et al. 1998). Die zur asiatischen Bevölkerung gemachten Aussagen beziehen sich häufig auf japanische Studien, die mittlerweile eine deutlich zunehmende Prävalenz zeigen können (Yamawaki et al. 2009). Dass diese Unterschiede nicht allein in der ethnischen Abstammung begründet sind, lässt sich dadurch vermuten, dass die Prävalenz in der schwarzen Bevölkerung in den USA bei 105/100.000 E. und somit deutlich höher als in Afrika liegt. Außerdem wird berichtet, dass sich in einem untersuchten Kollektiv der nigerianischen Bevölkerung eine gleiche Zahl von Fällen mit Lewykörperpathologie fand, wie in der westlichen Bevölkerung (Lang und Lozano 1998). Bezüglich der Inzidenz finden sich für die Welt Angaben von 16-19/100.000 E. / Jahr (Twelves et al. 2003). Nur in Italien finden sich geringere Zahlen mit etwa 8,6 / 100.000 E. / Jahr (Twelves et al. 2003), wobei dieser Unterschied von den Autoren der Studie mit Einschränkungen versehen wird. Die Bedingungen der italienischen Studie und die angewandten Kriterien werden als mögliche Fehlerpunkte benannt. Das Maximum der Inzidenz wird in der Regel in der Altersgruppe zwischen 70 und 79 Jahren angegeben (Twelves et al. 2003). Hierbei wird diskutiert, dass sich Hinweise für ein Unterschätzen der Zahlen in der noch älteren Bevölkerung finden, die mit zunehmenden Schwierigkeiten bei der Patientenuntersuchung erklärt werden könnten. Diskutiert und häufig beschrieben wird eine leichte Bevorzugung des männlichen Geschlechts (Verhältnis $\mathrm{M}: \mathrm{W}=1,5-2: 1$ ), wobei in sehr großen Studien bisweilen keine Beeinflussung durch das Geschlecht der Patienten gefunden wird (Twelves et al. 2003). Fasst man diese je nach Studie variablen Daten zusammen, erscheint eine Prävalenz von 100-600 / 100.000 E. wahrscheinlich. Die Inzidenz kann auf 
grob 10 bis 20 / 100.000 E. / Jahr geschätzt werden. Wichtig erscheinen die Aspekte, dass die Erkrankungswahrscheinlichkeit mit zunehmendem Alter deutlich steigt und es offensichtlich eine Umweltkomponente gibt.

\subsubsection{Name der Erkrankung}

In der Literatur findet sich die Erstbeschreibung 1817 durch James Parkinson in seinem „Essay on the Shaking Palsy“ (Parkinson 2002), sodass er heute namensgebend für die Erkrankung ist. Als Synonyme finden sich mitunter Paralysis agitans, Schüttellähme, idiopathischer Parkinsonismus, Parkinsonerkrankung vom Lewykörpertyp oder Lewykörperkrankheit des Hirnstamms. In der englischsprachigen Literatur wird von „Parkinson’s disease“ oder „Shaking palsy“ gesprochen.

\subsubsection{Klinik des Morbus Parkinson}

Die Klinik des Morbus Parkinson ist von der klassischen Trias Rigor, Tremor und Akinesie gekennzeichnet. Hinzu kommt vielfach eine Haltungsstörung. James Parkinson (1817) beschreibt einen typischerweise meist sehr schleichenden Beginn. Dieser ist gekennzeichnet von einer leichten allgemeinen Kraftlosigkeit sowie einem leichten regionalen Tremor, der oft eine Hand, seltener den Kopf betrifft. Mit dem Fortschreiten der Erkrankung über Monate und Jahre nehmen der Tremor zu und Kraft wie Geschicklichkeit deutlich ab. Auch sind später zunehmend die Beine betroffen, so dass Stürze zunehmend auftreten. Mit Fortschreiten der Erkrankung werden insbesondere das Schreiben und intendierte Bewegungen zu einer immer schwierigeren Herausforderung, da hierbei der zunehmende Tremor interferiert. Späterhin wird auch das Essen und Trinken zur schwierigen Aufgabe. Durch vermehrte Talgproduktion und die verminderte Mimik (Hypomimie) entsteht der Aspekt des so genannten Salbengesichts. Neben Einschränkungen durch die gestörte Motorik treten zunehmend auch vegetative Störungen auf. Die gastrointestinale Peristaltik ist vermindert und somit die Defäkation erschwert. Zusätzlich findet sich immer wieder eine vermehrte Salivation. Das Gangbild der Patienten wird zunehmend kleinschrittig und tippelig. Es besteht die Tendenz zum Zehenspitzengang („,Tiptoeing“). Häufig ist in der Folge eine Hilfsmaßnahme, wie ein Gehstock, nötig. Im Spätstadium ist der Körper meist gebeugt und der Rigor ist sehr schmerzhaft. Zunehmend tritt ein Verlust der Harn- und Stuhlkontinenz auf. Die immer weiter zunehmende Muskelschwäche und die mangelnde Kontrolle derselben führen zu Schwierigkeiten beim Kauen und Schlucken. Auch die mimische Muskulatur erschlafft zunehmend. Dadurch (mit-) bedingt rinnen häufig Speichel und Nahrungsanteile aus dem 
Mund der Patienten. In Illustrationen der Erkrankung findet sich daher häufig eine stehende Person mit gesenktem Kopf bei deutlich vorgeneigtem Oberkörper (ähnlich dem Aspekt bei starker Kyphose) und leicht in Hüften und Knien angewinkelten Beinen.

Interessanterweise beschreibt James Parkinson bereits eine Vorwärtsneigung des Oberkörpers bei fortschreitender Erkrankung, was als möglicher Ausdruck einer Kamptokormie diskutiert werden kann. Demgegenüber sind Verstand und Erinnerungsvermögen weitgehend unbeeinträchtigt. Man weiß heute allerdings auch, dass es Formen der Parkinsonerkrankung mit Demenzkomponente gibt, die in der Literatur als PDD abgekürzt und in ihrer differentialdiagnostischen Relevanz u.a. von McKeith (2006) dargestellt werden.

\subsubsection{Klinische Diagnosekriterien des M. Parkinson}

Bei Auftreten von entsprechenden Symptomen muss letztlich beachtet werden, dass es sich primär um eine Parkinsonsymptomatik handelt, die weiter abgeklärt werden muss. Ziel dabei ist die Abgrenzung des M. Parkinson von einem sekundären Parkinsonismus (Tolosa et al. 2006).

Klinisch werden die nachfolgend beschriebenen Kriterien in der abgrenzenden Diagnostik eines Parkinsonismus, orientiert an der Veröffentlichung von Gelb et al. (1999), angewendet. Die Kriterien werden in Deutschland auch von der AWMF (Arbeitsgemeinschaft der Wissenschaftlichen Medizinischen Fachgesellschaften) respektive der Deutschen Gesellschaft für Neurologie in ihren Leitlinien dargelegt, aus denen das in Grafik I dargestellte Schema abgeleitet ist (Diener und Putzki 2008).

Das klinische Staging lässt sich anhand der Kriterien von Hoehn und Yahr (1967) bzw. entsprechend der Unified Parkinson's Disease Rating Scale (UPDRS; Fahn et al. 1987) erstellen. Zentral für die Diagnoseentwicklung ist die klinisch neurologische Untersuchung und eine bildgebende Untersuchung des Kopfes mittels Computertomografie (CT) und / oder Magnetresonanztomografie (MRT). Die Anamnese umfasst dabei Angaben zu Beginn, Dauer und familiärer Komponente der Erkrankung, wie auch Angaben zu Störungen der Feinmotorik und autonomer / vegetativer Funktionen, Hypersalivation, Schlafstörungen, kognitiven Defiziten, Beeinträchtigung der Riechfunktion und Schulter-Arm-Schmerzen. Wichtig zu beachten ist, dass es „On-“ und „Off-Phasen“ der Krankheit geben kann. Bei entsprechenden klinischen Symptomen gehört der L-DOPA-Test zu den bestätigenden Kriterien für ein idiopathisches Parkinsonsyndrom / einen M. Parkinson. 
Zur Bestätigung der klinischen Diagnose eines M. Parkinson ist abschließend eine Autopsie notwendig. Auch die neuropathologischen Kriterien, dargestellt in Grafik II, sind in der Arbeit von Gelb et al. definiert (Gelb et al. 1999).

Grafik I: Klinische Diagnosekriterien des Parkinsonsyndroms

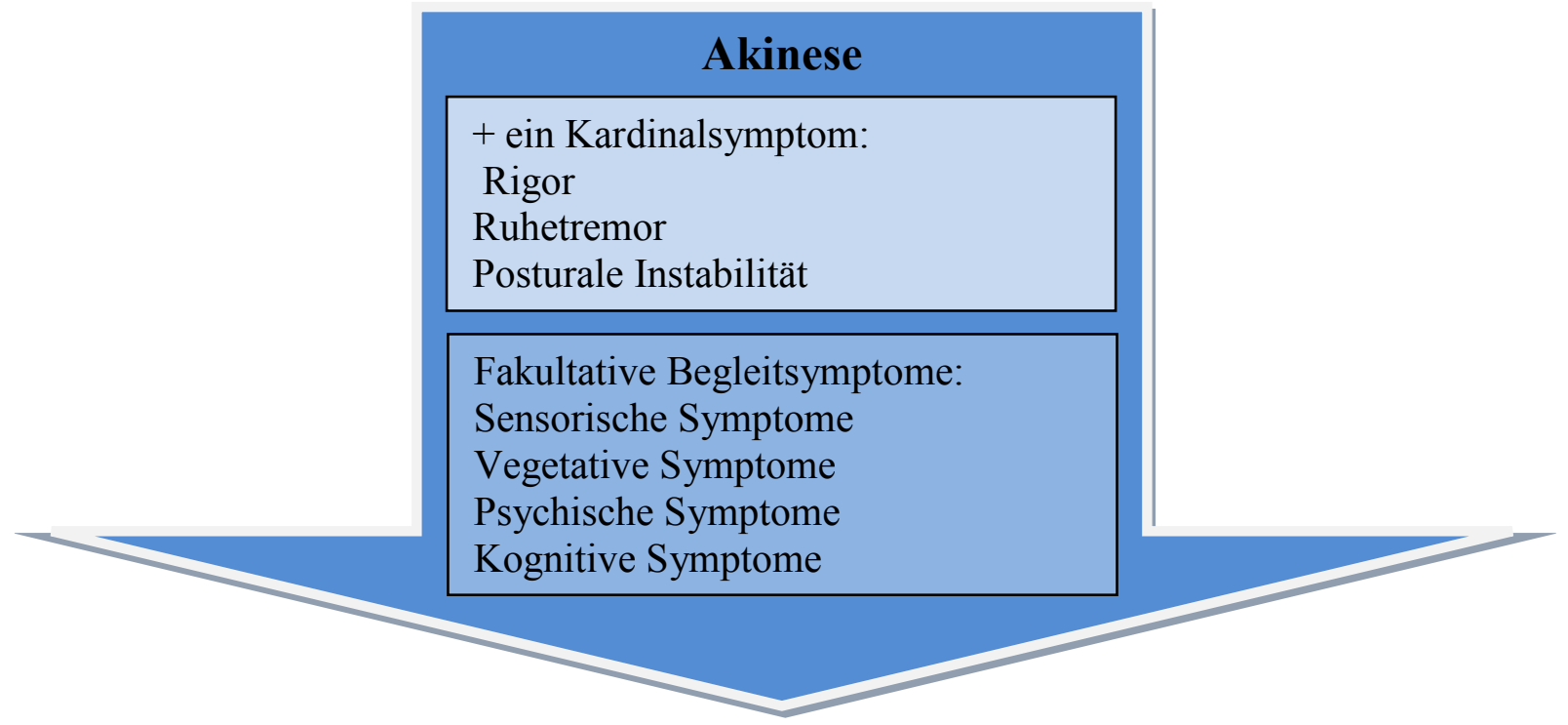

\section{Idiopathisches Parkinson-syndrom}

- Akinetisch-rigider Typ

- Äquivalenztyp

- Tremordominanztyp

- Monosymptomatischer Ruhetremor

- Demenz vom Lewy-Körper-Typ

\section{Familiäre Formen des Parkinson- Syndroms}

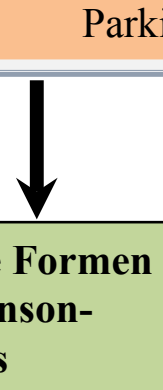

Parkinsonsyndrom

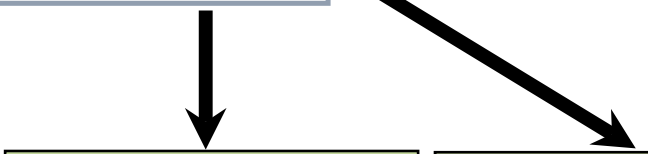

\begin{tabular}{|l|}
\hline Symptomatische \\
Parkinson- \\
Syndrome \\
- Vaskulär \\
- Normaldruck- \\
- hydrozephalus \\
- Medikamenten- \\
induziert \\
- Tumorbedingt \\
- Posttraumatisch \\
- Toxisch/metabol. \\
- Entzündlich \\
- Depression \\
- Essentieller
\end{tabular}

ParkinsonSyndrome im Rahmen neurodegenerativer Erkrankungen

- MSA

- PSP

- $\mathrm{CBD}$

- SCA

- DLB

Grafik erstellt gemäß der Leitlinie „Parkinson-Syndrome, Diagnostik und Therapie“ der Deutschen Gesellschaft für Neurologie (AWMF online, Stand 10/2008, Registernummer 030-010; Referenz Diener und Putzki 2008). 
Grafik II: Neuropathologische Kriterien

\section{Neuropathologische Kriterien für die Diagnose des M. Parkinson nach Gelb et al.}

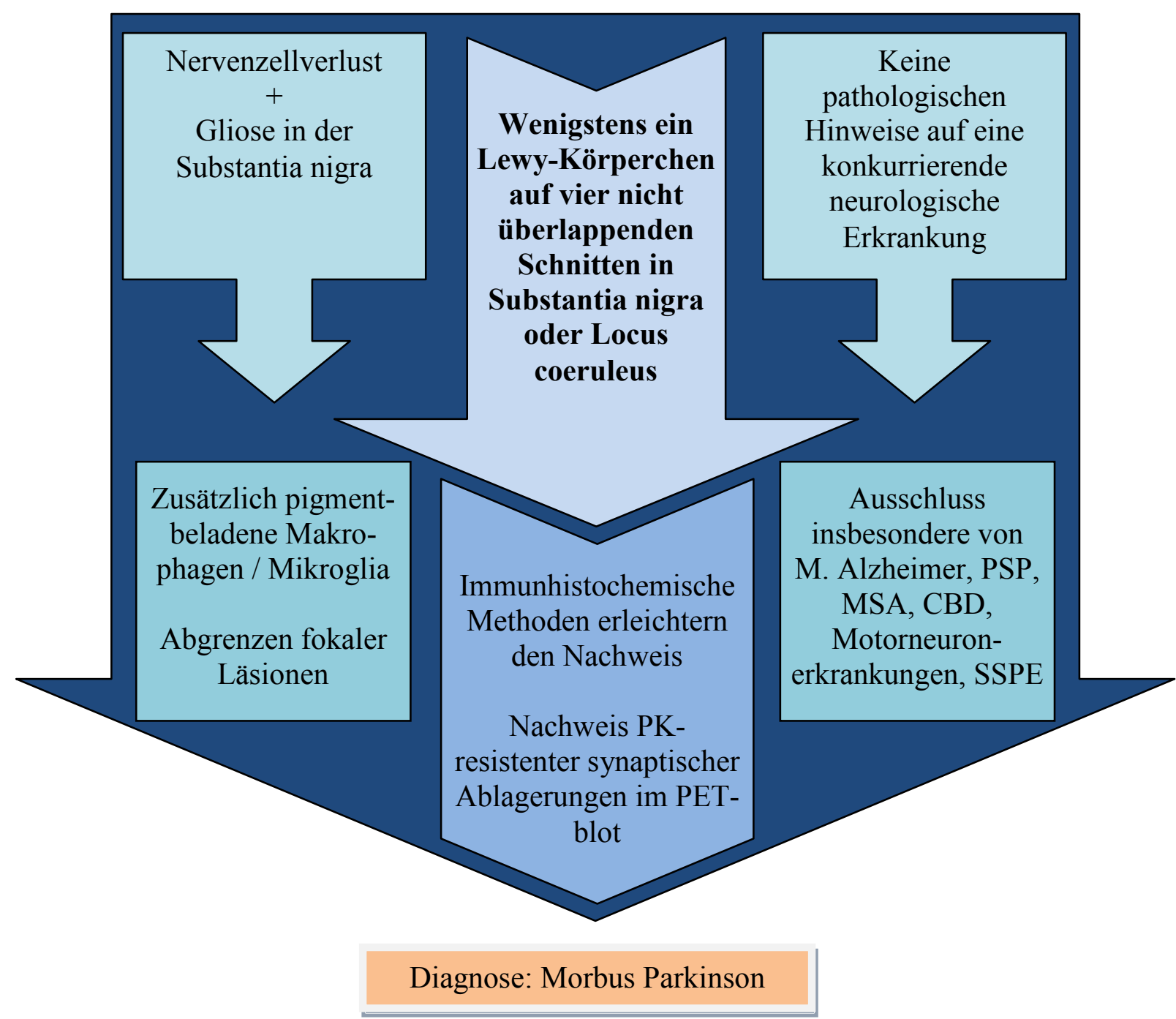

Schema erstellt gemäß den Kriterien von Gelb et al. (Gelb et al. 1999)

\subsubsection{Zur Pathophysiologie des M. Parkinson}

Pathophysiologisch liegt dem Morbus Parkinson eine progressive Degeneration des dopaminergen striatonigralen Systems als zentrale Komponente zugrunde. Gemäß Sandmann-Keil und Braak (2005) ist aber zu beachten, dass die pathologischen Veränderungen keineswegs nur das dopaminerge striatonigrale, sondern vielmehr auch das limbische und das motorische System betreffen. Einige Autoren führen an, dass es neben der Zerstörung von Funktionsbereichen im ZNS auch schwerwiegende pathologische Veränderungen im peripheren Nervensystem und im enterischen Nervensystem gibt (Braak et al. 2006c; Del Tredici et al. 2010). Aktuelle wissenschaftliche Herausforderung ist an dieser 
Stelle die Abgrenzung der Veränderungen von denen des normalen Alterns und Sekundärveränderungen im Rahmen anderer Krankheitsprozesse (Phillips et al. 2009). Das wesentliche neuropathologische Feature der Erkrankung, nämlich das Vorkommen der LewyKörperchen, wurde von Friederich Lewy (Lewy 1912; Lewy 1913) beschrieben. Bei den Lewy-Körperchen (Lewy bodies, LB's) handelt es sich um in der Hämatoxylin-EosinFärbung eosinophil erscheinende sphärische Gebilde, die als Zelleinschlüsse bevorzugt in den Nervenzellen der Substantia nigra nachgewiesen werden können.

Erst in den 1960er Jahren gelang es, die filamentäre Struktur der LB's zu zeigen (Roy und Wolman 1969). Dieser Befund ist letztlich entscheidend, um sich dem Terminus der Aggregation zu nähern. Interessanterweise lassen sich etliche Proteine in den LB's nachweisen, darunter neben mittlerweile etwa 70 Proteinen (Wakabayashi et al. 2007) Neurofilamente und Ubiquitin (Spillantini et al. 1997). Befunde, die die besondere Rolle von $\alpha$-Synuklein begründen, sind die im Rahmen einer seltenen familiären Form des Morbus Parkinson gefundenen Missensemutationen im $\alpha$-Synukleingen und die starke Immunreaktivität der LB's und der Lewy-Neuriten in den idiopathischen Fällen von M. Parkinson (Spillantini et al. 1997) und DLB (Spillantini et al. 1998b). Später konnte auch die Immunreaktivität der Fibrillen aus den LB's für $\alpha$-Synuklein gezeigt werden (Spillantini et al. 1998a). Weitere Studien haben außerdem gezeigt, dass rekombinant erzeugtes $\alpha$-Synuklein in der Lage ist, fibrilläre Strukturen zu formen, die denen aus LB's entsprechen und eine (partielle) Resistenz gegen einen Verdau mit PK besitzen (Miake et al. 2002).

Diskutiert wird heute auch das Vorkommen extrazellulär gelegener LB's.

Diese zuvor beschriebenen Veränderungen sind beim M. Parkinson besonders zahlreich, finden sich aber auch im Rahmen anderer neurodegenerativer Erkrankungen wie beispielsweise der DLB oder, dann in der Regel als untergeordnete Komponente, beim M. Alzheimer, bei der Progressiven supranukleären Blickparese (PSP), der subakuten sklerosierenden Panenzephalitis (SSPE), der kortikobasalen Degeneration (CBD) und anderen. Gelb führt an, dass 10 bis $40 \%$ dieser anderen neurodegenerativen Erkrankungen LB's aufweisen (Gelb et al. 1999). Als Zufallsbefund lassen sich auch im Autopsiegut von Patienten ohne Angabe einer neurologischen Erkrankung in einem gewissen Prozentsatz der Fälle LB's nachweisen, ohne dass sich weitere klinische oder histopathologische Aspekte einer entsprechenden Erkrankung nachweisen ließen (Gelb et al. 1999). Möglicherweise handelt es sich somit um eine, zumindest in einem gewissen Umfang auftretende Veränderung, die nicht notwendigerweise mit einer Erkrankung assoziiert sein muss, wie beispielsweise das Auftreten einzelner neuritischer Plaques in der Großhirnrinde nicht zur 
Diagnose eines M. Alzheimer führt. Es ist aber prinzipiell auch denkbar, dass es sich in diesen Fällen um sehr frühe Stadien einer mit $\alpha$-Synuklein assoziierten Erkrankung handelt, die erst wesentlich später klinisch und neuropathologisch apparent geworden wäre. Dieser Aspekt ließ sich bisher mit den derzeit verfügbaren Methoden nicht weiter klären. Neuere Untersuchungen könnten in diesem Zusammenhang zukünftig möglicherweise neue Erkenntnisse liefern. So konnte in Untersuchungen von Kramer und Schulz-Schaeffer (2007) gezeigt werden, dass die eigentlich relevante Veränderung bei Patienten mit DLB und konklusiv mutmaßlich auch Patienten mit M. Parkinson nicht das Auftreten von LB's und von Lewy-Neuriten, sondern vielmehr das Auftreten von feinsten Ablagerungen aggregierten $\alpha$ Synukleins an den präsynaptischen Terminalen der Dendriten ist. Aus diesem Befund lässt sich folgern, dass die Existenz der LB's und der Lewy-Neuriten zwar typisch für die Erkrankungen und diagnostisch histopathologisch durchaus relevant ist, nicht aber wirklich ein Ausmaß der Erkrankung abschätzen lässt. Diese synaptischen Ablagerungen sind in den normalen neuropathologischen Untersuchungen nicht zu erkennen.

\subsubsection{These: Synaptische $\alpha$-Synukleinaggregate führen zur Neurodegeneration}

Von der gedanklichen Vorstellung des Modells der Erkrankung kann man also folgendes aus diesen Untersuchungen von Kramer und Schulz-Schaeffer (2007) herleiten: Im Rahmen der Erkrankung kommt es zur Aggregation von $\alpha$-Synuklein im Bereich der präsynaptischen Endigungen der Axone und Neuriten. Wenn diese Aggregate nicht vom Körper wieder aufgelöst (z.B. Ubiquitin-Proteasom-Pathway) oder abtransportiert und in möglichst wenig schädlicher Form deponiert (z.B. in Form kompakter LB's im Soma der jeweiligen Zelle) werden können, kommt es zur Störung der Signalübertragung an der Synapse. Eine fehlende Signalübertragung mündet letztlich in einer Reduktion von postsynaptischen Dendritenköpfen, den empfängerseitigen Strukturen einer Synapse, wie mit Versilberungstechniken nach Gomori zu belegen ist (Kramer und Schulz-Schaeffer 2007). Bei Fortschreiten dieser synaptischen Verarmung kommt es schließlich zu einer immer weiter verminderten Kommunikation der betroffenen Nervenzelle, die somit letztlich überflüssig wird. In diesem Stadium ist dann gut zu erklären, warum es letztendlich zum Nervenzelluntergang kommen kann. Auch der zuvor bestehende Konflikt, dass LB's selbst eigentlich nicht, wie zuerst vermutet, zytotoxisch sind (Tompkins und Hill 1997) und es trotzdem zum Nervenzellverlust kommen kann, lässt sich so auflösen. Offen bleibt an der Stelle natürlich, warum $\alpha$-Synuklein überhaupt akkumuliert. Zentral ist in diesem 
Zusammenhang die Frage, ob es bei den sporadischen Krankheitsformen zuviel an Protein, ein verändertes biologisches Verhalten oder zu wenig Abbau / Abtransport gibt.

\subsubsection{Synuklein als neuronales Protein}

$\alpha$-Synuklein selbst gehört zu den im zentralen Nervensystem (ZNS) weit verbreiteten Proteinen, dessen physiologische Rolle nur in Teilen verstanden ist. Offensichtlich kommt $\alpha-$ Synuklein eine wichtige Rolle bei der Unterhaltung der Integrität der Synapse zu (SandmannKeil und Braak 2005). Es stammt aus der Familie der Synucleine, zu denen auch noch $\beta$ - und $\gamma$-Synuclein gehören. Der Name ist letztlich eine Neuschöpfung aus den Orten des ersten Nachweises: Synukleine finden sich besonders dicht im Bereich von Synapsen (Syn-) und im Bereich des Hülle des Zellkerns (-nuklein). Der erste Nachweis des Proteins gelang Maroteoux 1988 in Torpedo californica (Maroteaux et al.1988). In der Identifizierung des Proteins finden sich weitere wichtige Abschnitte: 1992 beschreiben Tobe et al. (Tobe et al. 1992) im Hirngewebe von Ratte und Rind ein Protein, das sie Phosphoneuroprotein 14 nennen. Ueda et al. (Ueda et al. 1993) identifizieren schließlich eine Aminosäuresequenz eines menschlichen Proteins, die sie als „non Amyloid $\beta$ Plaque Component Precursor“ (NAC-P) bezeichnen. Dieses NAC-Peptid entstammte einer Extraktion aus einer Präparation von $\beta$-Amyloidplaques von Alzheimer Patienten.

1994 gelang dann der Nachweis zweier homologer Proteine im menschlichen Hirngewebe (Jakes et al. 1994), die beide immunreaktiv für einen gegen „paired helical filaments“ gerichteten Antikörper waren. Eines dieser Proteine war identisch mit NAC-P, das andere entsprach Phosphoneuroprotein 14, dem zuvor bei Ratten als Synucleinäquivalent identifizierten Protein. Da diese beiden Proteine homolog zum Synuclein des Torpedo californica waren, wurden sie als $\alpha$ - und $\beta$-Synuclein bezeichnet. 1997 berichteten Ji et al. (1997) über ein bei Mammakarzinomen häufig vorkommendes Protein, das die Autoren als „breast cancer specific gene1“ (BCSG1) bezeichnen. Buchman et al. (1998) identifizierten ein identisches Protein, das die Autoren „persyn“ nennen. Wegen der hohen Sequenzhomologie zu den beiden zuvor beschriebenen Synukleinen wurde das Protein als $\gamma$-Synuclein bezeichnet.

\subsubsection{Eigenschaften des Proteins $\alpha$-Synuklein}

Codiert wird $\alpha$-Synuklein auf Chromosom 4 , wohingegen $\beta$ - und $\gamma$-Synuclein auf den Chromosomen 5 und 10 codiert werden (Spillantini et al. 1995). Die Proteine besitzen eine Länge von 127 bis 140 Aminosäuren und sind zu 55-62 \% identisch (Iwai et al. 1995). Das $\alpha$ - 
Synukleingen besteht aus 7 Exons, von denen 5 die codierende Region für das Protein darstellen. Alternative Splicevarianten des Proteins existieren, scheinen aber im menschlichen Gehirn keine Rolle zu spielen. Das Protein selbst weist einen sauren Anteil, eine hydrophobe Stretch-Region und eine Repeatregion auf. Diese Repeats bilden eine lipophile Region. Da $\alpha$-Synuklein ein potentielles Phosphoprotein ist, stellt die Phosphorylierung einen Regulationsmechanismus des Proteins dar. Von den drei Synukleinen wird nur $\alpha$-Synuklein mit den filamentären Einschlüssen in Verbindung gebracht. Die Ablagerungen von $\alpha$ Synuklein werden als phosphoryliert an der Aminosäure Serin an Position 129 beschrieben (Fujiwara et al. 2002). Als weitere regulierende Modifikation besteht die Möglichkeit der Nitrierung von $\alpha$-Synuklein im aminoterminalen Bereich. Diese nitrierte Form findet sich in LB's und Lewy-Neuriten. Als wesentliche physiologische Funktion von $\alpha$-Synuklein wird eine Rolle beim Transport synaptischer Vesikel postuliert (Clayton und George 1998; Jo et al. 2004). Dieser Transport ist ein Inhibitor von Phospholipase D2 und ein aktivitätsabhängiger Regulator der Freisetzung von Dopamin. Nativ liegt $\alpha$-Synuklein als ungefaltetes Protein vor, das bei Bindung an Membranen strukturiert wird (Eliezer et al. 2001). In ungefalteter Form wird es nach Ubiquitinylierung über den Proteasomweg degradiert. Im Rahmen pathologischer Prozesse kommt es dann zur Aggregation, bei der $\alpha$-Synuklein seine Konformation verändert und $\beta$-Faltblattstrukturen ausbildet.

\section{$1.4 \quad$ Kamptokormie}

Kamptokormie ist eine muskuläre Haltungsstörung, die als eigenständige Erkrankung oder aber im Rahmen einer Grunderkrankung vorkommt. Der Begriff setzt sich aus „Kamptos“ (griechisch für beugen oder gebeugt) und „Kormos“ (griechisch für Rumpf) zusammen. Als weitere Bezeichnungen finden sich „bent spine syndrome“ oder „cyphose hystérique“. Es handelt sich nach derzeitigem Wissenstand um ein durch verminderte Haltekraft der Rückenmuskulatur bedingtes Herabsinken des Kopfes oder des Rumpfes (Finsterer und Strobl 2010; Kocaaga et al. 2008). Betrifft die Symptomatik nur den Kopf, spricht man von einem so genannten „Dropped head““-Syndrom oder Camptocephalia (Sakas et al. 2010).

\subsubsection{Geschichte des Begriffs}

Erste Dokumentationen des Krankheitsbildes finden sich bei dem spanischen Maler Francisco de Zurbaran im 17. Jahrhundert (Bildnis: „San Hogo en el refectorio de los cartujos“, 1655). In der wissenschaftlichen Literatur taucht das Krankheitsbild in ersten Beschreibungen bei Earle (1815) und Brodie (1818) auf, wobei Brodie den Titel „Functionally bent spine“ für 
seine Ausführung wählt. Eine weitere Beschreibung findet sich unter dem Titel „functionally bent back" durch denselben Autor 1837 (Brodie 1837). Allerdings finden sich entsprechende Aspekte der Kamptokormie bereits in der Originalbeschreibung des M. Parkinson von James Parkinson für ein wesentliches Symptom in einer Untergruppe der Patienten (Parkinson 2002). Der eigentliche Begriff der Kamptokormie wurde um 1915 durch die französischen Neurologen Souques und Rosanoff-Saloff $(1915 ; 1916)$ geprägt. Diese beschrieben in ihrem Artikel im ersten Weltkrieg traumatisierte Soldaten. Weitere Fallbeschreibungen finden sich in der Literatur (Hurst 1918). Hierbei wird der Aspekt einer psychogenen Erkrankung angesprochen. Erst 1999 erfolgt eine Beschreibung der Assoziation mit dem M. Parkinson durch Djaldetti et al. (Djaldetti et al. 1999). Eine Kamptokormie im Rahmen einer genetischen Erkrankung wurde erstmals in einem Fall einer myotonen Dystrophie Typ 2 mit Vorliegen einer ZNF9-Mutation beschrieben (Serratrice 2007). Die Assoziation mit einer MSA erfolgte durch Reichel et al. 2001 (Reichel et al. 2001). Weiterhin wurde als Einzelfallbeschreibung der Zusammenhang mit einer Mutation im Gen eines Strukturproteins beschrieben (D'Amico et al. 2005). Die Übersichtsliteratur führt die Kamptokormie auch in Zusammenhang mit einer Dysferlinopathie (LGMD 2B) an, wobei die von mir gesichteten Artikel (Nagashima et al. 2004; Seror et al. 2008) zwar die Kamptokormie explizit erörtern, aber in einem Fall ausschließen (Seror et al. 2008) und im anderen Fall ein „Rigid spine“Syndrom beschreiben (Nagashima et al. 2004). Das „Rigid spine“-Syndrom ist explizit keine Kamptokormie, da hier die Flexion des Rückens aus der bestehenden Position durch übermäßigen Muskeltonus behindert oder unterbunden ist.

\subsubsection{Inzidenz, Prävalenz und Assoziation mit anderen Erkrankungen}

Zur Häufigkeit der Kamptokormie finden sich nur vereinzelte und teils unterschiedliche Angaben: Lepoutre et al. (Lepoutre et al. 2006) untersuchten über einen längeren Zeitraum 700 Patienten mit einer Parkinsonerkrankung und fanden dabei 23 Patienten mit einer Kamptokormie, sodass sie die Prävalenz vorsichtig auf 3 \% schätzen. In einer Einzelzentrumsstudie fand sich bei 275 untersuchten Parkinsonpatienten eine Prävalenz von 6,9\% (Tiple et al. 2009; Finsterer und Strobl 2010). Abe et al. (2009) finden in ihrer Studie an 153 Patienten mit einem M. Parkinson in 17\% eine Kamptokormie. In einer weiteren Studie werden bei 167 untersuchten Parkinsonpatienten (Ashour und Jankovic 2006) 20 Fälle mit einer Kamptokormie und 9 Fälle mit einem „Dropped head“ beschrieben, was einem Vorkommen von 12,2\% bezogen auf die Kamptokormie und 5,5\% bezogen auf den „Dropped head“" entspricht. Zusammengefasst finden sich somit in dieser Studie 17,7\% 
Parkinsonpatienten mit einer Kamptokormieform. Des Weiteren werden in dieser Studie 19 Patienten mit einer MSA beschrieben, von denen 15,8\% (10,5\% Kk. bzw. 5,3\% Dh.) eine Kamptokormieform zeigen. Untersucht wurden außerdem 19 Fälle mit einer progressiven supranukleären Blickparese (PSP), wobei sich hier 22,3\% (12,9\% Kk. bzw. 9,4\% Dh.) Fälle mit einer Kamptokormie finden. Einzelfallbeschreibungen finden auch Kamptokormiefälle in einem Patienten mit einer Demenz, die dem Alzheimertyp zugeordnet wird (Brucki und Nitrini 2008). Aus diesen heterogenen Angaben ergibt sich, dass die Prävalenz der Kamptokormie beim Morbus Parkinson zwischen 3 und etwa $17 \%$ liegen dürfte. Interessant ist auch, dass es einzelne Beschreibungen einer Kamptokormie auch im Zusammenhang mit primären Muskelerkrankungen gibt (Serratrice 2007; Dupeyron et al. 2009). Die Fallbeschreibung von Dupeyron et al. (2009) ist hierbei von besonderem Interesse, da die myotone Dystrophie Typ 1 genetisch gesichert werden konnte und somit nicht unter dem Verdacht einer noch unklaren Diagnose stehen muss. In einigen Fallbeschreibungen wird außerdem deutlich, warum immer wieder die genaue Abklärung, gegebenenfalls auch durch eine Biopsie, bei Neuauftreten einer Kamptokormie erfolgen sollte. Beispielsweise gibt es Fallbeschreibungen, in denen M. Parkinson die Grunderkrankung ist, aber eine Myasthenia gravis als Auslöser der Kamptokormie gefunden wird und unter entsprechender Therapie die Erkrankung rückläufig ist (Unal-Cevik und Temucin 2009). Eine andere wichtige zu diskutierende Kausalitätsreihe wird von Finsterer (2004) beschrieben: Über die Untersuchung der Kamptokormie wird die Diagnose einer Mitochondriopathie gestellt und schließlich ein Parkinsonismus im Rahmen der Mitochondriopathie diskutiert. Dieses wäre dann in gewisser Weise eine Umkehr der Kausalität, da über die Analyse der Kamptokormie eine Grunderkrankung, in diesem Fall die Mitochondriopathie, identifiziert worden ist, die die Symptomatik des Parkinsonsyndroms erklären kann.

In der Literatur findet sich zumindest eine Beschreibung einer familiären Häufung der Kamptokormie. Es wird der Fall einer österreichischen Familie beschrieben, bei der letztlich eine Mutation im FHL1-Gen (LIM-domain Protein) nachgewiesen werden konnte (Windpassinger et al. 2008). Beschrieben werden neun Personen unterschiedlicher Generationen, die eine Form der Gliedergürteldystrophie (XMPMA) zeigen. Fasst man den Abschnitt der Assoziation der Kamptokormie mit anderen Erkrankungen zusammen, so findet sich neben der starken Häufung des gemeinsamen Auftretens mit der Parkinsonerkrankung auch eine deutliche Häufung bei der MSA und der PSP. Axiale Dystonien bilden eine weitere durchaus relevante Gruppe von Fallbeschreibungen. Unter den 
Muskelerkrankungen findet immer wieder die Mitochondriopathie Erwähnung. Etliche Einzelfallbeschreibungen finden sich für unterschiedliche entzündliche Prozesse, die jeweils als Auslöser angesehen werden. In der nachfolgenden Tabelle wird deutlich, wie weitreichend die Erkrankungen sind, die in Zusammenhang mit einer Kamptokormie gebracht werden.

Tabelle I: Literaturangaben mit Berichten einer Kamptokormie

\begin{tabular}{|c|c|c|}
\hline $\begin{array}{l}\text { Übergeordnete } \\
\text { Erkrankungs- } \\
\text { gruppe }\end{array}$ & $\begin{array}{l}\text { Grunderkrankung } \\
\text { Auswahl der Diagnosen in } \\
\text { Anlehnung an den } \\
\text { Übersichtsartikel von } \\
\text { Finsterer und Strobl } 2010\end{array}$ & $\begin{array}{l}\text { Fallzahl (Literaturreferenz) } \\
\text { Angabe: } \frac{n+x(y / z)}{\mathrm{n}=\text { Kamptokormiefälle der referenzierten }} \\
\text { Grunderkrankung (eingeschlossen in diese Studie) } \\
x=\text { andere Kamptokormieform; Angabe nur, wenn } \\
\text { separat genannt } \\
y=\text { Fälle der referenzierten Grunderkrankung } \\
z=\text { Gesamtfallzahl der Studie } \\
-=\text { keine Fallzahl genannt }\end{array}$ \\
\hline \multirow[t]{10}{*}{ ZNS-organisch } & M. Parkinson & 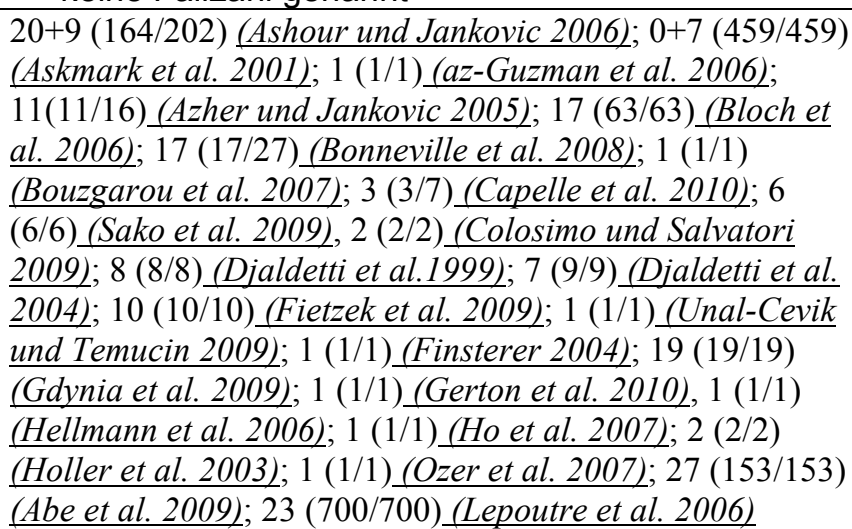 \\
\hline & CBD & $-(7 / 38)$ (Godeiro-Junior et al. 2008) \\
\hline & Axiale Dystonien & $\begin{array}{l}4(\mathrm{n}=4 / 16) \text { (Azher und Jankovic 2005); } ;-(-/ 63) \text { (Bloch et al. } \\
\text { 2006); } 4(4 / 7) \text { (Capelle et al. 2010); } 3(36 / 36) \text { (Fukaya et al. }\end{array}$ \\
\hline & $\begin{array}{l}\text { Abdominale segmentale } \\
\text { Dystonie }\end{array}$ & \\
\hline & MSA & $\begin{array}{l}5+8(19 / 202) \text { (Ashour und Jankovic 2006); } 2 \text { (2/63) (Bloch } \\
\text { et al. 2006); } 1 \text { (1/1) (Diederich et al. 2006); } 1 \text { (1/1) (Takei et } \\
\text { al. 2009), } 1 \text { (23/38) (Godeiro-Junior et al. 2008) }\end{array}$ \\
\hline & M. Alzheimer & $1(1 / 1)$ (Brucki und Nitrini 2008) \\
\hline & Basalganglienstörungen & $5(5 / 16)$ (Hilliquin et al. 1992) \\
\hline & Essentieller Tremor & \\
\hline & Viliuisk Enzephalomyelitis & $\begin{array}{l}-(-/ 390)(\text { Goldfarb et al. })^{* *}, \text { Goldfarb und Gajdusek } \\
\text { 1992)*** }\end{array}$ \\
\hline & PSP & $\begin{array}{l}\text { 1+2 (19/202)_(Ashour und Jankovic 2006); - (8/38) } \\
\text { (Godeiro-Junior et al. 2008) }\end{array}$ \\
\hline \multirow[t]{4}{*}{ ZNS-organisch } & ALS & $1 ?(1 / 1)$ (Feriha et al. 2004) \\
\hline & Spasmodischer Torticollis & - (-/1) (Beekman et al. 2002) \\
\hline & SCA & $1(1 / 1)($ (Gamez et al. 2010$)$ \\
\hline & Partiale Cataplexie & -(-11) (Beekman et al. 2002) \\
\hline \multirow[t]{4}{*}{ Psychiatrisch } & $\begin{array}{l}\text { Gilles de la Tourette } \\
\text { Syndrom }\end{array}$ & $1(1 / 16)$ (Azher und Jankovic 2005) \\
\hline & Konversionserkrankungen & \\
\hline & $\begin{array}{l}\text { Psychogene } \\
\text { Kamptokormie }\end{array}$ & $\begin{array}{l}1(1 / 1) \text { (Ballenger 1976), } 1 \text { (1/1)(Gomez und Drooby 1987), } \\
5(5 / 5) \text { (Hurst 1918) }\end{array}$ \\
\hline & Neurosen & \\
\hline $\begin{array}{l}\text { Peripheres } \\
\text { Nervensystem }\end{array}$ & CIDP & $\begin{array}{l}\text { 1 (1/1)(Terashima et al. 2009), } 1 \text { (1/1)_Hoffman und } \\
\text { Gutmann 1994) }\end{array}$ \\
\hline
\end{tabular}




\begin{tabular}{|c|c|c|}
\hline Gruppe & Grunderkrankung & Fallzahl (Literaturreferenz) \\
\hline $\begin{array}{l}\text { Peripheres } \\
\text { Nervensystem }\end{array}$ & $\begin{array}{l}\text { Neurogene } \\
\text { Schädigungszeichen }\end{array}$ & 4 (4/16)_(Hilliquin et al. 1992) \\
\hline \multirow[t]{9}{*}{$\begin{array}{l}\text { Primäre } \\
\text { Myopathien }\end{array}$} & $\begin{array}{l}\text { Dystone Myopathie (DM) } \\
1\end{array}$ & $1(1 / 1)$ (Dupeyron et al. 2009) \\
\hline & DM 2 & $1(1 / 1)$ (Serratrice 2007) \\
\hline & Axiale Myopathie & \\
\hline & Dysferlinopathie * & 1 (1/1)_Nagashima et al. 2004); 1 (1/1)_(Seror et al. 2008) \\
\hline & Nemalin Myopathie & 1 (1/1)_Lomen-Hoerth et al. 1999) \\
\hline & Mitochondriale Myopathie & $\begin{array}{l}2(5 / 459) \text { (Askmark et al. 2001); } 1 \text { (1/7) (Delcey et al. } \\
\text { 2002); } 1(1 / 1) \text { (Finsterer 2004); } 1 \text { (1/1) (Gomez-Puerta et } \\
\text { al. 2007) }\end{array}$ \\
\hline & Congenitale Myopathie & $1(1 / 7)($ Delcey et al. 2002) \\
\hline & XMPMA & - (9/9)_Windpassinger et al. 2008) \\
\hline & $\begin{array}{l}\text { Mutation LMNA-/ SEPN1- } \\
\text { Gen }\end{array}$ & $2(2 / 2)\left(D^{\prime}\right.$ Amico et al. 2005) \\
\hline \multirow[t]{9}{*}{$\begin{array}{l}\text { Sekundäre } \\
\text { Myopathien }\end{array}$} & $\begin{array}{l}\text { Hypothyreotische } \\
\text { Myopathie }\end{array}$ & \\
\hline & Hyperparathyreoidismus & -/1 (1/1)_Beekman et al. 2002) \\
\hline & Carnitinmangel & - (-/1) (Beekman et al. 2002) \\
\hline & $\begin{array}{l}\text { Myopathie der } \\
\text { Kopfextensoren }\end{array}$ & $5(5 / 459)$ (Askmark et al. 2001) \\
\hline & $\begin{array}{l}\text { Isolierte Myopathie der } \\
\text { Thoraxstrecker }\end{array}$ & \\
\hline & $\begin{array}{l}\text { Myopathie mit Nemalin } \\
\text { Rods }\end{array}$ & $1(1 / 1)($ Ozer et al. 2007) \\
\hline & FSHD & $1(1 / 1)($ Kottlors et al. 2010) \\
\hline & Myasthenia gravis & $\begin{array}{l}1 \text { (1/1)_(D'Amelio et al. 2007); } 1 \text { (1/1)_(Unal-Cevik und } \\
\text { Temucin 2009) }\end{array}$ \\
\hline & Amyloidmyopathie & $1(1 / 7)($ Delcey et al. 2002$)$ \\
\hline \multirow{5}{*}{$\begin{array}{l}\text { Entzündliche } \\
\text { Myopathien }\end{array}$} & Polymyositis & $4(4 / 7)$ (Delcey et al. 2002) \\
\hline & Dermatomyositis & $4(4 / 7)$ (Delcey et al. 2002) \\
\hline & Chronisch axiale Myositis & $-(-/-)($ Hachulla 2001) \\
\hline & Fokale Myositis & $\begin{array}{l}1(1 / 1) \text { (Bahnof 1999), } 1 \text { (1/1)(Charpentier et al. 2005), } 1 \\
(1 / 1) \text { (Dominick et al. 2006) }\end{array}$ \\
\hline & IBM & $1(1 / 1)$ (Hund et al. 1995) \\
\hline \multirow[t]{5}{*}{ Medikamente } & Olanzapin & \\
\hline & Donepezil & \\
\hline & Valproat & $1(1 / 1)($ Amin et al. 2004) \\
\hline & Steroide systemisch & \\
\hline & Botulinumtoxin (ther.) & - (-/1) (Beekman et al. 2002); 1 (1/1)_(Hogan et al. 2006) \\
\hline \multirow[t]{9}{*}{ Diverse } & Traumatisch & \\
\hline & Bandscheibenherniation & $1(1 / 1)$ (Duman et al. 2008) \\
\hline & Arthritis & $1(1 / 16)$ (Hilliquin et al. 1992) \\
\hline & Neoplastisch & \\
\hline & Idiopathisch & 14 (14/14)_(Delisle et al. 1993) \\
\hline & Biomechanisch & 1 (1/1) (Abdulhadi und Kerrigan 1996) \\
\hline & Tardive Dystonie & -(-/1) (Beekman et al. 2002) \\
\hline & Nach Malaria mit Koma & $1(1 / 5)$ ((Hurst 1918) \\
\hline & $\begin{array}{l}\text { Postoperativ } \\
\text { (Appendizitis) }\end{array}$ & $1(1 / 5)$ (Hurst 1918) \\
\hline \multirow[t]{2}{*}{ Diverse } & Riesenzellangiitis & $1(1 / 16)$ (Hilliquin et al. 1992) \\
\hline & Chondrokalzinose & $3(3 / 16)$ (Hilliquin et al. 1992) \\
\hline
\end{tabular}

In den freigebliebenen Feldern konnte die Angabe nicht in der Originalliteratur nachgeprüft werden, da diese nicht zur Verfügung stand; Grundstruktur der Tabelle in Anlehnung an Finsterer und Strobl (2010)

* Bei der Dysferlinopathie liegt in einem Fall keine Kamptokormie, in dem anderen Fall ein „Rigid Spine“ vor!

** Im Paper wird von einem „Stiff neck“ gesprochen. *** Es wird von genereller „Stiffness“ berichtet und ein auffälliges „bent foreward“ zur Initiierung des Gehens benannt. 


\subsubsection{Klinik}

Die Fehlhaltung des Rumpfes bei der Kamptokormie oder des Kopfes beim „Dropped head“Syndrom besteht in einer Vorwärts- oder Seitwärtsneigung von über $30^{\circ}$ und bis zu $90^{\circ}$.

Interessant ist, dass eine Kamptokormie und ein „Dropped head“ Syndrom selten gemeinsam auftreten (Dominick et al. 2006, Umapathi et al. 2002).

Die Kamptokormie tritt in einigen Fällen kombiniert mit einer Schwäche des Gluteus maximus, sowie der Muskulatur der Hüft- und Kniebeuger auf (Bloch et al. 2006, Djaldetti et al. 2004). Dieses Bild kann beim Parkinson im späten Stadium identifiziert werden und wird dann als Kombination aus „bent spine“- und „bent knee“-Syndrom angesehen.

Von der Kamptokormie abzugrenzen sei nach Meinung einiger Autoren (Finsterer und Strobl 2010) das Pisa-Syndrom (Pleurothotonus), bei dem es sich um eine Seitneigung von Kopf und Rumpf durch tonische Flexion handele, die mit einer Skoliose einhergehe. Auch andere muskulär bedingte Fehlhaltungen sind hiervon abzugrenzen. Zu diesen gehört beispielsweise der Schiefhals (Torticollis). Klinisch sind von der Kamptokormie außerdem nicht muskulär bedingte Fehlhaltungen abzugrenzen. Hierbei sind vor allen Dingen knöcherne Deformitäten der Wirbelsäule, zum Beispiel im Rahmen eines Morbus Bechterew oder einer Skoliose abzugrenzen.

Der Beginn einer Kamptokormie wird als rasch progredient, genauer über einige Wochen zunehmend beschrieben (Bloch et al. 2006). Die Ausprägung der Symptome kann dabei variabel stark sein; einige Patienten beschreiben eine Verschlimmerung in den Off-Phasen und während Phasen mit einer Fatigue-Symptomatik (Djaldetti et al. 1999, Holler et al. 2003). Immer wieder wird in der Literatur der Aspekt von Schmerzen kontrovers diskutiert. In vielen Fällen ist die Kamptokormie an sich schmerzlos, aber es werden auch mit Schmerzen verbundene Fälle berichtet (Margraf et al. 2010, Bloch et al. 2006, Shinjo et al. 2008), (Dupeyron et al. 2009, Lepoutre et al. 2006). Bloch et al. (2006) beschreiben eine Untersuchung von 17 Patienten, unter denen 80\% Schmerzen im unteren Rücken angeben. Diese sind offensichtlich im Zuge der Kamptokormie entstanden, da keiner der Patienten eine zurückverfolgbare Geschichte der Rückenschmerzen zeige. Wichtig ist in diesem Zusammenhang, dass nahezu alle Kamptokormiepatienten in entsprechenden Studien auch eine Spondylarthrose aufweisen (Djaldetti und Melamed 2006).

Einerseits wird die Kamptokormie als relativ einheitliches Symptom beschrieben, aber es werden auch Unterschiede je nach zugrunde liegender Erkrankung angesprochen. So sei nach Djaldetti et al. (Djaldetti et al. 1999) die Kamptokormie bei MSA ein striktes „Dropped head“- Syndrom, während in den von ihr untersuchten Parkinsonfällen die thorakolumbale 
Muskulatur betroffen gewesen sei. Teilweise werde der Kopf sogar angehoben, um eine Orientierung zu erhalten, was im Gegensatz zur MSA häufig mit Hilfe der autochthonen Muskulatur allein möglich gewesen sei.

Es wird beschrieben, dass sich die Kamptokormie im Rahmen des Morbus Parkinson immer erst nach der Manifestation des M. Parkinson selbst nachweisen lässt (Bloch et al. 2006). Allerdings gibt es zumindest eine Einzelfallbeschreibung, in der die Kamptokormie zur Entdeckung des M. Parkinson geführt habe (Bouzgarou et al. 2007).

\subsubsection{Beurteilung und Bewertung einer Kamptokormie}

Zur klinischen Erfassung einer Kamptokormie wurde in der Neurologie des

Universitätsklinikums Kiel von Dr. Margraf und Kollegen (Margraf et al. 2010) ein

Bewertungsbogen entwickelt, der nachfolgend tabellarisch (Tabelle II) wiedergegeben wird.

Tabelle II: Kamptokormieerfassung nach Margraf et al. (2010, S. 544)

\begin{tabular}{|c|c|c|c|}
\hline \multirow[t]{2}{*}{ Erfasste Information } & \multirow{2}{*}{$\begin{array}{l}\text { Offene } \\
\text { Frage }\end{array}$} & \multicolumn{2}{|c|}{ Bewertung auf einer numerischen Analogskala } \\
\hline & & Codierung & Score \\
\hline \multirow[t]{5}{*}{ Durchschnittlicher Beugewinkel } & & Keine Beugung & 0 \\
\hline & & $0-29^{\circ}$ & 1 \\
\hline & & $30-59^{\circ}$ & 2 \\
\hline & & $60-89^{\circ}$ & 3 \\
\hline & & $>90^{\circ}$ & 4 \\
\hline \multirow{5}{*}{$\begin{array}{l}\text { Umstände, unter denen die } \\
\text { Kamptokormie auftritt }\end{array}$} & & Keine Kamptokormie & 0 \\
\hline & & $\begin{array}{l}\text { Nach nennenswerter Zeit des Stehens } \\
\text { oder Gehens }\end{array}$ & 1 \\
\hline & & Nach 50m Gehstrecke & 2 \\
\hline & & Sofort nach dem Aufstehen & 3 \\
\hline & & Schon während des Sitzens & 4 \\
\hline \multirow{5}{*}{$\begin{array}{l}\text { Tägliche Präsenz der } \\
\text { Kamptokormie }\end{array}$} & & Keine Kamptokormie & 0 \\
\hline & & Nur vereinzelt & 1 \\
\hline & & $\begin{array}{l}\text { Nur am Abend / bei Erschöpfung / bei } \\
\text { schwerer Fatigue }\end{array}$ & 2 \\
\hline & & Mehrere Stunden pro Tag & 3 \\
\hline & & Den ganzen Tag & 4 \\
\hline \multirow[t]{2}{*}{ Bestehen von Rückenschmerzen } & & Keine Schmerzen & 0 \\
\hline & & $\begin{array}{l}\text { Schmerzintensität auf einer Skala von } 1= \\
\text { geringe bis } 10=\text { stärkste Schmerzen }\end{array}$ & $1-10$ \\
\hline \multirow{2}{*}{$\begin{array}{l}\text { Einschränkungen im Alltag allein } \\
\text { aufgrund der Kamptokormie }\end{array}$} & & Keine Einschränkung & 0 \\
\hline & & $\begin{array}{l}\text { Grad der Einschränkung auf einer Skala } \\
\text { von } 1=\text { gering bis } 10=\text { hochgradig }\end{array}$ & $1-10$ \\
\hline Dauer der Kamptokormie & + & & \\
\hline $\begin{array}{l}\text { Veränderung des Schweregrades } \\
\text { über die Zeit }\end{array}$ & + & & \\
\hline Benutzung von Gehhilfen & + & & \\
\hline $\begin{array}{l}\text { Einfluss der Medikation auf die } \\
\text { Kamptokormie }\end{array}$ & + & & \\
\hline
\end{tabular}

Aus den hier gemachten Angaben kann ein Wert zwischen 1 und 32 errechnet werden, wobei ein höherer Wert für einen höheren Schweregrad steht. 
Ergänzt werden kann der hier ermittelte Wert durch weitere Werte, die aus anderen Wertungsschemata entnommen werden können. Beispielsweise lässt sich ein „axialer Score“ nach Bloch et al. (2006) errechnen. Diese Berechnung umfasst die Werte mehrerer Punkte des UPDRS-III-Systems. Enthaltene Punkte sind Sprache, Gesichtsausdruck, Nackensteifigkeit, Gang und Haltungsinstabilität (posturale Instabilität).

Wie Tabelle X zu entnehmen ist, wurden in dieser Untersuchung nur Biopsien bearbeitet, bei denen der Beugewinkel des Patienten $30^{\circ}$ oder mehr beträgt.

\subsubsection{Pathophysiologie}

In der mechanischen Erklärung der Symptomatik der Kamptokormie werden zwei wesentliche Mechanismen diskutiert. Einerseits wäre ein vermehrter Tonus der beugenden Muskeln denkbar. Bezogen auf das „dropped head“-Syndrom stünde der M. sternokleidomastoideus, bezogen auf die Rumpfform die Bauchmuskelgruppe (vor allem der M. rectus abdominis) im Vordergrund. Der zweite diskutierte und weithin akzeptierte Mechanismus ist die Tonusminderung bzw. die Minderung der Kontraktionskraft in der autochtonen Rückenmuskulatur. Je nach betroffener Höhe der autochtonen Muskulatur ist dann ein isoliertes „dropped head“-Syndrom oder eine Rumpffehlhaltung in entsprechender Höhe zu erklären.

Neben dem Mechanismus wird auch die zugrunde liegende Pathologie diskutiert: Hierbei reicht das Spektrum von einer psychogenen Störung über entzündliche Veränderungen bis hin zu einer Mitochondriopathie. Dabei fällt auf, dass der Aspekt einer psychogenen Erkrankung eher in den historischen Beschreibungen zu finden ist. Die Gruppe der entzündlichen Fälle ist interessant, da sie die gruppe darstellt, bei der eine klare therapeutische Linie zu erkennen ist. Der Erfolg einer antiinflammatorischen Therapie wird dabei in der Literatur heterogen berichtet, was aber nahe legt, dass zumindest eine Gruppe von Kamptokormiepatienten mit einer wesentlichen entzündlichen Komponente in der Tat existiert. Für die Mitochondriopathie als Auslöser werden morphologische Aspekte der jeweiligen Biopsie, für genetische Erkrankungen jeweils der Nachweis einer entsprechenden Mutation angeführt. Ein Fall einer erfolgreichen „Backpack“-Therapie wird als Hinweis auf einen dystonen Prozess diskutiert. Auffällig ist, dass die wesentlichen Arbeiten ein myopathisches Bild berichten (Askmark et al. 2001; Margraf et al. 2010; Spuhler et al. 2009).

Die Tatsache, dass die Kamptokormie ein relativ charakteristisches klinisches Erscheinungsbild bietet, legt prinzipiell auch einen einheitlichen Pathomechanismus nahe. Grundsätzlich ließe sich natürlich vorstellen, das auch mehrere Mechanismen existieren, 
jedoch ist gerade bei den Grunderkrankungen mit gehäuftem Auftreten der Kamptokormie ein einheitlicher Mechanismus innerhalb dieser Gruppe anzunehmen.

\subsubsection{Risikofaktoren}

Als Faktoren, die vermehrt mit einer Kamptokormie einhergehen wurden beispielsweise spondylarthrotische Veränderungen beschrieben (Djaldetti et al. 1999).

Bei Parkinsonpatienten findet sich eine Assoziation mit dem Schlafapnoesyndrom.

\subsubsection{Therapie}

In der Literatur finden sich unterschiedliche therapeutische Ansätze. Versucht wird und wurde unter anderem der Einsatz der tiefen Hirnstimulation durch Implantation von Elektroden. Für die Implantation der Elektroden bei axialer Dystonie finden Capelle et al. (Capelle et al. 2010) eine deutliche Verbesserung der Symptomatik, bei drei untersuchten Parkinsonpatienten mit Kamptokormie ist das Ergebnis heterogener mit unterschiedlich klarer Verbesserung.

Demgegenüber berichten Sako et al. (2009) in ihrer Studie von sechs Patienten mit deutlicher Besserung der muskulären Symptomatik einschließlich der Kamptokormie nach Tiefenhirnstimulation. Unterschieden wird hierbei noch die Platzierung der Elektroden (Substantia nigra, Globus pallidus internus). Der Effekt physiotherapeutischer Maßnahmen wird je nach Autor eher positiv (Bahnof 1999) oder negativ beurteilt (az-Guzman et al. 2006). Weiterer therapeutischer Ansatz und auch mechanistisch zur Ätiopathologie der Kamptokormie interessanter Punkt ist die gezielte Injektion von Botulinumtoxin in die Psoasmuskulatur und die Längsmuskulatur des Bauches (Rectus abdominis). Diese zeigte in den publizierten Versuchen keinen Effekt (Colosimo und Salvatori 2009).

Bei Kamptokormiefällen auf entzündlicher Basis werden immer wieder Erfolge, jedoch auch Misserfolge durch immunsuppressive Therapieansätze (Steroide, Immunglobuline, Cyclosporin) beschrieben (Delcey et al. 2002).

Interessant ist darüber hinaus der Ansatz der so genannten „Backpack“-Therapie (Gerton et al. 2010): Der Patient bekommt einen leichten Rucksack auf den Rücken geschnallt. Dieser führt dazu, dass sich der Patient wieder aufrichtet. Dieses Aufrichten sei nicht durch ein Gegengewicht, sondern durch einen taktilen Stimulus ausgelöst. Somit spricht dieser Aspekt für die Theorie eines dystonen Prozesses. In der hier präsentierten Tabelle III werden die in der Literatur gemachten Angaben zu Therapien und deren Erfolge kurz zusammengefasst. 
Tabelle III: Therapieansätze gemäß Literatur

\begin{tabular}{|c|c|c|c|c|c|c|c|c|c|c|}
\hline$\frac{.0}{\frac{0}{0}}$ & $\begin{array}{l}\varangle \\
0 \\
0 \\
ٌ \\
د\end{array}$ & 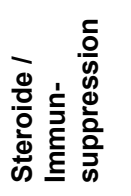 & 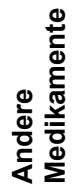 & $\begin{array}{l}\Phi \\
\$ \\
\stackrel{\$}{ \pm} \\
\text { ț }\end{array}$ & 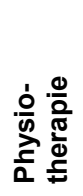 & $\begin{array}{l}\mathscr{p} \\
\stackrel{p}{a}\end{array}$ & 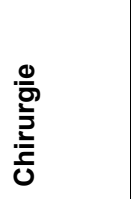 & 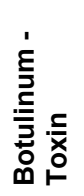 & 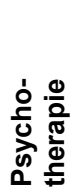 & $\frac{0}{\frac{0}{0}}$ \\
\hline (Amin et al. 2004) & & & & & & & $1(?)$ & & & \\
\hline (Ashour und Jankovic 2006) & + & & & & & & & & & \\
\hline (Askmark et al. 2001) & + & & & & & & & & & \\
\hline (az-Guzman et al. 2006) & $+(-)$ & $+(-)$ & & & $+(-)$ & & & & & \\
\hline (Bahnof 1999) & & & & & $+(+)$ & & & & & \\
\hline (Ballenger 1976) & & & & & & & & & $1(?)$ & \\
\hline (Beekman et al. 2002) & & & & & & & $1(+) \mathrm{TR}$ & & & \\
\hline (Bloch et al. 2006) & $17(+/-)$ & & & & & & & & & \\
\hline (Bouzgarou et al. 2007) & $+(-)$ & & & & & & & & & \\
\hline (Brucki und Nitrini 2008) & $1(-)$ & & & & & & & & & \\
\hline (Capelle et al. 2010) & & & & & & $7(+/-)$ & & & & \\
\hline (Sako et al. 2009) & & & & & & $6(+)$ & & & & \\
\hline $\begin{array}{l}\text { (Colosimo und Salvatori } \\
\text { 2009) }\end{array}$ & & & & & & & & $2(-)$ & & \\
\hline (D'Amelio et al. 2007) & & $1(?)$ & & & & & $1(+) \mathrm{TR}$ & & & \\
\hline (de Seze et al. 2008) & & & & $\begin{array}{l}15 \\
(+)\end{array}$ & $\begin{array}{l}15 \\
(+)\end{array}$ & & & & & \\
\hline (Delcey et al. 2002) & & $4(3+/ 1-)$ & & & & & & & & \\
\hline (Djaldetti et al. 1999) & $8(3+/ 3-)$ & & & & & & & & & \\
\hline (Dominick et al. 2006) & & $1(+) I V I g$ & & & & & & & & \\
\hline (Duman et al. 2008) & & & & & & & & & $1(+)$ & \\
\hline (Takei et al. 2009) & & & $1(+)$ & & & & & & & \\
\hline (Fietzek et al. 2009) & & & & & & & & $\begin{array}{l}10 \\
(10-)\end{array}$ & & \\
\hline (Fukaya et al. 2006) & & & & & & $3(3+) \mathrm{GPi}$ & & & & \\
\hline (Gamez et al. 2010) & & $1(-)$ IVIg & $1(-)$ & & & & & $1(-)$ & & \\
\hline (Gerton et al. 2010) & $1(-)$ & & $1(-)$ & & & & & $1(-)$ & & $\begin{array}{l}1(+) \\
\mathrm{BP}\end{array}$ \\
\hline (Gomez-Puerta et al. 2007) & & $1(-)$ & $1(-)$ & & & & & & & \\
\hline (Hellmann et al. 2006) & $1(-)$ & $1(-)$ & & & & $\begin{array}{l}1(+) \\
\text { NcIST }\end{array}$ & & & & \\
\hline (Hilliquin et al. 1992) & & $\begin{array}{l}13(11+/ \\
2-)\end{array}$ & & & & & & & & \\
\hline (Ho et al. 2007) & $1(+)$ & & & & & & & & & \\
\hline (Hurst 1918) & & & & & & & & & $\begin{array}{l}5 \\
(5+)\end{array}$ & \\
\hline (Terashima et al. 2009) & & $1(+) \mathrm{IVIg}$ & & & & & & & & \\
\hline $\begin{array}{l}\text { (Hoffman und Gutmann } \\
\text { 1994) }\end{array}$ & & $1(-)$ & & & & & & & & \\
\hline (Hund et al. 1995) & & $1(+\rightarrow-)$ & & & & & & & & \\
\hline
\end{tabular}

Darstellung: $\mathrm{n}=$ Fallzahl (wenn nicht angegeben nur + ); in Klammern Erfolg (+), Misserfolg (-) oder unklare bzw. fehlende Angabe (?), ggf. mit Angabe Fallzahl); $\rightarrow$ klinischer Verlauf; ggf. Zusatzinfo

$\mathrm{TR}=$ Tumorresektion; GPi = Globus pallidus internus; NclST = Nucleus subthalamicus; BP = „Backpack“-

Therapie; DBS = Tiefenhirnstimulation; IVIg = intravenöse Gabe von Immunglobulinen 


\subsubsection{Morphologische Beschreibungen}

In etlichen Publikationen finden sich hier kurze Aussagen. Eine systematische Analyse findet sich beispielsweise bei Delisle et al. (1993). In der Untersuchung werden offensichtlich idiopathische Kamptokormiefälle mit solchen verglichen, die im Rahmen eines Diskusprolapses oder einer Spinalkanaleinengung entstanden sind. Hierbei wird als hervorstechendes Merkmal der Kamptokormie die massive endomysiale Fibrose beschrieben. Darüber hinaus werden in beiden Gruppen teils abnorme Mitochondrien, einige „ragged red“Fasern, zentrale Aufhellungen und eine, soweit überhaupt zu beurteilende, Typ I Faserprädominanz beschrieben. Elektronenmikroskopisch werden teilweise Z-Band-Strömen und „Rods“ identifiziert. Spuler et al. (2009) berichten ein myopathisches Bild mit teils ähnlichen Aspekten, wie wir es berichten (Margraf et al. 2010). Allerdings diskutieren Spuler et al. (2009) ihre Befunde in Richtung einer MFM.

\subsection{Zielsetzung dieser Arbeit}

Die Kamptokormie findet sich als eine mögliche Begleiterkrankung oder ein Symptom im Rahmen des Morbus Parkinson, aber auch im Rahmen anderer Erkrankungen. In der Literatur finden sich sehr viele unterschiedliche Erklärungsansätze bezüglich der Entstehung dieses einschneidenden und ungewöhnlichen Krankheitsbildes. Eine einheitliche Symptomatik legt zunächst einmal einen einheitlichen Pathomechanismus nahe. Allerdings können auch mehrere unterschiedliche Mechanismen in eine einheitliche Symptomatik münden. Dies ist insbesondere von Bedeutung, wenn mehrere unterschiedliche Erkrankungen mit der gleichen Symptomatik vergesellschaftet sind. Da die Pathomechanismen offensichtlich bis heute trotz intensiver Untersuchungen nicht zu klären waren, soll mit dieser Studie der Versuch unternommen werden, durch eine klare Analyse der pathologischen Veränderungen herauszufinden, ob sich ein morphologisch einheitliches Krankheitsbild finden lässt. Um die Möglichkeit mehrerer Genesewege im Rahmen der unterschiedlichen Grunderkrankungen mit daraus denkbar unterschiedlichen pathologischen Veränderungen möglichst herauszufiltern, wurde hier ein Kollektiv von Parkinsonpatienten gewählt.

Die Idee bezüglich der Genese bei den Parkinsonpatienten war eine mögliche Rolle von pathologischen Ablagerungen von $\alpha$-Synuklein, die sich dann in der Muskulatur auswirkt. Hierbei sind prinzipiell diverse Regionen für eine solche Ablagerung denkbar: Die motorischen und sensorischen Anteile des ZNS, efferente und afferente periphere Nerven, Spinalganglien sowie die Neuromuskulären Junktionszonen (NMJ) im Muskel und die Muskelfasern selbst. In dieser Studie galt es somit neben der morphologischen Analyse auch 
nach Ablagerungen von $\alpha$-Synuklein in den mit der Muskelbiopsie erfassbaren Bereichen, nämlich der Muskelfasern, der NMJ und den innervierenden Nervenfasern zu suchen. 


\section{Material und Methoden}

\subsection{Muskelbiopsien}

Basis einer Untersuchung von Muskelbiopsien ist die an Gefrierblöcken durchgeführte feingewebliche Beurteilung von enzymatischen Schnittfärbungen. Wir konnten für die vorliegenden Untersuchungen auf Muskelbiopsien von 14 Parkinsonpatienten mit einer Kamptokormie zurückgreifen. Diese wurden unter der klinischen Frage nach Vorliegen einer Entzündung im Zeitraum 2004 bis 2010 an die Institute für Neuropathologie in Göttingen oder in Mainz geschickt. Diese Patienten wurden alle im Universitätsklinikum in Kiel klinisch betreut. Die Beurteilung des Krankheitszustandes erfolgte anhand der UPDRS-Kriterien (Fahn et al. 1987). Die klinische Bewertung der Kamptokormie erfolgte anhand der in Grafik II dargestellten Kriterien. Generell wird für eine Muskelbiopsie ein Muskel ausgewählt, der von der Erkrankung klinisch betroffen ist. Dieser Muskel darf aber andererseits nicht zu weit in seiner Schädigung fortgeschritten sein, da pathologische Veränderungen in der Endstrecke häufig ätiologisch nicht mehr einzuordnen sind. Zur Auswahl der Muskeln werden die Angaben des Patienten (Schmerz, Schwäche, Fehlfunktion), der Befund der klinischen Untersuchung (Schwellung, Atrophie, Änderung des palpatorischen Befundes), Ultraschall, Elektrophysiologie (Elektromyographie, Nervenleitgeschwindigkeit) und radiologische Bildgebung (v.a. MRT, selten CT) herangezogen. In den vorliegenden Biopsien erfolgte die Auswahl sowohl nach klinischen Gesichtspunkten,als auch nach radiologischen und elektrophysiologischen Kriterien. Die Biopsie erfolgte dann unter lokaler Anästhesie und sollte Gewebe mit einer Größe von etwa $0,5 \times 0,5 \times 1 \mathrm{~cm}$ hervorbringen.

In der ursprünglichen Routinebefundung ergab sich kein einheitliches Bild, wie aus der nachfolgenden Tabelle IV hervorgeht.

Jedoch fanden sich zumindest die zur Frage stehenden entzündlichen Veränderungen mit Ausnahme eines Begleitinfiltrates in einem Fall nicht. Etliche Veränderungen wurden wahrgenommen, aber die Einordnung erscheint schwierig. Einen Überblick über die jeweils im Befund notierten Veränderungen gibt die nachfolgende Tabelle V.

Daraus ergibt sich die Notwendigkeit einer Definition von möglichst klaren Kriterien, anhand derer eine entsprechende Diagnose gestellt werden kann.

Die Muskelbiopsien wurden von der einsendenden Klinik auf eine Gewebeblockgröße mit einer Kantenlänge von jeweils rund 0,5 cm zugeschnitten. Diese wurden dann in ein Gefriermedium überführt. Mit diesem wurden die Proben auf Korkplättchen aufgesetzt und eingefroren. Hierbei wurde eine Ausrichtung der Muskelfasern quer zur späteren 
Schnittrichtung am Gefriermikrotom angestrebt. Üblicherweise werden Muskelproben dabei in Isopentan oder Methylbutan eingefroren, der in flüssigem Stickstoff auf etwa $-80^{\circ} \mathrm{C}$ heruntergekühlt wurde. Kleinere Gewebefragmente mit einer Größe von rund ein bis drei Millimetern Durchmesser wurden in einigen Fällen in Glutaraldehyd (3 \%) fixiert. Die Präparate wurden dann auf Trockeneis (Gefrierblöcke) oder ungekühlt (Glutaraldehyd) an die neuropathologischen Institute versandt.

Im neuropathologischen Institut erfolgt die Aufarbeitung zur weiteren Untersuchung. An einem Rotationsgefriermikrotom wurden vom Gefrierblock Gefrierschnitte von 5 bis $8 \mu \mathrm{m}$ Dicke angefertigt. Diese wurden auf Glasobjektträger (silanisiert oder Super Frost) aufgezogen und für wenige Minuten an der Luft bei Raumtemperatur getrocknet. Danach wurden sie bei Bedarf eingefroren (zur Lagerung) oder in einem entsprechenden Ablauf gefärbt (histochemisch, enzymhistochemisch oder immunhistochemisch). Wenn sich starke Artefakte oder ein falsche Orientierung der Muskelfasern in den Schnittpräparaten zeigten, wurden die Proben bei Raumtemperatur wieder aufgetaut, mit Löschpapier abgetupft, der Muskelfaserrichtung entsprechend ausgerichtet und dann wieder aufgefroren.

Tabelle IV: Diagnosen der neuropathologischen Befunde

\begin{tabular}{|l|l|}
\hline Fall & Diagnose \\
\hline B1 & $\begin{array}{l}\text { SM mit myopathischen Veränderungen und endomysialer Fibrose mit Nachweis einer diffusen } \\
\text { lymphozytären Entzündung }\end{array}$ \\
\hline B2 & $\begin{array}{l}\text { SM mit Nachweis von RRF und vermehrten COX-def. Fasern sowie myopathischen } \\
\text { Veränderungen, hinweisend für eine mögliche Mitochondriopathie }\end{array}$ \\
\hline B3 & SM mit myopathischen und neurogenen Veränderungen sowie reduzierter MAD-Expression \\
\hline B4 & SM mit Typ-II-Faseratrophie \\
\hline B5 & SM mit Nachweis einer RRF bei sonst unspezifischem pathologischen Befund \\
\hline B6 & SM mit deutlichen myopathischen Veränderungen; kein Hinweis auf eine Myositis \\
\hline B7 & SM mit myopathischen Veränderungen \\
\hline B8 & SM ohne Hinweis auf entzündliches Geschehen \\
\hline B9 & $\begin{array}{l}\text { SM mit myopathischen Veränderungen und subsarkolemmaler fuchsinophiler } \\
\text { Zeichnungsvermehrg. }\end{array}$ \\
\hline B10 & SM ohne Hinweise für eine Myositis \\
\hline B11 & SM mit geringgradig myopathischen Veränderungen und diskreter Typ-II-Faseratrophie \\
\hline B12 & Diskrete Einzelfaseratrophie, vorwiegend Typ II, keine überzeugenden Zeichen einer Myositis \\
\hline B13 & $\begin{array}{l}\text { Neurogener Prozess, teils myopathische Komponente mit Entzündungszellen und } \\
\text { Hochregulierung von MHC-I auf zahlreichen Fasern }\end{array}$ \\
\hline B14 & SM mit hochgradig myopathischem Schädigungsbild und deutlichem fibrotischem Umbau \\
\hline SM = Skelettmuskulatur; RRF = ,ragged red“-Fasern
\end{tabular}


Tabelle V: Angaben aus den neuropathologischen Befunden

\begin{tabular}{|c|c|c|c|c|c|c|c|c|c|c|c|c|c|}
\hline$\frac{\bar{\pi}}{\stackrel{\mathbb{N}}{ }}$ & 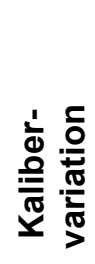 & 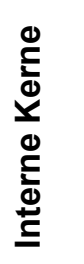 & 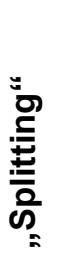 & 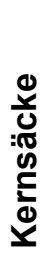 & 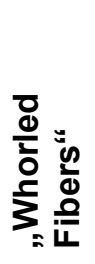 & 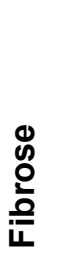 & 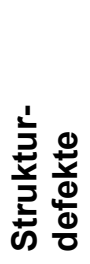 & $\frac{u}{\frac{\alpha}{\alpha}}$ & 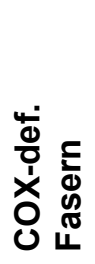 & 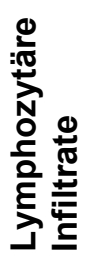 & 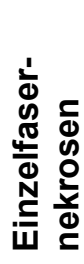 & 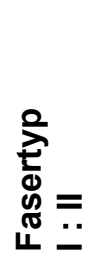 & 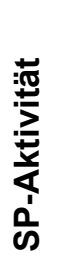 \\
\hline B1 & ++ & + & - & - & - & ++ & - & - & n.v. & + & - & n.b. & NB \\
\hline B2 & ++ & + & + & - & - & + & - & + & ++ & - & + & $>$ & - \\
\hline B3 & ++ & + & - & - & - & ++ & - & - & n.v. & - & - & - & + \\
\hline B4 & ++ & - & - & - & - & - & - & - & + & - & - & - & - \\
\hline B5 & ++ & - & n.v. & - & - & + & - & + & + & - & + & $>>$ & - \\
\hline B6 & + & + & + & - & - & + & $(+)$ & - & - & - & + & $>>$ & + \\
\hline B7 & ++ & ++ & + & - & - & ++ & - & - & - & - & - & $=$ & - \\
\hline B8 & ++ & - & - & + & - & - & - & - & + & - & - & n.b. & - \\
\hline B9 & ++ & + & + & - & - & +++ & - & ++ & ++ & - & + & $>$ & - \\
\hline B10 & - & n.v. & n.v. & - & - & - & n.b. & n.b. & n.b. & - & n.b. & $=$ & n.b. \\
\hline B11 & + & + & - & - & - & + & + & + & + & $(+)$ & + & - & + \\
\hline B12 & ++ & + & - & + & - & - & - & - & + & + & $(+)$ & $=$ & $(+)$ \\
\hline B13 & +++ & +++ & - & - & - & +++ & +++ & + & + & + & + & $>>$ & +++ \\
\hline B14 & +++ & +++ & + & + & + & +++ & ++ & - & ++ & $(-)$ & - & $>>$ & +++ \\
\hline
\end{tabular}

n.v. = nicht vermehrt; n.b. = nicht beurteilbar; $\mathrm{NB}=$ Normalbefund; k.A. = keine Angaben; $\mathrm{SP}=$ Saure

Phosphatase; Befunddarstellung: - = keine; $+=$ gering; mittel; $+++=$ stark; $(+)=$ fraglich positiver Befund; < und $>=$ überwiegen eines Typs; $>>$ und $<<=$ starkes Überwiegen

\subsection{Kontrollen}

Für die vorliegende Studie stellte sich die Frage, welche Kontrollen geeignet sein würden.

Hierbei ist zu beachten, dass sich Muskelbiopsien je nach genommener Lokalisation durchaus im physiologischen Zustand unterscheiden. Dies ist allein schon durch die unterschiedlichen Aufgaben zu erklären. So variieren die Fasertypen in ihrer Verteilung je nach dem, ob der Muskel primär Halte- oder schnelle Kontraktionsaufgaben bewältigen muss. Je nach Länge eines Muskels ist eine Biopsie sicher ohne einstrahlendes Sehnengewebe oder häufig mit einstrahlendem Sehnengewebe versehen. Auch der Durchmesser von Fasern variiert deutlich je nach benötigter Kraft. Folglich sind in der Standardliteratur einige Muskeln mit ihren typischen Befunden referenziert. Andere nur selten biopsierte Muskeln werden dagegen nicht beschrieben, woraus sich das Problem ergibt, dass Befunde in einem der nicht standardisiert biopsierten Muskeln schwieriger zu interpretieren sind. Somit erschien ein Vergleich mit anderen Muskelbiopsien aus üblicher Lokalisation nicht sehr sinnvoll. Ein Vergleich mit Muskelbiopsien aus dem Bereich der autochthonen Rückenmuskulatur ist hierbei als sinnvoll anzustreben. Da diese üblicherweise nicht unter dem normalen Biopsiegut zu finden sind, wurde für die hier gemachten Untersuchungen auf Muskelproben zurückgegriffen, die in Autopsien entnommen wurden. Es handelt sich dabei um Proben aus der zervikalen oder lumbalen Rückenmuskulatur. Die prinzipielle Eignung für die Untersuchung von postmortalen Muskelproben mittels enzymhistochemischer Färbungen wurde bereits von 
anderen Arbeitsgruppen gezeigt (Eriksson et al. 1980, Goebel et al. 1975). Auch eine elektronenmikroskopische Auswertung ist sehr gut möglich, wie Goebel et al. zeigen konnten (Goebel et al. 1975). Gewisse Alterationen werden erkannt, aber selbst feine lysosomale Speicherstrukturen sind klar zu erkennen. Da unklar war, welche Pathologie sich darstellen würde, wurden die entnommenen Rückenmuskeln mit den jeweiligen Proben aus dem Deltoidmuskel oder der Quadrizepsmuskulatur der gleichen Person verglichen. Die Aufarbeitung der Muskulatur erfolgte wie bei den Routinebiopsien. Wo möglich, wurde auch Material für die elektronenmikroskopischen Untersuchungen asserviert.

Tabelle VI: Verwendete Substanzen

\begin{tabular}{|c|c|}
\hline Substanz & Hersteller \\
\hline Aceton & Baker, Deventer, Niederlande \\
\hline $\begin{array}{l}\text { Adenosin-5-monophosphat-Dinatriumsalz } \\
\text { (AMP) }\end{array}$ & Serva Electrophoresis GmbH, Heidelberg, Deutschland \\
\hline Ammoniumsulfit & Merck, Darmstadt, Deutschland \\
\hline Ampuwa-Wasser & Fresenius Kabi, Bad Homburg, Deutschland \\
\hline Immu-Mount & Thermo Scientific, Waltham, USA \\
\hline Aquatex & Merck, Darmstadt, Deutschland \\
\hline $\begin{array}{l}\text { Araldit (inkl. Weichmacher, Beschleuniger, } \\
\text { Härter) }\end{array}$ & Serva Electrophoresis GmbH, Heidelberg, Deutschland \\
\hline Azur II & Merck, Darmstadt, Deutschland \\
\hline Barbitalnatrium & Merck, Darmstadt, Deutschland \\
\hline Bernsteinsäure-Dinatriumsalz-Hexahydrat & Merck, Darmstadt, Deutschland \\
\hline Bleizitrat & Serva Electrophoresis GmbH, Heidelberg, Deutschland \\
\hline Borax (Dinatriumtetraborat-10-hydrat) & Merck, Darmstadt, Deutschland \\
\hline Brij 35 & Sigma-Aldrich Chemie GmbH, Steinheim, Deutschland \\
\hline Brom-4-chlor-3-indoxylphosphat (BCIP) & Roche, Mannheim, Deutschland \\
\hline Calciumchlorid $\left(\mathrm{CaCl}_{2}\right)$ & Merck, Darmstadt, Deutschland \\
\hline Caseinblock & Sigma-Aldrich Chemie GmbH, Steinheim, Deutschland \\
\hline Catalase & Sigma-Aldrich Chemie GmbH, Steinheim, Deutschland \\
\hline Chromotrop R2 & $\begin{array}{l}\text { Fluka Chemie GmbH, Oberhaching, Deutschland Chemie GmbH, } \\
\text { Oberhaching, Deutschland }\end{array}$ \\
\hline Collagenase & Sigma-Aldrich Chemie GmbH, Steinheim, Deutschland \\
\hline Cytochrom C & Sigma-Aldrich Chemie GmbH, Steinheim, Deutschland \\
\hline Depex & Serva Electrophoresis GmbH, Heidelberg, Deutschland \\
\hline Diaminobenzidin (DAB) & Sigma-Aldrich Chemie GmbH, Steinheim, Deutschland \\
\hline Dimethylformamid (DMF) & Sigma-Aldrich Chemie GmbH, Steinheim, Deutschland \\
\hline Dinatriumhydrogenphosphat $\left(\mathrm{Na}_{2} \mathrm{HPO}_{4}\right)$ & Merck, Darmstadt, Deutschland \\
\hline Dithiothreitol & Sigma-Aldrich Chemie GmbH, Steinheim, Deutschland \\
\hline Eisessig & Merck, Darmstadt, Deutschland \\
\hline Eosin $\mathrm{G}$ & Merck, Darmstadt, Deutschland \\
\hline Ethanol & Carl Roth GmbH \& Co.KG, Karlsruhe, Deutschland \\
\hline Fast Green & Serva Electrophoresis GmbH, Heidelberg, Deutschland \\
\hline Formaldehyd $37 \%, 1 \%$ Methanol & Chemie Vertrieb Hannover, Hannover, Deutschland \\
\hline Glutaraldehyd 25\% & Merck, Darmstadt, Deutschland \\
\hline Glycerin-1-phosphat-Dinatrium & Fluka Chemie GmbH, Oberhaching, Deutschland \\
\hline Guanidinthiocyanat (GdnSCN) & Carl Roth GmbH \& Co.KG, Karlsruhe, Deutschland \\
\hline Hämalaun nach Mayer & Merck, Darmstadt, Deutschland \\
\hline I-Block & Tropix Inc., Bedford, USA \\
\hline Isopropanol & Chemie Vertrieb Hannover, Hannover, Deutschland \\
\hline Kaliumchlorid $\mathrm{KCl}$ & Merck, Darmstadt, Deutschland \\
\hline
\end{tabular}




\begin{tabular}{|c|c|}
\hline Substanz & Hersteller \\
\hline Kaliumdihydrogenphosphat $\left(\mathrm{KH}_{2} \mathrm{PO}_{4}\right)$ & Merck, Darmstadt, Deutschland \\
\hline Kobaltchlorid $\left(\mathrm{CoCl}_{2}\right)$ & Merck, Darmstadt, Deutschland \\
\hline Kupfersulfat $\left(\mathrm{CuSO}_{4}\right)$ & Merck, Darmstadt, Deutschland \\
\hline Levamisolhydrochlorid & MP Biomedicals, Solon, USA \\
\hline Magnesiumchlorid $\left(\mathrm{MgCl}_{2}\right)$ & Serva Electrophoresis GmbH, Heidelberg, Deutschland \\
\hline Magnesiumsulfat $\left(\mathrm{MgSO}_{4}\right)$ & Merck, Darmstadt, Deutschland \\
\hline Menadione & Sigma-Aldrich Chemie GmbH, Steinheim, Deutschland \\
\hline Methylbutan & Sigma-Aldrich Chemie GmbH, Steinheim, Deutschland \\
\hline Methylenblau & Merck, Darmstadt, Deutschland \\
\hline Methylgrün-Zinkchlorid Doppelsalz & Merck, Darmstadt, Deutschland \\
\hline NADH & Serva Electrophoresis GmbH, Heidelberg, Deutschland \\
\hline Naphthol-AS-Biphosphat & Serva Electrophoresis GmbH, Heidelberg, Deutschland \\
\hline Natriumacetat & Merck, Darmstadt, Deutschland \\
\hline Natriumchlorid $(\mathrm{NaCl})$ & Merck, Darmstadt, Deutschland \\
\hline Natriumzitrat-Dihydrat & Merck, Darmstadt, Deutschland \\
\hline Natriumhydroxid $(\mathrm{NaOH})$ & Merck, Darmstadt, Deutschland \\
\hline Natriumnitrit $\left(\mathrm{NaNO}_{2}\right)$ & Merck, Darmstadt, Deutschland \\
\hline Natriumsuccinat & Serva Electrophoresis GmbH, Heidelberg, Deutschland \\
\hline Natronlauge $(\mathrm{NaOH})$ & Merck, Darmstadt, Deutschland \\
\hline Neufuchsin & Sigma-Aldrich Chemie GmbH, Steinheim, Deutschland \\
\hline Nitroblautetrazoliumchlorid (NBT) & Sigma-Aldrich Chemie GmbH, Steinheim, Deutschland \\
\hline Oil red $\mathrm{O}$ & Sigma-Aldrich Chemie GmbH, Steinheim, Deutschland \\
\hline Osmiumtetroxid $\left(\mathrm{OsO}_{4}\right)$ & Serva Electrophoresis GmbH, Heidelberg, Deutschland \\
\hline Papain & Sigma-Aldrich Chemie GmbH, Steinheim, Deutschland \\
\hline Paraosanilin & Sigma-Aldrich Chemie GmbH, Steinheim, Deutschland \\
\hline Pepsin & Sigma-Aldrich Chemie GmbH, Steinheim, Deutschland \\
\hline Phosphate buffered Saline ( PBS) & Applichem GmbH, Darmstadt, Deutschland \\
\hline Pikrofuchsin & Merck, Darmstadt, Deutschland \\
\hline Propylenoxid & Serva Electrophoresis GmbH, Heidelberg, Deutschland \\
\hline Protease & Sigma-Aldrich Chemie GmbH, Steinheim, Deutschland \\
\hline Proteinase $\mathrm{K}$ & Sigma-Aldrich Chemie GmbH, Steinheim, Deutschland \\
\hline Salzsäure $(\mathrm{HCl})$ & Merck, Darmstadt, Deutschland \\
\hline Succrose $99,5 \%$ & Sigma-Aldrich Chemie GmbH, Steinheim, Deutschland \\
\hline Thermolysin & Sigma-Aldrich Chemie GmbH, Steinheim, Deutschland \\
\hline Tris & Carl Roth GmbH\&Co.KG, Karlsruhe, Deutschland \\
\hline Tris-Hydrochlorid & Merck, Darmstadt, Deutschland \\
\hline Tris-hydroxymethylaminomethan & Merck, Darmstadt, Deutschland \\
\hline Tween 20 & Carl Roth GmbH \& Co.KG, Karlsruhe, Deutschland \\
\hline Uranylacetat & Serva Electrophoresis GmbH, Heidelberg, Deutschland \\
\hline Weigerts Resorcin Fuchsin & Waldeck GmbH \& Co. KG, Münster, Deutschland \\
\hline Wolframatophosphorsäure & Merck, Darmstadt, Deutschland \\
\hline Xylol & Baker, Deventer, Niederlande \\
\hline Zitronensäuremonohydrat & Merck, Darmstadt, Deutschland \\
\hline
\end{tabular}

TabelleVII: Verwendete Geräte und Materialien

\begin{tabular}{|l|l|l|}
\hline Geräte / Material & Hersteller & Modell \\
\hline Ausgießstation & Thermo Scientific, Waltham, USA & Shandon Histocentre 2 \\
\hline Computer & Dell, Round Rock, USA & Optiplex 780 \\
\hline Computer & $\begin{array}{l}\text { Fujitsu-Siemens Computers, München, } \\
\text { Deutschland }\end{array}$ & \\
\hline Dateiausgabesoftware & Adobe Corporation, San Jose, USA & Acrobate 7 Professional \\
\hline Deckgläschen & G. Menzel, Braunschweig, Deutschland & \\
\hline Einbettautomat & Thermo Scientific, Waltham, USA & Excelsior ES \\
\hline Feinwaage & Sartorius, Göttingen, Deutschland & \\
\hline Fotosoftware Elektronenmikroskop & $\begin{array}{l}\text { Olympus Soft Imaging Systems GmbH, } \\
\text { Münster, Deutschland }\end{array}$ & Analysis und CellF \\
\hline Gefriermikrotom & Leica & CM 3050S \\
\hline
\end{tabular}




\begin{tabular}{|l|l|l|}
\hline Gerät/Material & Hersteller & Modell \\
\hline Gefriermikrotom & Reichert-Jung, Wien, Österreich & 2800 Frigocut \\
\hline Gefrierschrank & Liebherr, Kirchdorf a.d. Iller, Deutschland & Premium \\
\hline Gefrierschrank & Sanyo Electric Co. Ltd., Moriguchi, Japan & Ultra Low $-80^{\circ} \mathrm{C}$ \\
\hline Grafiksoftware & GraphPad Software, La Jolla,USA & GraphPad Prism 5 \\
\hline Grafiksoftware & Microsoft Corp., Redmont, USA & Office PowerPoint 2003 \\
\hline Kühlschrank & Liebherr, Kirchdorf a.d. Iller, Deutschland & Premium \\
\hline Kupfergrids & Plano GmbH, Wetzlar, Deutschland & \\
\hline Laptop & Samsung Group, Seoul, Südkorea & R55 \\
\hline Literatursoftware & The Thomson Corp., New York, USA & Reference Manager 11 \\
& & Network \\
\hline Mikroskop (Auswertung) & Olympus, Tokyo, Japan & BX41 \\
\hline Mikroskop (Fotodokumentation) & Olympus, Tokyo, Japan & BX51 mit Fotoeinheit \\
\hline Mikrotom (Paraffin) & Leica Microsystems, Wetzlar, Deutschland & SM 2000R \\
\hline Mikrotomklingen & Feather Razor, Osaka, Japan & \\
\hline Mikrowelle & Bauknecht, Schorndorf, Deutschland & 750 Watt \\
\hline Nitrozellulosemembran & BioRad Laboratories, Hercules, USA & $0,45 \mu m$ Porengröße \\
\hline Objektttäger & G. Menzel, Braunschweig, Deutschland & Superfrost \\
\hline Objektträger & $\begin{array}{l}\text { Waldemar Knittel Glasbearbeitungs-GmbH, } \\
\text { Bielefeld, Deutschland }\end{array}$ & $\begin{array}{l}\text { Objektträger } \\
\text { geschnitten }\end{array}$ \\
\hline Schüttler & Heidolph Instruments GmbH\&Co. KG, & Reax top \\
\cline { 3 - 4 } Schwenktisch & Schwalbach, Deutschland & Duomax 1030 \\
\hline Tabellensoftware & Microsoft Corp., Redmont, USA & Office Excell 2003 \\
\hline Textsoftware & Microsoft Corp., Redmont, USA & Office Word 2003 \\
\hline Transmissionselektronenmikroskop & Zeiss, Oberkochen, Deutschland & EM10 \\
\hline Ultramikrotom & Reichert-Jung, Wien, Österreich & Typ 701701 \\
\hline Ultramikrotommesser & Diatome AG, Biel, Schweiz & Ultra 45 \\
\hline Wärmeschrank & Heraeus, Hanau, Deutschland & kelvitron \\
\hline & & \\
\hline
\end{tabular}

\subsection{Enzymfärbungen / Histochemische Färbungen}

Für die nachfolgend beschriebenen enzymatischen Muskelgewebsfärbungen wurden die angefertigten Gefrierschnitte verwendet, die zuvor 10 bis $20 \mathrm{~min}$. an der Luft bei Raumtemperatur getrocknet worden sind. Bei abweichendem Procedere wird dies im jeweiligen Protokoll genannt. Die Rezepte orientieren sich an den Standardwerken der neuropathologischen Muskelbiopsiediagnostik (Dubowitz und Sewry 2007, Schröder 1982). Die (aufsteigende) Alkoholreihe umfasst Isopropanol in den Konzentrationen 50 \%, 70 \%, $90 \%, 2$ x $100 \%$, Isoxylol (Isopropanol und Xylol 1:1 gemischt) und 2 x Xylol. Die Exposition der Schnitte gegenüber den Alkoholschritten beträgt 5 min., gegenüber Isoxylol 1 min. und gegenüber Xylol je $10 \mathrm{~min}$.

\section{Übersichtsfärbung Hämatoxylin Eosin (HE)}

5 min. Mayers Hämalaun

$>$ Schnitte kurz in Aqua dest. spülen und in $1 \% \mathrm{HCl}$-Alkohol differenzieren

$>10$ min. Bläuen in Leitungswasser.

$>5$ min. Eosinlösung

$>$ Abspülen der Färbelösung in entmineralisiertem Wasser 
aufsteigende Alkoholreihe, Eindeckelung mit Depex.

Rezept Eosin:

$1 \%$ Eosin G in 70 \% Isopropanol lösen, rühren, anschließend filtrieren; vor Gebrauch mit etwas Eisessig ansäuern (wird etwas grünlich). Mayers Hämalaun ist gebrauchsfertig; metallische Beläge auf der Lösung können mit etwas Filterpapier abgenommen werden.

Bindegewebsfärbung Elastica van Gieson $(E v G)$

$>10$ min. Resorcin

$>1$ min. in Leitungswasser spülen

$>$ kurz den Hintergrund in 90 \% Isopropanol entfärben; Fasern erscheinen schwarzblau.

$>$ kurz 70 \% Isopropanol, dann 5 min. in Weigert's Eisenhämatoxylin (gebrauchsfertig)

$>$ kurz Spülen in Aqua dest. und Differenzierung in HCl-Isopropanol

$>10$ min. Leitungswasser

$>5$ min. Pikrofuchsin

$>$ kurzes Spülen in 90 \% Isopropanol, dann jeweils 3 min. in 2 x $100 \%$ Isopropanol, 1 x Isoxylol und 2 x Xylol, eindeckeln mit Depex.

Nicotinamid-Adenin-Dinucleotid-Dehydrogenase (NADH); auch Nicotinamid Dehydrogenase Tetrazolium Reduktase (NADH-TR)

90 min. Inkubation bei $37^{\circ} \mathrm{C}$ im Wärmeschrank in geschlossener Hänendahlküvette mit der Inkubationslösung (30 ml Gomori's Tris-HCl-Puffer $(6,06 \mathrm{~g}$

Tris(hydroximethyl)aminomethan + 3,4 $\mathrm{ml} \mathrm{25 \%} \mathrm{HCl}+1000 \mathrm{ml}$ Aqua bidest.; pH 7,4 mit 1 n $\mathrm{HCl}$ einstellen $)+300 \mu 1 \mathrm{NBT}(1 \mathrm{~g}$ NBT gelöst in $10 \mathrm{ml}$ 70\% DMF) $+12 \mathrm{mg}$ NAD-Na2 salt; $\mathrm{pH} 7,4$ mittels $1 \mathrm{n} \mathrm{HCl}$ oder $1 \mathrm{n} \mathrm{NaOH}$ einstellen).

$>$ Spülen mit Aqua dest., wässrig eindeckel (Aquamount)

Menadion-linked $\alpha$-Glygerophosphatase (MAG)

90 min. bei $37^{\circ} \mathrm{C}$ im Wärmeschrank in geschlossener Hänendahlküvette in der Inkubationslösung (Gemisch aus Lösung I (30 ml Gomori's Tris-HCl-Puffer (6,06g Tris(hydroximethyl)aminomethan + 3,4 $\mathrm{ml} \mathrm{25 \%} \mathrm{HCl}+1000 \mathrm{ml}$ Aqua bidest.; $\mathrm{pH}$ 7,4 mit $1 \mathrm{n} \mathrm{HCl}$ einstellen $)+300 \mu \mathrm{l}$ NBT (1 g NBT gelöst in $10 \mathrm{ml}$ 70\% DMF $)+90 \mathrm{mg}$ Glycerin-1-phosphat-di-Natriumsalz und Lösung II (12 mg Menadione + $2 \mathrm{ml}$ Aceton); $\mathrm{pH}$ 7,52 mit $1 \mathrm{n} \mathrm{NaOH}$ einstellen; nach Mischen filtrieren) inkubieren

3 x Spülen in Aqua dest., wässrig eindeckeln (Aquamount) 


\section{Succinatdehydrogenase (SDH)}

> 90 min. bei $37^{\circ} \mathrm{C}$ im Wärmeschrank in geschlossener Hänendahlküvette mit Inkubationslösung (15 ml Natriumsuccinat 0,2 mol/1 (32,4 g BernsteinsäureDinatriumsalz in $1000 \mathrm{ml}$ Aqua bidest $)+15 \mathrm{ml}$ Phosphatpuffer 0,2 mol/l (22,72 g $\mathrm{Na}_{2} \mathrm{HPO}_{4}$ und 5,4 $\mathrm{g} \mathrm{KH}_{2} \mathrm{PO}_{4}$ in $1000 \mathrm{ml}$ Aqua bidest, pH-Wert 7,4) + 300 $\mu 1 \mathrm{NBT}(1 \mathrm{~g}$ NBT gelöst in $10 \mathrm{ml}$ 70\% DMF); pH 7,5 abschließend einstellen) inkubieren

3 x Spülen in Aqua dest., wässrig eindeckeln (Aquamount)

\section{Myoadenylatdeaminase (MAD)}

$>180$ min. mit der Inkubationslösung (27 ml Aqua bidest. $+300 \mu 1$ NBT (1 g NBT gelöst in $10 \mathrm{ml} \mathrm{70 \%} \mathrm{DMF)}+12 \mathrm{mg}$ AMP $+2,1 \mathrm{ml}$ tropfenweise hinzugefügte $3 \mathrm{M}$ $\mathrm{KCl}(22,4 \mathrm{~g} \mathrm{KCl}$ in $100 \mathrm{ml}$ Aqua bidest.) + $15 \mathrm{mg}$ Dithiothreitol in $900 \mu$ l Aqua bidest. gelöst; pH 6,1 einstellen) in geschlossener Küvette bei RT inkubieren.

> $3 \mathrm{x}$ spülen in $\mathrm{KCl} /$ NatriumZitrat-Lösung $(11,2 \mathrm{~g} \mathrm{KCl}(150 \mathrm{mmol} / \mathrm{l})+0,441 \mathrm{~g}$ NatriumZitrat $(1,5 \mathrm{mmol} / \mathrm{l})+1000 \mathrm{ml}$ Aqua bidest.)

$>$ Wässrig eindeckeln (Aquamount)

\section{Cytochrom-C-Oxidase (COX)}

$>120$ min. mit der Lösung (18 ml 50 mM Phosphatpuffer pH 7,4 (7,098 g Na $\mathrm{HPO}_{4}$, $6,804 \mathrm{~g} \mathrm{KH}_{2} \mathrm{PO}_{4}, 1000 \mathrm{ml}$ Aqua bidest. $)+10 \mathrm{mg} \mathrm{DAB}+1,5 \mathrm{~g}$ Sucrose $+20 \mathrm{mg}$ Cytochrom C; dann $2 \mathrm{ml}$ Catalase (1:5000 in $50 \mathrm{mM}$ Phosphatpuffer) zur angesetzten Inkubationslösung) in geschlossener Küvette bei $37^{\circ} \mathrm{C}$ inkubieren

$>3$ x spülen in Aqua bidest., wässrig eindeckeln (Aquamount)

\section{Kombinierte COX / SDH-Färbung (COX/SDH)}

Für die kombinierte COX-SDH-Färbung werden die Schnitte zuerst für ein bis zwei Stunden in der COX-Lösung inkubiert, dann dreimal in Aqua dest. gespült und danach eine Stunde in der SDH-Lösung inkubiert. Abschließend werden die Schnitte in Aqua dest. abermals dreimal gewaschen, um schließlich mit Aquamount eingeschlossen zu werden. Die Lösungen und die Bedingungen entsprechen denen der jeweiligen Einzelfärbungen.

\section{Saure Phosphatase (SP)}

$>60$ min. bei $37^{\circ} \mathrm{C}$ in verschlossener Küvette mit der Inkubationslösung inkubieren

$>3$ x spülen in Aqua dest. 
$>$ Kurz (30 sek. bis 3 min.) gegenfärben mit Methylgrün $(0,2 \mathrm{~g}$ Methylgrün $+20 \mathrm{ml}$ $\mathrm{Na}_{2} \mathrm{HPO}_{4}\left(28,4 \mathrm{~g} \mathrm{Na}_{2} \mathrm{HPO}_{4}\right.$ in $1000 \mathrm{ml}$ Aqua bidest)).

$>$ Spülen in Aqua bidest

$>$ Schnitte an der Luft bei Raumtemperatur trocknen lassen (ca. 30 min.)

Eindeckeln mit Depex

Inkubationslösung:

a) $36 \mathrm{ml}$ Aqua bidest. $+15 \mathrm{ml}$ Veronalacetat-Gebrauchslösung (20 ml Stammlösung $(14,714 \mathrm{~g}$ Barbitalnatrium $+9,714 \mathrm{~g}$ Natrium-Acetat $+500 \mathrm{ml}$ Aqua bidest.) $+32 \mathrm{ml} \mathrm{0,1} \mathrm{M} \mathrm{HCl}+48 \mathrm{ml}$ Aqua bidest.)

b) 2,4 ml Paraosanilin azotiniert ( $1 \mathrm{~g}$ Paraosanilin $+20 \mathrm{ml}$ Aqua bidest. $+5 \mathrm{ml} 37 \%$ $\mathrm{HCl}$; Lösung erwärmen, Substanzen lösen, abkühlen. Filtrierte Lösung im Kühlschrank lagern, haltbar) +2,4 $\mathrm{ml} 4 \%$ Natriumnitrit (4 g Natriumnitrit in $100 \mathrm{ml}$ Aqua bidest.)

c) $3 \mathrm{ml} \mathrm{N}-\mathrm{N}$-Dimethylformamid + $30 \mathrm{mg}$ AS-Bi-Phosphat

Lösung b zu a, dann c in Lösung zugeben. Einstellen des $\mathrm{pH}$-Wertes auf 5; filtrieren.

Kombination der sauren Phosphatase mit oxidativen Fermentreaktionen (eigene Austestung): Die Kombination (mit NADH, SDH oder COX) kann nur erfolgen, wenn die oxidative Fermentreaktion zuerst durchgeführt wird und die saure Phosphatase als zweite Reaktion ausgeführt wird. Die Rezepte entsprechen denen der Einzelfärbungen. Eindeckelung erfolgte mittels Aquamount, allerdings mit deutlicher Blasenbildung (erneutes Eindeckeln teilweise nötig).

\section{Trichrom (modifiziert nach Gomori)}

$>3$ min. Mayers Hämalaunlösung

$>10$ min. in Leitungswasser bläuen, dann 2 x spülen mit Ampuwa-Wasser

$>10$ min. mit Gomori's Mixture (12 g Chromotrop R2 + 6 g Fast Green +12 g Wolframatophosphorsäure + $10 \mathrm{ml}$ Eisessig + $1000 \mathrm{ml}$ Aqua bidest; pH 3,4 einstellen; Lösung im Kühlschrank lange haltbar) inkubieren (RT).

$>1 \times$ spülen in Ampuwa

$>$ Entwässerung in aufsteigender Alkoholreihe, eindeckeln mit Depex. 
Adenosintriphosphatase (ATPase)

ATPase 4,4

5 min. Vorinkubation in

Vorinkubationslsg. $\mathrm{pH} \mathrm{4,4}$

5 min. Waschen in Waschlsg.

pH 9,4

45 min. Inkubationslsg.

$\mathrm{pH} 9,4$ bei $37^{\circ} \mathrm{C}$
ATPase 4,7

5 min. Vorinkubation in

Vorinkubationslsg. $\mathrm{pH} \mathrm{4,7}$

5 min. Waschen in Waschlsg.

pH 9,4

45 min. Inkubationslsg.

$\mathrm{pH} 9,4$ bei $37^{\circ} \mathrm{C}$

$3 \times$ Waschen in $1 \% \mathrm{CaCl}_{2}$

$3 \min .2 \% \mathrm{CoCl}_{2}$

$3 \mathrm{x}$ spülen in Aqua bidest.

$1 \mathrm{~min}$. Ammoniumdisulfid
ATPase 10,4

10 min. Vorinkubation in

Vorinkubationslsg. pH 10,4

25 min. Inkubationslsg.

$\mathrm{pH} 9,4$ bei $37^{\circ} \mathrm{C}$

5 min. spülen in Leitungswasser, lufttrocknen, kurz in Xylol tauchen, mit Depex eindeckeln Rezepte:

Lösung A:

$40 \mathrm{ml} \mathrm{0,1} \mathrm{M} \mathrm{Natriumbarbiturat} \mathrm{(20,62} \mathrm{g} \mathrm{Natriumbarbiturat} \mathrm{auf} 1000 \mathrm{ml}$ Aqua bidest.)

$+24 \mathrm{ml} 2 \% \mathrm{CaCl}_{2}\left(20 \mathrm{~g} \mathrm{CaCl}_{2}\right.$ in $1000 \mathrm{ml}$ Aqua bidest. $)+160 \mathrm{ml}$ Aqua bidest.

Daraus werden folgende Lösungen erstellt:

Inkubationslösung $\mathrm{pH}$ 9,4:

100 ml Lösung A + 0,2 g ATP; pH 9,4 einstellen

Waschlösung $\mathrm{pH}$ 9,4:

$80 \mathrm{ml}$ werden auf pH 9,4 eingestellt

Vorinkubationslösung pH 10,4:

$30 \mathrm{ml}$ werden auf $\mathrm{pH}$ 10,4 eingestellt

Lösung B:

33,8 $\mathrm{ml} \mathrm{0,2} \mathrm{M} \mathrm{Natriumacetat} \mathrm{(27,2} \mathrm{g} \mathrm{Natriumacetat} \mathrm{auf} 1000 \mathrm{ml}$ Aqua bidest.) +

41,2 $\mathrm{ml} \mathrm{0,2} \mathrm{M} \mathrm{Essigsäure} \mathrm{(11,6} \mathrm{ml} \mathrm{Eisessig} \mathrm{auf} 1000 \mathrm{ml}$ Aqua bidest.)

Daraus werden folgende Lösungen hergestellt:

Vorinkubationslösung $\mathrm{pH}$ 4,4: $30 \mathrm{ml}$ werden auf $\mathrm{pH}$ 4,4 gebracht

Vorinkubationslösung $\mathrm{pH}$ 4,7: $30 \mathrm{ml}$ werden auf $\mathrm{pH}$ 4,7 gebracht

Folgende Basislösungen werden benutzt:

$1 \%$ bzw. $2 \% \mathrm{CaCl}_{2}$ : $\quad$ Es werden $10 \mathrm{~g}$ bzw. $20 \mathrm{~g} \mathrm{CaCl}_{2}$ in $1000 \mathrm{ml}$ Aqua bidest. gelöst

$2 \% \mathrm{CoCl}_{2}$ : $\quad$ Es werden $20 \mathrm{~g} \mathrm{CoCl}_{2}$ in $1000 \mathrm{ml}$ Aqua bidest. gelöst

$1 \%$ Ammoniumsulfit: $\quad 0,5 \mathrm{ml}$ Ammoniumsulfit auf $50 \mathrm{ml}$ Aqua bidest 


\section{Oil-red-O (ORO)}

$>10$ min. fixieren in Baker's Formol (100 ml 37 \% Formaldehyd +270 ml Aqua bidest. $\left.+3,2 \mathrm{~g} \mathrm{CaCl}_{2}\right)$

$>3 \mathrm{x}$ spülen in Leitungswasser

$>2 \mathrm{x}$ spülen in Aqua dest.

$>10$ min. Inkubation in der Ölrot-Gebrauchslösung (24 ml Stammlösung (2,5 g Oil-Red in $500 \mathrm{ml} 100 \%$ Isopropanol lösen) + $16 \mathrm{ml}$ Aqua dest. lange mit dem Magnetrührer rühren und filtrieren) bei Raumtemperatur.

$>$ Spülen mit Aqua dest.

$>2$ min. Mayer's Hämalaun

$>10$ min. in Leitungswasser bläuen

$>$ Eindeckeln erfolgt wässrig (Aquamount)

\section{$2.4 \quad$ Allgemeine Rezepte}

Formaldehyd zur Gewebefixierung:

$4 \%$ Formalin $=5000 \mathrm{ml} 37 \%$ Formalin + Puffer $\left(440 \mathrm{~g} \mathrm{NaCl}+120 \mathrm{~g} \mathrm{Na}_{2} \mathrm{HPO}_{4}+\right.$

13,5 $\mathrm{g} \mathrm{K}_{2} \mathrm{HPO}_{4}+2000 \mathrm{ml}$ Aqua dest.) mischen; auffüllen auf 501 mit Aqua dest.

Paraformaldehyd (PAF) zur Gewebefixierung:

$4 \%$ PFA $=160$ g PFA + 96 g PBS + 1000ml Wasser; erhitzen unter Rühren, bis

Lösung klar, pH 7,4 einstellen.

„, Tris buffered saline“ (TBS) als Puffer:

10mM TrisHCl + $100 \mathrm{mM} \mathrm{NaCl}$; pH 7,8 (für TBST: Zugabe von 0,05\% Tween 20)

„Phosphate buffered saline“ (PBS) als Puffer:

9,6 g PBS mit 1000ml Aqua dest. auffüllen und schütteln, bis Salze gelöst PK-Verdaupuffer:

$10 \mathrm{mM}$ TrisHCl $+100 \mathrm{mM} \mathrm{NaCl}+0,1 \%$ Brij 35; pH 7,8

Caseinblock als unspezifischer Proteinblock:

0,2 \% Caseinblock: 2 g I-Block $+100 \mathrm{ml}$ PBS; Rühren zum lösen bei $50^{\circ} \mathrm{C}$;

herunterkühlen, dann $1 \mathrm{ml} 100 \%$ Tween 20 zugegeben

Natrium-Tris-Magnesium-Puffer (NTM):

$100 \mathrm{mM}$ TrisHCl pH 9,5 + $100 \mathrm{mM} \mathrm{NaCl}+50 \mathrm{mM} \mathrm{MgCl}_{2}$

PET-blot-Färbelösung:

$45 \mu 1 \mathrm{NBT}(75 \mathrm{mg} / \mathrm{ml}$ NBT in $70 \%$ DMFA $)+33 \mu 1$ BCIP $(50 \mathrm{mg} / \mathrm{ml} \mathrm{BCIP}$ in $100 \%$ DMFA) + 10 ml NTM 


\section{AEC-Chromogen:}

Stammlösung: 2 g 3-Amino-9-Ethylcarbazol in $500 \mathrm{ml}$ DMF lösen, dunkel verwahren Gebrauchslösung: 4 ml AEC-Stammlösung + 56 ml 0,1 M Acetatpuffer pH 5,2, dann

Filtrieren; Zugabe von $20 \mu 130 \% \mathrm{H}_{2} \mathrm{O}_{2}$

Acetatpuffer 0,1 M:

$300 \mathrm{ml} \mathrm{Lsg}$. A (5,75 ml Eisessig + $1000 \mathrm{ml}$ Aqua dest.) $+700 \mathrm{ml} \mathrm{Lsg.} \mathrm{B}$

$(13,61 \mathrm{~g}$ Natriumacetat-Trihydrat $+1000 \mathrm{ml}$ Aqua dest.) mischen, $\mathrm{pH}$ 5,2 einstellen

DAB-Chromogen:

Stammlösung: 1 g 3,3-Diaminobenzidin + 40 ml PBS; aliquotiert einfrieren

Gebrauchslösung: $1 \mathrm{ml}$ DAB-Stammlösung $+50 \mathrm{ml} \mathrm{PBS}+20 \mu 1 \mathrm{H}_{2} \mathrm{O}_{2}$

Neufuchsinchromogen:

Stammlösung: $30 \mathrm{ml} 25 \% \mathrm{HCl}+70 \mathrm{ml}$ Aqua dest. mischen, $5 \%$ Neufuchsin lösen

Gebrauchslösung: Lsg. A (10 mg NaNO $2+250 \mu 1$ Aqua bidest. $+100 \mu 1$

Neufuchsins-Stammlsg.) und Lsg. B (14 mg Naphthol-AS-Biphosphat + $300 \mu 1$ DMF)

jeweils anmischen; dann in Lsg. C (50 ml TBS pH 8,8 + $20 \mathrm{mg}$ Levamisol)

pipettieren, kurz schwenken, dann filtrieren

\subsection{Immunhistochemie}

Für die immunhistochemischen Untersuchungen existieren unterschiedliche Protokolle, von denen in den hier vorliegenden Untersuchungen drei zum Einsatz kamen. Wichtig ist, dass für die Studien im vorliegenden Fall Gefriergewebe vorlag, bei dem eine Maskierung von Antigenen durch eine Quervernetzung von Proteinen (z.B. durch Fixierung in Aldehyden wie Formalin) nicht vorliegt. Somit sind die Färbungen teilweise als Färbung auf dem völlig unfixierten und lediglich luftgetrockneten (über Nacht bei RT) Gewebeschnitt etabliert. In diesen Fällen werden die Schnitte nach dem Trocknen zuerst mit $3 \%$ Wasserstoffperoxyd $\left(\mathrm{H}_{2} \mathrm{O}_{2}\right)$ für 10 min. inkubiert, um die muskeleigenen Peroxydasen zu blockieren. Es folgt ein Spülschritt mit PBS. Danach wird der nur in PBS gelöste Antikörper für 90 min. auf den in einer feuchten Kammer befindlichen Schnitt pipettiert (je nach Größe des Schnittes sind zwischen 30 und $120 \mu 1$ Antikörperlösung nötig). Nach der Inkubation folgt dreimaliges Waschen in PBS. Danach werden die Schnitte mit dem biotinylierten oder einem APgekoppelten Sekundärantikörper beschickt, der gegen die Spezies gerichtet ist, in der der Primärantikörper erzeugt worden ist. Die Schnitte inkubieren nun 45 bis 60 min. in der feuchten Kammer. Nach der Inkubation wird abermals 3 x 5 min. in PBS gespült. Um den an das Epitop gebundenen Primärantikörper, der durch den Sekundärantikörper mit Biotin 
versehen ist, nachzuweisen, erfolgt die Inkubation (feuchte Kammer) mit ExtravidinHRP(1:1000 in PBS), bei AP-gekoppelten Antikörpern entfällt dieser Schritt. Hierbei handelt es sich um ein Streptavidin, dass an Meerrettichperoxidase gebunden ist. Nach diesem Schritt wird wieder 3 x 5 min. in PBS gespült. Die Farbreaktion erfolgt mit DAB- oder AECChromogen (HRP) oder Neufuchsin-Chromogen (AP). Die Reaktion benötigt 5 bis 30 min. und wird bei erreichen einer kräftigen Farbintensität in PBS abgestoppt (Beurteilung mittels Mikroskop). Die Schnitte werden noch in Aqua dest. gespült. Je nach Antikörper wird mit Hämalaun eine Minute gegengefärbt. Eine Gegenfärbung erfolgt nur, wenn sie das eigentliche Färbesignal nicht in der Beurteilbarkeit einschränkt. Schwache membranständige Signale werden beispielsweise oft überdeckt, weshalb in diesen Fällen die Gegenfärbung unterbleibt. Nach der Inkubation mit Hämalaun werden die Schnitte in Leitungswasser für 10 min. gebläut. Zum Eindeckeln wird Immumount /Aquamount verwendet. Dabei handelt es sich um ein hydrophiles Eindeckmedium. Hierfür wird die Lösung auf das Deckglas aufgetropft, wobei die Bildung von Luftblasen möglichst vermieden werden sollte. Deckglas am Schnittrand ansetzen und auf das Präparat gleiten lassen.

Eine Variation dieses Protokolls besteht in der Fixierung der Schnittpräparate nach der Lufttrocknung. Diese Erfolgt dann für $20 \mathrm{~min}$. in eiskaltem Aceton bei $-20^{\circ} \mathrm{C}$. Vorteil dieser Fixierung ist die deutlich bessere Haftung des Gewebes auf dem Objektträger und die geringere Schädigung durch die anschließenden Färbeprozeduren. Nächster Unterschied ist die zusätzlich vorgenommene Blockierung unspezifischer Proteinbindung durch 20 min. Inkubation mit 0,2 \% Caseinblock. Nach diesen beiden Schritten wird wie im zuvor beschriebenen Protokoll verfahren (Peroxidblock, Primärantikörper, Sekundärantikörper, ggf. Extravidin-HRP, Chromogen, ggf. Gegenfärbung).

Die dritte Variante umfasst eine Fixierung der getrockneten Schnitte für eine Stunde in PFA bei RT. In dieser Färbung wird das Gewebe fest an die Objektträger gebunden und die Proteine werden miteinander quervernetzt. Daraus ergibt sich häufig die Notwendigkeit einer Freilegung von Epitopen, die in den hier vorliegenden Fällen mittels ,heat induced epitope retrieval (HIER)“ durchgeführt wurde. Dazu werden die Schnitte in eine Kunststoffküvette gestellt, in der sich Zitratpuffer befindet. In dieser werden die Schnitte entweder im Dampftopf für 30 min. gekocht oder in der Mikrowelle 5 x 3 min. gekocht. Die hierbei verdunstende Flüssigkeit wird durch Aqua bidest. ersetzt. Nach dem Erhitzen lässt man die Küvetten bei RT für etwa 20 min. abkühlen. Dann erfolgt der Blockschritt gegen unspezifische Antikörperbindung mit Hilfe von 0,2 \% Caseinblock für 20 min. Nach diesem Schritt wird wie im zuerst genannten Immunhistochemieprotokoll verfahren (Peroxidblock, 
Primärantikörper, Sekundärantikörper, ggf. Extravidin-HRP, Chromogen, ggf.

Gegenfärbung). Zum Eindeckeln werden die Schnitte bei DAB-Färbung durch eine aufsteigende Alkoholreihe einschließlich Xylol entwässert und dann mit Depex eingedeckelt. Neufuchsin- und AEC-gefärbte Schnitte werden wässrig (Immu-Mount) eingedeckelt.

Tabelle VIII: Verwendete Antikörper für immunologische Detektionsverfahren

\begin{tabular}{|c|c|c|c|c|c|c|}
\hline $\begin{array}{c}\text { Erst- } \\
\text { antikörper }\end{array}$ & Spezies & Klon & Quelle & Verd. & $\begin{array}{c}\text { Epitop- } \\
\text { demaskierung }\end{array}$ & Zielstruktur \\
\hline$\alpha$-actinin & Maus mk & EA-53 & $\begin{array}{l}\text { Sigma-Aldrich } \\
\text { Chemie GmbH, } \\
\text { Steinheim, } \\
\text { Deutschland }\end{array}$ & $1: 800$ & Protease & \\
\hline $\begin{array}{l}\beta- \\
\text { Crystallin }\end{array}$ & $\begin{array}{l}\text { Kaninchen } \\
\text { pk }\end{array}$ & - & $\begin{array}{l}\text { Oncogene Research } \\
\text { Products, San } \\
\text { Diego, USA }\end{array}$ & $1: 2000$ & Keine & \\
\hline Actin & Maus mk & $1 \mathrm{~A} 4$ & $\begin{array}{l}\text { Beckman Coulter, } \\
\text { Brea, USA }\end{array}$ & Keine & Zitrat MW & $\begin{array}{l}\text { Glatte Muskel- } \\
\text { zellen }\end{array}$ \\
\hline $\begin{array}{l}\alpha-5- \\
\text { Laminin }\end{array}$ & Maus mk & $4 \mathrm{C} 7$ & $\begin{array}{l}\text { Merck KGaA } \\
\text { (Chemicon), } \\
\text { Darmstadt, } \\
\text { Deutschland }\end{array}$ & $1: 50$ & & Kapillaren \\
\hline AT8 (Tau) & Maus mk & & $\begin{array}{l}\text { Pierce } \\
\text { Biotechnology, } \\
\text { Rockford, USA }\end{array}$ & $1: 100$ & Keine & Tauprotein \\
\hline $\begin{array}{l}\text { BA4 } \\
\text { (Amyloid) }\end{array}$ & Maus mk & $6 \mathrm{E} 10$ & $\begin{array}{l}\text { Merck KGaA } \\
\text { (Chemicon), } \\
\text { Darmstadt, } \\
\text { Deutschland }\end{array}$ & $1: 2000$ & $\begin{array}{l}30 \text { “ } 50 \% \\
\text { Ameisensäure, } \\
\text { Zitrat MW }\end{array}$ & Beta-Amyloid \\
\hline $\begin{array}{l}\text { Cathepsin } \\
\text { D }\end{array}$ & $\begin{array}{l}\text { Kaninchen } \\
\text { pk }\end{array}$ & - & $\begin{array}{l}\text { Dianova GmbH, } \\
\text { Hamburg, } \\
\text { Deutschland }\end{array}$ & $1: 100$ & Zitrat MW & Lysosomen \\
\hline CD3 & Ratte $\mathrm{mk}$ & CD3-12 & $\begin{array}{l}\text { AbD Serotec, } \\
\text { Kidlington, Groß } \\
\text { Britannien }\end{array}$ & & & T-Zellen \\
\hline CD8 & Maus mk & $\mathrm{C} 8 / 144 \mathrm{~B}$ & $\begin{array}{l}\text { Dako, Glostrup, } \\
\text { Dänemark }\end{array}$ & & & $\begin{array}{l}\text { zytotoxischeT- } \\
\text { Zellen }\end{array}$ \\
\hline CD20 & Maus mk & $\mathrm{L} 26$ & $\begin{array}{l}\text { Dako, Glostrup, } \\
\text { Dänemark }\end{array}$ & $1: 100$ & Zitrat MW & B-Zellen \\
\hline CD56 & Maus mk & $123 \mathrm{C} 3$ & $\begin{array}{l}\text { Zymed / Invitrogen, } \\
\text { Carlsbad, USA }\end{array}$ & & & N-CAM \\
\hline $\begin{array}{l}\text { Dystrophin } \\
\text { I }\end{array}$ & Maus mk & Dy4/6D3 & $\begin{array}{l}\text { Novocastra / Leica } \\
\text { Microsystems, } \\
\text { Wetzlar, } \\
\text { Deutschland }\end{array}$ & $1: 40$ & $\varnothing$ & $\begin{array}{l}\text { Dystrophin } \\
\text { (,,rod-region“) }\end{array}$ \\
\hline $\begin{array}{l}\text { Dystrophin } \\
\text { II }\end{array}$ & Maus mk & Dy8/6C5 & $\begin{array}{l}\text { Novocastra / Leica } \\
\text { Microsystems, } \\
\text { Wetzlar, } \\
\text { Deutschland }\end{array}$ & $1: 40$ & $\varnothing$ & $\begin{array}{l}\text { Dystrophin (C- } \\
\text { terminal) }\end{array}$ \\
\hline $\begin{array}{l}\text { Dystrophin } \\
\text { III }\end{array}$ & Maus mk & Dy10/12B2 & $\begin{array}{l}\text { Novocastra / Leica } \\
\text { Microsystems, } \\
\text { Wetzlar, } \\
\text { Deutschland }\end{array}$ & $1: 40$ & $\varnothing$ & $\begin{array}{l}\text { Dystrophin (N- } \\
\text { terminal) }\end{array}$ \\
\hline Desmin & Maus mk & D33 & $\begin{array}{l}\text { Dako, Glostrup, } \\
\text { Dänemark }\end{array}$ & konz. & Zitrat MW & Desmin \\
\hline Filamin & Maus mk & FLMN 01 & $\begin{array}{l}\text { Dianova GmbH, } \\
\text { Hamburg, Deutschl. }\end{array}$ & $1: 200$ & & Filamin \\
\hline
\end{tabular}




\begin{tabular}{|c|c|c|c|c|c|c|}
\hline $\begin{array}{c}\text { Erst- } \\
\text { antikörper }\end{array}$ & Spezies & Klon & Quelle & Verd. & $\begin{array}{c}\text { Epitop- } \\
\text { demaskierung }\end{array}$ & Zielstruktur \\
\hline KiM1P & Maus mk & KiM1P & $\begin{array}{l}\text { Universitätsmedizin } \\
\text { Kiel, Kiel, } \\
\text { Deutschland }\end{array}$ & $1: 1000$ & & Makrophagen \\
\hline LAMP-1 & Maus mk & E 5 & $\begin{array}{l}\text { Santa Cruz } \\
\text { Biotechnologies, } \\
\text { Santa Cruz, USA } \\
\end{array}$ & $1: 50$ & Zitrat MW & Lysosomen \\
\hline LB509 & Maus mk & LB509 & $\begin{array}{l}\text { Signet / Covance, } \\
\text { Princeton, USA }\end{array}$ & $1: 250$ & Zitrat MW & $\alpha$-Synuklein \\
\hline MHC-I & Maus mk & W6/32 & $\begin{array}{l}\text { Dako, Glostrup, } \\
\text { Dänemark }\end{array}$ & $1: 500$ & & $\begin{array}{l}\text { MHC-I- } \\
\text { Komplex }\end{array}$ \\
\hline MuSK & $\begin{array}{l}\text { Kaninchen } \\
\text { pk }\end{array}$ & & $\begin{array}{l}\text { Abcam plc, } \\
\text { Cambridge, Groß } \\
\text { Britannien }\end{array}$ & $1: 50$ & & $\begin{array}{l}\text { NMJ post- } \\
\text { synaptisch }\end{array}$ \\
\hline Myotilin & Maus mk & & $\begin{array}{l}\text { Novocastra / Leica } \\
\text { Microsystems, } \\
\text { Wetzlar, } \\
\text { Deutschland }\end{array}$ & $1: 50$ & & Myotilin \\
\hline $\begin{array}{l}\text { Neuro- } \\
\text { filament }\end{array}$ & Maus mk & $2 \mathrm{~F} 11$ & $\begin{array}{l}\text { Dako, Glostrup, } \\
\text { Dänemark }\end{array}$ & $1: 100$ & Zitrat MW & Axone \\
\hline Prohibitin & Maus mk & II-14-10 & $\begin{array}{l}\text { Abcam plc, } \\
\text { Cambridge, Groß } \\
\text { Britannien }\end{array}$ & $1: 100$ & Zitrat MW & Mitochondrien \\
\hline Prohibitin & $\begin{array}{l}\text { Kaninchen } \\
\text { pk }\end{array}$ & & $\begin{array}{l}\text { Dianova GmbH, } \\
\text { Hamburg, } \\
\text { Deutschland }\end{array}$ & $1: 100$ & Zitrat MW & Mitochondrien \\
\hline pSer87 & $\begin{array}{l}\text { Kaninchen } \\
\text { pk }\end{array}$ & & $\begin{array}{l}\text { Santa Cruz } \\
\text { Biotechnologies, } \\
\text { Santa Cruz, USA }\end{array}$ & $1: 100$ & & \\
\hline pSer129 & $\begin{array}{l}\text { Kaninchen } \\
\text { pk }\end{array}$ & - & $\begin{array}{l}\text { Abcam plc, } \\
\text { Cambridge, Groß } \\
\text { Britannien }\end{array}$ & $1: 100$ & Zitrat MW & $\alpha$-Synuklein \\
\hline pSyn64 & Maus mk & pSyn\#64 & Wako, Osaka, Japan & $1: 1000$ & $\begin{array}{l}5 \text { min. } \\
\text { Ameisensäure; } \\
15 \text { min. } 0,05 \% \\
\text { Trypsin bei } \\
37^{\circ} \mathrm{C}\end{array}$ & $\alpha$-Synuklein \\
\hline P62 & Maus mk & $\begin{array}{l}\text { 3/P62 LCK } \\
\text { LIGAND }\end{array}$ & $\begin{array}{l}\text { BD Biosciences, } \\
\text { Franklin Lakes, } \\
\text { USA }\end{array}$ & $1: 500$ & Zitrat Steamer & Ubiquitin \\
\hline SERCA 1 & Maus mk & VE121G9 & $\begin{array}{l}\text { Dianova / Thermo } \\
\text { Scientific }\end{array}$ & $1: 500$ & Zitrat MW & $\begin{array}{l}\text { Sarkoendo- } \\
\text { plasmatische } \\
\text { Ca-ATPase }\end{array}$ \\
\hline Syn-1/42 & Maus mk & Syn-1/42 & $\begin{array}{l}\text { BD Biosciences, } \\
\text { Franklin Lakes, } \\
\text { USA }\end{array}$ & $1: 50$ & & $\alpha$-Synuklein \\
\hline Syn 204 & Maus mk & Syn204 & $\begin{array}{l}\text { Acris Antibodies } \\
\text { GmbH, Herford, } \\
\text { Deutschland }\end{array}$ & $1: 50$ & Zitrat MW & $\alpha$-Synuklein \\
\hline $3 \mathrm{~F} 4$ & Maus mk & $3 \mathrm{~F} 4$ & $\begin{array}{l}\text { Deutsches } \\
\text { Primatenzentrum } \\
\text { (DPZ), Göttingen, } \\
\text { Deutschland }\end{array}$ & $1: 200$ & Zitrat MW & Prionprotein \\
\hline 4B12 & Maus mk & 4B12 & $\begin{array}{l}\text { Abcam plc, } \\
\text { Cambridge, Groß } \\
\text { Britannien }\end{array}$ & 1.500 & Zitrat MW & $\alpha$-Synuklein \\
\hline $12 \mathrm{~F} 10$ & Maus mk & $12 \mathrm{~F} 10$ & $\begin{array}{l}\text { DPZ, Göttingen, } \\
\text { Deutschland }\end{array}$ & $1: 500$ & $\begin{array}{l}\text { GdSCN } 30^{\prime}, \\
\text { Zitrat MW }\end{array}$ & Prionprotein \\
\hline
\end{tabular}




\begin{tabular}{|l|l|l|l|l|l|l|}
\hline $\begin{array}{l}\text { Sekundär- } \\
\text { antikörper }\end{array}$ & Spezies & $\begin{array}{c}\text { Konju- } \\
\text { gation }\end{array}$ & \multicolumn{1}{|c|}{ Quelle } & $\begin{array}{c}\text { Ver- } \\
\text { dünnung }\end{array}$ & Chromogen & \\
\hline anti-Maus & Schaf & Biotin & $\begin{array}{l}\text { GE Healthcare, } \\
\text { Chalfont St. Giles; } \\
\text { Groß Britannien }\end{array}$ & $1: 200$ & $\begin{array}{l}\text { Detektion mit } \\
\text { Extravidin- } \\
\text { peroxidase } \\
\text { (Sigma-Aldrich, } \\
1: 1.000) \text { und } \\
\text { DAB oder AEC }\end{array}$ & \\
\hline $\begin{array}{l}\text { Anti- } \\
\text { Kaninchen }\end{array}$ & Esel & Biotin & $\begin{array}{l}\text { GE Healthcare, } \\
\text { Chalfont St. Giles; } \\
\text { Groß Britannien }\end{array}$ & $1: 200$ & & \\
\hline anti-Ratte & Kaninchen & Biotin & $\begin{array}{l}\text { Dako, Glostrup, } \\
\text { Dänemark }\end{array}$ & $1: 200$ & & \\
\hline anti-Maus & Ziege & $\begin{array}{l}\text { Alkalische } \\
\text { Phos- } \\
\text { phatase }\end{array}$ & $\begin{array}{l}\text { Dako, Glostrup, } \\
\text { Dänemark }\end{array}$ & $1: 500$ & Neufuchsin & \\
\hline
\end{tabular}

\subsection{Elektronenmikroskopie}

a) Fixierung:

Gewebe wird über Nacht bei $4^{\circ} \mathrm{C}$ in $3 \%$ Glutaraldehyd fixiert $(12 \mathrm{ml} 25 \%$ Glutaraldehyd, $88 \mathrm{ml}$ PBS)

Hernach 2 x 5 min. Spülen in PBS

b) Nachfixierung:

$1 \mathrm{~h}$ bei $4^{\circ} \mathrm{C}$ in $1 \% \mathrm{OsO}_{4}$ (Stock: $2 \% \mathrm{OsO}_{4}=1 \mathrm{~g} \mathrm{OsO}_{4}$ in $50 \mathrm{ml}$ Aqua bidest. gelöst; zum

Gebrauch 1:1 in PBS verdünnen)

2 x 5 min. spülen in PBS

c) Dehydrieren:

10 min. $50 \%$ Ethanol

$1 \mathrm{~h}$ bei $4{ }^{\circ} \mathrm{C}$ in $0,5 \%$ Uranylacetat in $70 \%$ Ethanol

10 min. $80 \%$ Ethanol

10 min. $96 \%$ Ethanol

2 x 15 min. $100 \%$ Ethanol

2 x 20 min. Propylenoxid

d) Einbettung:

35 min. in Gemisch $1: 1$ Araldit und Propylenoxid

35 min. in Gemisch 2: 1 Araldit und Propylenoxid

$1 \mathrm{~h}$ reines Araldit offen im Abzug

Die Proben werden dann mit einem Beschriftungszettel in die Vertiefung eines auf $60{ }^{\circ} \mathrm{C}$ vorgewärmten Silikonförmchens gelegt. Diese Vertiefungen werden dann mit Araldit ausgefüllt. Unter dem Stereomikroskop werden die Präparate dann in der Regel so 
ausgerichtet, dass die Muskelfasern später längs und nicht quer angeschnitten werden.

Abschließend werden die Proben bei $60^{\circ} \mathrm{C}$ für 72 Stunden im Wärmeschrank gehärtet. Rezept $10 \mathrm{ml}$ Araldit (ist gekühlt einige Zeit haltbar):

5,65 ml Araldit $+5.55 \mathrm{ml}$ Härter $+0,1 \mathrm{ml} \mathrm{Weichmacher} \mathrm{(Dibutylphthalat)}+0,2 \mathrm{ml}$ Beschleuniger

e) Schneiden der Kunstharzblöcke:

Das Schneiden der Kunstharzblockpräparate erfolgt an einem Ultramikrotom, entweder mit einem Glasmesser für Semidünnschnitte oder mit einem Diamantmesser für die Ultradünnschnitte. Zum Schneiden der Ultradünnschnitte ist häufig ein Zutrimmen der Kunstharzblöcke mittels Rasierklinge notwendig, um die Schnittfläche an das Grid anzupassen. Die Semidünnschnittpräparate werden auf normale Glasobjektträger aufgezogen und nach Richardson gefärbt. Die Ultradünnschnitte werden üblicherweise auf Kupfergrids aufgezogen und auf diesen kontrastiert.

\section{f) Färbung der Semidünnschnitte nach Richardson:}

Die im Wasserbad schwimmenden Semidünnschnitte werden auf Objektträger aufgezogen und auf einer Wärmeplatte bei $60^{\circ} \mathrm{C}$ für eine Stunde getrocknet. Die Objektträger werden dabei mit einer umgestülpten Petrischale überdeckt. Mit Hilfe einer Pasteurpipette wird dann die Färbelösung nach Richardson als dicker Tropfen über die Schnitte geschichtet. Wenn nach ca. 3 min. die Farbe am Rand zu trocknen beginnt, wird die Farbe mit Aqua dest. abgespült und die Objektträger werden wieder auf der Wärmplatte getrocknet. Eingedeckelt werden die Schnitte dann mit Araldit oder Depex.

Rezept Färbelösung nach Richardson:

2 Teile $1 \%$ Azur II +1 Teil $2 \%$ Methylenblau +1 Teil $1 \%$ Borax

\section{g) Kontrastieren der Ultradünnschnitte:}

Vorbereitet wird eine mit Wachs ausgegossene Petrischale. Zuerst wird die benötigte Menge Bleizitrat filtriert (Faltenfilter). Einige Natriumhydroxidplätzchen werden in die Petrischale gegeben und diese mit einem Deckel verschlossen. Mit einer Pasteurpipette wird dann je Grid ein Tropfen Bleizitrat in die Petrischale gegeben. Auf jeden dieser Tropfen wird dann ein Grid mit dem Schnitt nach unten gelegt. Nach zehnminütiger Inkubation werden die Grids in vier Bechergläschen mit Aqua dest. gespült. Mit Filterpapier wird die dem Schnitt abgewandte Seite der Grids getrocknet. Die Petrischale wird nur zum Arbeiten jeweils kurz geöffnet. Getrocknete Grids werden in eine Gridbox sortiert und die Positionen werden notiert, da Grids selbst keine Kennung tragen. Die Spülgläser werden mit Aqua dest. gereinigt. Trichter 
und Becherglas, die mit Bleizitrat in Kontakt gekommen sind, werden in 40 \% Essigsäure über Nacht gereinigt und dann mit Wasser ausgespült.

Rezept Bleizitrat:

1,41 g Bleizitrat in $50 \mathrm{ml}$ Kolben mit $10 \mathrm{ml}$ Aqua bidest. schwenken (per Hand)

$8 \mathrm{ml} 1 \mathrm{~N} \mathrm{NaOH}$ kommen dazu, per Hand schwenken, bis die Lösung klar ist; mit Aqua bidest. auf $50 \mathrm{ml}$ auffüllen.

\subsection{PET-blot}

\subsubsection{Einleitung zur Methode}

Um neurodegenerative Erkrankungen an Biopsie- oder Autopsiegewebe zu erkennen bedient man sich zunächst klassischer histologischer Färbemethoden, zu denen in erster Linie die HEFärbung und verschiedene Versilberungstechniken gehören. Hiermit gelingt der Nachweis mehr oder minder charakteristischer Veränderungen von Zellen, Geweben oder Strukturen (z.B. Identifizierung von Plaques und Tangles). Ein weiterer Fortschritt bei diesen Untersuchungen ist die Technik der Immunhistochemie, bei der mittels einer AntigenAntikörperreaktion eine Identifizierung bestimmter Proteine möglich wird. Mit dieser Methode lassen sich also auch feine Ablagerungen von Proteinen nachweisen und zusätzlich eine Zuordnung der gefundenen Veränderungen vornehmen. In der Immunhistochemie wird letztlich lediglich das Vorhandensein eines Proteins / Epitops an einer bestimmten Stelle im Gewebe nachgewiesen. Für viele neurodegenerative Erkrankungen ist zum einen ein sehr sensitiver Nachweis der Proteine notwendig und andererseits wird die Diskriminierung der pathologischen von der physiologischen Proteinform angestrebt. Für diese Aufgabe wurde die Technik des PET-blots („Paraffin embedded tissue-blot“) von Schulz-Schaeffer et al. (2000) entwickelt.

\subsubsection{Protokoll PET-blot}

Hierbei werden histologische Schnittpräparate von Paraffinböcken (Schnittdicke in der Regel $1 \mu \mathrm{m})$ statt auch Glasobjektträger auf Nitrozellulosemembranen aufgezogen. Dazu fängt man die Schnitte in kaltem Wasser auf und entnimmt sie diesem mit einer feuchten, auf einem Glasobjektträger aufgelegten Membran. In einem warmen Wasserbad werden die Schnitte dann gestreckt. Auf einer Wärmeplatte werden die Objektträger mit den anhaftenden Membranen getrocknet. Dann werden die Membranen durch Trennpapiere jeweils voneinander separiert, aufgestapelt und zischen Glasplatten im Wärmeschrank bei $55-60^{\circ} \mathrm{C}$ gepresst. Hernach können die Membranen im Dunkeln bei Raumtemperatur über Jahre 
gelagert werden. Zur Färbung werden die Membranen dann, wie Objektträger auch, entparaffiniert. Hierzu sortiert man die Membranen zwischen Glasobjektträger (Platzhalter) in Histoschaukeln ein. Mit diesen werden die Membranen nacheinander in drei Becken mit Xylol für je zehn min. entparaffiniert. Es folgt ein zehnminütiger Schritt mit einem gleichteiligen Gemisch von Xylol und Isopropanol. Darauf folgen fünfminütige Spülschritte mit dem Ziel der Rehydrierung in $100 \%, 100 \%, 90 \%, 70 \%, 50 \%$ und $25 \%$ Isopropanol. Abschließend werden die Membranen für fünf min. in ein Becken mit PBS, welches 0,1 \% Tween 20 als Detergenz enthält, eingestellt. Die Membranen können nun zwischen Papierhandtüchern getrocknet werden. Nach einem kurzen antrocknen werden die Membranen zwischen Streifen der Papierhandtücher an beiden Enden eingeklemmt und zwischen Glasplatten weiter getrocknet. Nun sind die Membranen mit dem Gewebe zur Färbung bereit.

Das folgende Färbeprotokoll ist in der Regel immer gleich, variiert aber insbesondere im Verdauschritt je nach Protein. Selbstverständlich ist auch die Wahl des primären Antikörpers vom nachzuweisenden Protein abhängig. Der Grundgedanke hinter dieser Technik ist, dass die Proteine eines Gewebes aus dem Schnitt auf die Membran transferiert werden, wie beispielsweise bei der Western-blot Technik. Im Gegensatz zum Western-blot Technik wird aber keine Gewebehomogenat, sondern das Gewebe als Schnitt verwandt. Darin begründet sich der große Vorteil, dass eine morphologisch-topographische Zuordnung des Befundes möglich ist. Ein „Poolen“ mehrerer Gewebe oder dergleichen ist allerdings nicht möglich. Die auf die Membran transferierten Proteine sind nun mittels Epitopdetektion über Antikörper nachweisbar. Durch die Behandlung der Membranen mit Enzymen, wie beispielsweise der Proteinase K, aber auch durch thermische Behandlung (autoklavieren) oder durch chemische Faktoren (Änderung des pH-Wertes) lassen sich Epitope freilegen beziehungsweise bestimmte Proteine oder bestimmte Zustandsformen von Proteinen selektiv nachweisbar machen. Als klassisch ist hierbei sicherlich der selektive Abdau des physiologischen Prionproteins durch Proteinase K zu erwähnen, bei dem letztlich nur die pathologische Form des Proteins auf der Membran zurück und somit nachweisbar bleibt.

\subsubsection{PET-blot zum Demenzstaging}

In der hier vorliegenden Doktorarbeit haben wir den PET-blot zur nachträglichen Untersuchung der Autopsiefälle im Hinblick auf das Vorliegen einer neurodegenerativen Erkrankung genutzt. Hierzu führten wir PET-blot Untersuchungen mit Antikörpern gegen Tauprotein (AT8), $\beta$-Amyloid (6E10) und $\alpha$-Synuklein (LB509, 4B12) durch. Letztlich wäre 
eine Pathologie vom Alzheimertyp als wahrscheinlichste Form zu erwarten, deshalb hier die Wahl von Tau und $\beta$-Amyloid als Zielproteine. Da das zu untersuchende Patientenkollektiv eine Gruppe von Parkinsonpatienten darstellt, sollte auch eine solche Pathologie abgeklärt werden, daher die Untersuchung hinsichtlich pathologischer Ablagerungen von $\alpha$-Synuklein. Das Protokoll ist für alle drei Antikörper gleich. Der Verdau der Membranen erfolgt mit Proteinase K (Stammlösung sind 50 mg PK / ml; Verdünnt wird im PK-Verdaupuffer in einer Konzentration von $250 \mu \mathrm{g} / \mathrm{ml}$. Hierzu werden die Membranen auf einer mit Verdaupuffer und Enzym getränkten Zelluloseeinlage in einer geschlossenen Kunststoffbox (so genannte Kissentechnik) unter mehrmaligem Schwenken für 8-12 Stunden im Wärmeschrank bei 55$60^{\circ} \mathrm{C}$ verdaut. Pro Box werden ca. $13 \mathrm{ml}$ Lösung benötigt. Die Membranen müssen von beiden Seiten befeuchtet werden und blasenfrei inkubieren. Nach dem Verdauschritt werden die Membranen in einer Box ohne Einlage 3 x 5 min. in TBST gewaschen. Im nächsten Schritt werden die Schnitte mit 4 M Guanidinthiocyanat (GdnSCN) für 15 min. inkubiert. Es folgt wieder ein Waschschritt für 3 x 5 min. in TBST.

Die eigentlichen Färbeschritte werden auf einem Tischschüttler durchgeführt. Die Schnitte werden hierfür am Boden einer leeren Box mittels Brackets befestigt, damit sie nicht übereinander schwimmen. Der unspezifische Proteinblock erfolgt für $45 \mathrm{~min}$. mit 0,2 \% Caseinblock. Nach abgießen des Blocks wird der Primärantikörper in 0,02 \% Caseinblock in TBST zugegeben (10 ml je Box; Antikörperverdünnung orientiert sich an der Verdünnung für Western blot Analysen) und für 90 min. inkubiert. Danach wird 5 x 10 min. in TBST gewaschen. Auch der sekundäre Antikörper (hier Goat anti-Mouse-AP) wird in TBST mit 0,02 \% Caseinblock angesetzt und für 60 min. inkubiert. Bei dem Sekundärantikörper handelt es sich immer um einen mit alkalischer Phosphatase (AP) gekoppelten Antikörper, da es sich bei der späteren Farbreaktion um eine Formazanreaktion handelt. Abermals wird 5 x 10 min. in TBST gewaschen. Es folgen zwei Waschschritte in NTM.

Die Färbelösung ist lichtempfindlich und muss daher direkt vor der Benutzung frisch zubereitet werden. Man benötigt etwa $20 \mathrm{ml}$ pro Box, wenn in dieser alle Schnitte gefärbt werden (gesammelt aus mehreren Boxen). Die Membranen werden in die Box gelegt und dann wird die PET-blot-Färbelösung zugegeben. Die Farbreaktion benötigt etwa 10 bis 30 min. und wird abgestoppt, sobald ein adäquates Signal erkennbar ist. Das Stoppen der Reaktion erfolgt durch 15 bis 30 Minuten dauerndes Spülen auf dem Shaker. Hernach werden die Membranen noch in Aqua bidest. 3 x 15 min. gespült. Das Färbesignal dunkelt während des Waschens nach. Nach dem Waschen werden die Membranen zwischen stabilen saugfähigen Platten getrocknet, wobei die Trocknung zwischen beschwerten Glasplatten 
erfolgt. Die Aufbewahrung der Membranen erfolgt in Diahüllen, die auf jeden Fall im Dunkeln verwart werden müssen. Die Auswertung der Membranen erfolgt mittels eines Auflichtmikroskops, sodass eine bis zu 400 fache Vergrößerung möglich ist.

\subsubsection{PET-blot an Muskelgewebe zur Suche nach aggregiertem $\alpha$-Synuklein}

Von sieben der Kamptokormiefälle lagen Paraffingewebsblöcke vor. Diese wurden durch

Einbettung eines Teils des in Glutaraldehyd fixierten Gewebes erzeugt. Fixierung in

Glutaraldehyd ist dafür bekannt, dass sie eine immunhistochemische Detektion von vielen Epitopen behindert bzw. unmöglich macht. Von den hier vorliegenden Blöcken wurden PETblot-Membranen angefertigt, um eine mögliche Ablagerung pathologischer Aggregate von $\alpha-$ Synuklein zu untersuchen. Schneiden, Aufziehen, Trocknen und Entparaffinieren entsprachen dem zuvor beschriebenen PET-blot-Protokoll. Im ersten Durchgang wurde das für Hirngewebe angewandte Protokoll des PET-blot für $\alpha$-Synuklein wie oben beschrieben mit PK-Verdau eingesetzt.

In einem zweiten Durchgang wurde die Vorbehandlung mit GdnSCN variiert. Die Vorinkubation erfolgte in je Membran entweder mit 0,5M, 1M, 2M oder 3M GdnSCN. Der übrige Teil des Protokolls wurde beibehalten.

\section{8 "Tissueblot" als Zwischenform zwischen PET-blot und Histoblot}

Die Technik des PET-blots basiert auf in Formalin fixiertem und in Paraffin eingebettetem Gewebe, welches auf Nitrocellulosemembranen aufgezogen wird. Die Proteine werden ähnlich dem Western-blot an die Membran gebunden und durch Vorbehandlung zugänglich gemacht bzw. durch selektiven Verdau voneinander unterschieden. Der Histoblot basiert auf der Untersuchung von Gefrierschnitten, die nach Aufziehen auf Nitrozellulosemembranen in ähnlicher Weise behandelt werden. Der PET-blot hat den entscheidenden Vorteil, im Gegensatz zum Histoblot eine sehr distinkte Morphologie zu zeigen. Der Nachteil ist, dass in Paraffin eingebettetes Gewebe nötig ist und die Einbettungsschritte antigene Epitope verändern können. Um hier Gefriergewebe nutzen zu können und eine bessere Morphologie zu erreichen wurden die Membranen mit den Gefrierschnitten in PFA oder Isopropanol fixiert. Dieses im Rahmen meiner Untersuchungen etablierte Verfahren wird hier als „Tissueblot"“ bezeichnet.

Protokoll , Tissueblot“

Am Cryostaten werden 6 bis $8 \mu \mathrm{m}$ dicke Gefrierschnitte angefertigt, die auf mit Wasser kurz angefeuchtete Nitrozellulosemembranen aufgezogen werden. Danach werden die Membranen 
für 30 min. bei Raumtemperatur getrocknet. Zur Lagerung können die Membranen dann, durch Trennpapiere separiert, in geschlossenen Boxen verpackt eingefroren und so länger gelagert werden. Nach 10 minütigem Auftauen an der Luft werden die Membranen für 90 min. in 4 \% PFA gelegt. Hernach werden sie wenigstens 10 min. gewässert. Dann werden die Membranen für 15 bis 30 min. in TBST gelegt, um sie besser zugänglich für wässrige Lösungen zu machen. Es folgt dann der enzymatische Verdau, der in den nachfolgend beschriebenen Durchgängen variiert wird. Auf den Verdau erfolgt der Blockierungsschritt zur Verhinderung unspezifischer Antikörperbindung durch die 20 min. Inkubation mit 0,2 \% Caseinblock. Nach Abschütten des Caseinblocks wird der Primärantikörper gelöst in 0,02 \% Caseinblock zugegeben. Die Inkubation erfolgt für 90 min. bei RT. Gespült wird 3 x 5 min. mit TBST, dann 3 x 10 min. mit TBS. Als Sekundärantikörper wird ein von der Ziege stammender gegen die Spezies des Primärantikörpers gerichteter Antikörper benutzt (1:500 in TBS), der an alkalische Phosphatase gekoppelt ist. Spülschritte 2 x 5 min. TBST, dann $3 \times 10$ min. TBS. Zur Entwicklung wird die PET-blot-Färbelösung zugegeben. Die Farbreaktion wird nach 5 bis 30 min. durch Spülen in TBS gestoppt. Die Membranen werden dann zwischen stabilen Saugkartonplatten unter Druck getrocknet.

\subsection{Die Auswertung der Proben}

\subsubsection{Enzymfärbungen}

Jede Muskelbiopsie sollte nach modernem Standard als Gefrierprobe aufgearbeitet werden, um daran die etablierten enzymatischen Färbungen durchführen zu können. Diese Diagnostik ist Zentrum und Rückgrat jeglicher Muskelbiopsiediagnostik und steht daher auch im Zentrum der hier vorliegenden Studie. Ziel ist es, die ersten wesentlichen Befunde zu erheben und gegebenenfalls eine erste Einordnung in die zwei Grundtypen der Muskelpathologie vorzunehmen: Myopathische oder neurogene Veränderungen. Bei ersterer Gruppe handelt es sich um Veränderungen, deren Ursache primär im Muskel selbst zu suchen ist oder bei denen die Schädigung primär die Muskelfasern betrifft. Bei den neurogenen Veränderungen handelt es sich um Störungen der Innervation des Muskels, die ein relativ charakteristisches Schädigungsbild hervorrufen. Verfeinert werden können diese groben Einteilungen durch die weiteren Gruppen der entzündlichen Muskelerkrankungen (Myositiden), bei denen der Muskel selbst in der Regel ein myopathisches Bild aufweist (welches dann typischerweise von entzündlichen Infiltraten begleitet wird) und die Gruppe der metabolischen Erkrankungen. Lediglich wenn der Entzündliche Prozess als systemischer Prozess primär die 
Nerven betrifft (Neuritis, Vaskulitis des Nerven), findet sich ein neurogen dominiertes Schädigungsbild, mitunter bei fehlenden entzündlichen Infiltraten im Muskel.

\subsubsection{Wert der einzelnen histochemischen Färbung}

Die Standardfärbung $H E$ ist eine der beiden klassischen Übersichtsfärbungen.

Bindegwebestrukturen stellen sich hellrosa, Zytoplasmaanteile je nach pH-Wert hell bis dunkel rosa und nukleinsäurehaltige Strukturen (Zellkerne) kobaltblau dar. Bereits im Überblick können Form (polygonal), Größe (einheitlich), Zahl und Verteilung der Muskelfasern beurteilt werden. Faszikel können abgegrenzt werden. Man erkennt die weiteren anatomischen Strukturen, wie Nerven, Gefäße, Muskelspindeln und angrenzende Strukturen (Fett, Bindegewebe etc.). Entzündliche Infiltrate können ebenso, wie Makrophageninfiltrate oft bereits abgegrenzt werden. Folglich können auch nekrotische Untergänge einzelner Fasern erfasst werden. Typische pathologische Befunde, die hier erhoben werden können sind: Atrophie und Hypertrophie von Muskelfasern, sowie die Anzahl und Form der betroffenen Fasern. Als Zeichen neurogener Veränderungen werden angulär atrophe Fasern gewertet, als Zeichen eher myopathischer Schädigung solche mit abgerundeter Struktur. Bei Denervation einzelner Fasern eines peripheren Nervs finden sich atrophe Fasern in netzartiger Verteilung über den gesamten Faszikel oder den Muskelquerschnitt verteilt. Sind ganze Nerven oder übergeordnete Steuerzentren (Motorneurone) betroffen, finden sich ganze Gruppen oder Faszikel atropher Fasern. Die Zahl von Kernsäcken entspricht Fasern, die durch maximale Atrophie nahezu ihre gesamten kontraktilen Filamente verloren haben und daher lediglich noch die vom Sarkolemm umhüllten Kerne aufweisen. Eine Hypertrophie von Fasern wird als Folge einer vermehrten Beanspruchung angesehen, die aus einer Vermehrung kontraktiler Elemente pro Faser resultiert. Sie kann somit Folge eines Muskeltrainings oder Ausdruck der Kompensation bei Schädigung sein. Man erkennt die im Rahmen von faserinternen Umbauprozessen auftretende zentrale Verlagerung der normalerweise randständig gelegenen Zellkerne, was als pathologisch gewertet wird, wenn mehr als 5\% der Fasern betroffen sind. Vermehrte Substanz in den Faserzwischenräumen kann erkannt werden. Diffus eingestreute Lymphozyten werden gern als unspezifische Reaktion gewertet. Werden einzelne Muskelfasern von ihnen umlagert, spricht dies eher für einen entzündlichen Prozess. Die Invasion intakter Muskelfasern durch Lymphozyten spricht klar für das Vorliegen einer Entzündung. Lymphozytäre Infiltrate mit striktem Gefäßbezug weisen eher auf einen primär systemischen Entzündungsprozess (z.B. 
Vaskulitis). Als Muskelfasernekrosen werden Muskelfasern bezeichnet, die gerade von Makrophagen eingenommen und abgebaut werden.

In der $E v G$ - Färbung stellen sich Kerne und elastische Fasern schwarz, kollagene Fasern rot und weitere Strukturen gelb dar. Man erkennt hier früh das Einsprossen von Bindegewebe in den Faserzwischenraum, was als pathologischer Umbauprozess anzusehen ist. Die Existenz von perimysealem Bindegewebe wurde in der hier gemachten Auswertung vermerkt. Die Ölrotfärbung zeigt einerseits den Gehalt an Neutralfetten (Speicherfetten) in den Muskelfasern, andererseits das Vorkommen von Fettzellen im Muskel, was als Zeichen des Ersatzes von defekten Muskelfasern durch Fett (Fettvakatwucherung) angesehen wird. Eine Vermehrte Speicherung von Neutralfetten findet sich im Rahmen von Störungen des Energiemetabolismus im Muskel (mitochondriale Störungen).

Die $P A S$-Färbung dient der Darstellung des Glycogengehaltes der Muskelfasern und der Identifizierung eventuell auffindbarer kompakter Ablagerungen. Diese

Glycogenansammlungen finden sich beispielsweise im Rahmen der Glycogenosen und können auf diese hinweisen. Auch regional begrenzte Ablagerungen unterschiedlicher Stoffe lassen sich häufig in der PAS-Färbung erkennen (z.B. Proteine).

Als modifizierte Trichromfärbung nach Gomori (Trichrom) bezeichnet man die zweite zentrale Standardfärbung der Muskelpathologie. Hier stellen sich die Kerne grünblau, das Sarkoplasma mit den Filamenten grün, Bindegewebe hellgrün, Mitochondrien rot (fuchsinophil) und Einschlusskörperchen teils rot und teils grün mit opakem Aspekt dar. Die Färbung gibt einen guten allgemeinen Überblick und weist darüber hinaus auf Fasern hin, in denen vermehrt Mitochondrien akkumuliert sind (Hinweis auf mitochondriale Störungen). Bei starker Akkumulation mit einem zerrissenen Aspekt der Fasern spricht man von „,ragged red“Fasern. Außerdem lassen sich viele Proteinablagerungen bereits erkennen (z.B. myofibrilläre Myopathien). Eine besondere Form von Abgelagerten Proteinen stellen hierbei die so genannten „Rods“ dar, die sich im Rahmen einiger genetischer Erkrankungen als Verdichtung muskeleigener Proteine mit kristallinem Charakter präsentieren. Bei Vakuolen lässt sich in dieser Färbung zwischen geränderten (z.B. Einschlußkörpermyositis / -myopathie) und nicht geränderten Vakuolen differenzieren.

In der NADH-Reaktion wird das sarkoplasmatische Retikulum nachgezeichnet, sodass strukturelle Defekte (z.B. Cores und Minicores) in dieser Färbung gut nachvollzogen werden können. Darüber hinaus ist in der Regel eine Differenzierung in die Fasertypen I und II möglich. Die Typ-I-Fasern erscheinen hier dunkel, die Typ-II-Fasern erscheinen hell. Die hier gemachte Auswertung zielt genau auf diese Aspekte ab (Strukturelle defekte, 
Fasertypisierung). Interessant ist, dass die $M A G$-Reaktion sich normaler Weise reziprok zur NADH-Reaktion verhält, was die Darstellung der Fasertypen angeht. Das bedeutet, dass sich Typ-I-Fasern hell und Typ-II-Fasern dunkel darstellen.

$\mathrm{Zu}$ den mitochondrial lokalisierten Enzymen gehört die $S D H$, deren blaues Reaktionsprodukt sich in einer Verteilung erkennen lässt, die der COX-Färbung ähnelt. In seltenen Fällen mitochondrialer Defekte ist die SDH-Enzymreaktion vermindert oder fehlt. Vermehrte Ansammlungen von Mitochondrien imponieren in der Regel als „ragged blue“-Fasern. Dieser Terminus entspricht den „ragged red“-Fasern im Trichrom, wird hier aber aufgrund des blauen Reaktionsproduktes als „ragged blue“ bezeichnet. Strukturelle Defekte stellen sich dar hier häufig dar.

Für die COX-Reaktion gelten ähnliche Aspekte: Es handelt sich um ein mitochondrial lokalisiertes Enzym, welches in der Reaktion ein braunes Produkt hervorruft. Somit stellen sich Fasern mit Akkumulation von Mitochondrien als „,ragged brown“-Fasern dar. Ein Ausfall der Enzymreaktivität weist auf eine gestörte mitochondriale Funktion in der betroffenen Faser hin. Diese COX-defizienten Fasern fallen besonders in der Kombination von COX- und SDH-Reaktion auf, da die Fasern dann als kräftig blaue Fasern hervortreten. Erst ab einer gewissen Anzahl von defizienten Fasern pro Schnittfläche weist dieser Befund auf eine tatsächlich bestehende Mitochondriopathie hin. Das bedeutet, dass sich auch im Muskel von gesunden Menschen einzelne COX-defiziente Fasern finden lassen können, wobei die zu tolerierende Anzahl offenbar mit zunehmendem Alter des Patienten zunimmt. Feste Werte existieren hierzu in der Standardliteratur nicht. Strukturdefekte stellen sich häufig gut dar. In der Myoadenylatdeaminasefärbung (MAD) wird lediglich die Effizienz des Enzyms beurteilt. Zentral ist hierbei die Aussage, ob eine Defizienz vorliegt. Der Befund wird in einer Färbung mit Kontrollmuskel validiert.

Mit Hilfe der ATPasereaktion werden die Fasertypen bestimmt, wobei die Differenzierung nach Vorinkubation bei unterschiedlichen $\mathrm{pH}-$ Werten erfolgt. Nach Vorinkubation bei saurem pH-Wert stellen sich Typ-I-Fasern dunkel, nach Vorinkubation im alkalischen $\mathrm{pH}$-Bereich stellen sich Typ-II-Fasern dunkel dar. Eine feine Variation der $\mathrm{pH}-\mathrm{Werte}$ im sauren Milieu ermöglicht teilweise noch eine Differenzierung in Untergruppen der Fasertypen (Typ-IIa-, Typ-IIb-Fasern etc.). Limitiert ist die Aussagekraft der Färbungen teilweise bei schweren Krankheitsbildern oder bei sehr stark ungleich verteiltem Faserspektrum, insbesondere wenn ein Fasertyp deutlich atrophiert erscheint. Hier können Kapillaren nicht von atrophierten Muskelfasern unterschieden werden. Störungen der Struktur des sarkoplasmatischen Retikulums können teilweise als Auslöschung der Struktur wahrgenommen werden. 
Die Auswertung der vorbeschriebenen Befunde erfolgt gemäß der folgenden Tabelle. Verwendet wurde hierzu ein Mikroskop Olympus BX41. Hierbei gibt es Veränderungen, die in Prozent angegeben werden. Dies wird in der Regel dann gemacht, wenn eine Veränderung in einzelnen Fasern zu vernachlässigen und als weitgehend normal anzusehen ist. Die Auswertung nach Gesichtfeldern wird immer dann gewählt, wenn die zu untersuchende Veränderung bisweilen auch nur in einzelnen Muskelfasern pro Biopsie zu finden ist, trotzdem aber zumindest potentiell als pathologisch anzusehen ist. Hierfür ist ein guter Überblick über die Gesamtbiopsie wichtiger, als die genaue quantitative Analyse. Die Auswahl der Vergrößerung (,Low-power-field“ = LPF = 100fache Vergrößerung; ,Mediumpower-field“ = MPF = 200fache Vergr.; „High-power-field“ $=$ HPF = 400fache Vergr.) richtet sich hierbei nach der Größe der zu bewertenden Veränderung. Veränderungen, die eine gesamte Fasern betreffen (z.B. ,ragged red“-Fasern) werden besser in der Übersicht beurteilt, wohingegen in den Fasern befindliche Veränderungen (z.B. geränderte Vakuolen) nur in der detailierteren Auflösung zu erkennen sind. Bestimmte Veränderungen lassen sich weder in Prozent, noch in einer anderen Größe erfassen und werden daher primär in einer analogen Nominalskala eingeordnet. Stufe 1 stellt die geringste und 4 die höchste Stufe dar.

Der angegebene Versuch einer Einordnung aller Befunde auf einer Skala von 0 bis 4 („Endwert“) stellt den Versuch dar, diese Veränderungen letztlich in ihrer Bedeutung zu bewerten. Es handelt sich bei diesen Werten um eine Einschätzung, die sich an Erfahrungen aus der alltäglichen Routinediagnostik orientiert und das hier bewertete Kollektiv mit einbezieht. Damit wird klar, dass es sich hierbei um einen Interpretationsfaktor hat, der auf diagnostischen Kriterien fußt, aber durchaus zur Diskussion anregen kann. 0 ist hierbei als geringster Wert gesetzt, der einem Normalbefund gleichgesetzt wird. Demgegenüber steht der Wert 4 für die maximale Ausprägung einer Veränderung. Eine Zusammenfassung der Kriterien liefert Tabelle IX.

Der Aspekt der Kalibervariation wurde zusätzlich mittels softwareunterstützter Vermessung von mehr als 100 Fasern je Fall validiert und grafisch erfassbar gemacht. Verwendet wurde hierfür ein Olympus BX51 Mikroskop mit Fotoeinheit. Die Auswertung erfolgte mit der vom Hersteller gelieferten CellF-Software, die graphische Darstellung mit Graph Pad Prism. 
Tabelle IX: Auswertungsaspekte der Enzymfärbungen

\begin{tabular}{|c|c|c|c|c|}
\hline Färbung & Feature & Erfassung & Befund & Endwert \\
\hline \multirow[t]{40}{*}{$\mathrm{HE}$} & \multirow[t]{5}{*}{ Kalibervariation } & \multirow[t]{5}{*}{ Rel. Einheiten } & Keine Schwankungen & 0 \\
\hline & & & Geringe Schwankungen & 1 \\
\hline & & & Mäßige Schwankungen & 2 \\
\hline & & & Atrophe Fasern & 3 \\
\hline & & & Atrophe und hypertrophe Fasern & 4 \\
\hline & \multirow[t]{5}{*}{ Interne Kerne } & \multirow[t]{5}{*}{$\%$} & Normal (bis 5\%) & 0 \\
\hline & & & Etwas verm. (>5-7\%) & 1 \\
\hline & & & Mäßig verm. (>7-10\%) & 2 \\
\hline & & & Deutl. Verm. (>10-20\%) & 3 \\
\hline & & & Hochgr. Verm. (>20\%) & 4 \\
\hline & \multirow[t]{5}{*}{ "Splitting“ } & \multirow{5}{*}{ Fasern / PF } & Kein & 0 \\
\hline & & & Bis 1/10 PF & 1 \\
\hline & & & $1-5 / 10 \mathrm{PF}$ & 2 \\
\hline & & & $>5-10 / 10 \mathrm{PF}$ & 3 \\
\hline & & & $>10 / 10 \mathrm{PF}$ & 4 \\
\hline & \multirow[t]{5}{*}{ Entzündung } & \multirow[t]{5}{*}{ Infiltrate } & Keine & 0 \\
\hline & & & $\begin{array}{l}\text { Einzelne Fasern oder Gefäße } \\
\text { locker umringt }\end{array}$ & 1 \\
\hline & & & Fokal klar abgrenzbares Infiltrat & 2 \\
\hline & & & Mehrere deutliche Infiltrate & 3 \\
\hline & & & $\begin{array}{l}\text { Regelmäßig viele Infiltrate / } \\
\text { breite Cuffs um Gefäße / } \\
\text { sekundäre Veränderungen } \\
\text { (Nekrosen, Granulome) }\end{array}$ & 4 \\
\hline & \multirow{5}{*}{$\begin{array}{l}\text { Angulär atrophe } \\
\text { Fasern }\end{array}$} & \multirow[t]{5}{*}{ Fasern / PF } & Keine & 0 \\
\hline & & & Bis 1/10 PF & 1 \\
\hline & & & $1-2 / 10 \mathrm{PF}$ & 2 \\
\hline & & & $>2-10 / 10 \mathrm{PF}$ & 3 \\
\hline & & & $>10 / 10 \mathrm{PF}$ & 4 \\
\hline & \multirow[t]{5}{*}{ Atrophe Fasern } & \multirow[t]{5}{*}{ Faser / PF } & Keine & 0 \\
\hline & & & Bis $1 / 10 \mathrm{PF}$ & 1 \\
\hline & & & $1-2 / 10 \mathrm{PF}$ & 2 \\
\hline & & & $>2-10 / 10 \mathrm{PF}$ & 3 \\
\hline & & & $>10 / 10 \mathrm{PF}$ & 4 \\
\hline & \multirow[t]{5}{*}{ Kernsäcke } & \multirow[t]{5}{*}{ Kernsäcke / PF } & Keine & 0 \\
\hline & & & Bis $1 / 10 \mathrm{PF}$ & 1 \\
\hline & & & $1-2 / 10 \mathrm{PF}$ & 2 \\
\hline & & & $>2-10 / 10 \mathrm{PF}$ & 3 \\
\hline & & & $>10 / 10 \mathrm{PF}$ & 4 \\
\hline & \multirow[t]{5}{*}{ „Whorled fibers“ } & \multirow[t]{5}{*}{ Fasern / LPF } & Keine & 0 \\
\hline & & & Bis 1/10 PF & 1 \\
\hline & & & $1-2 / 10 \mathrm{PF}$ & 2 \\
\hline & & & $>2-5 / 10 \mathrm{PF}$ & 3 \\
\hline & & & $>5 / 10 \mathrm{PF}$ & 4 \\
\hline \multirow[t]{7}{*}{ EvG } & \multirow{5}{*}{$\begin{array}{l}\text { Endomysiales } \\
\text { Bindegewebe }\end{array}$} & \multirow[t]{5}{*}{ Rel. Einheiten } & Keine Vermehrung & 0 \\
\hline & & & Fokal diskrete Einsprossung & 1 \\
\hline & & & $\begin{array}{l}\text { Regelmäßig leichte } \\
\text { Einsprossung }\end{array}$ & 2 \\
\hline & & & $\begin{array}{l}\text { Deutliche Einsprossung mit } \\
\text { verbreiterten Anteilen }\end{array}$ & 3 \\
\hline & & & $\begin{array}{l}\text { Ummauerung nahezu aller } \\
\text { Fasern }\end{array}$ & 4 \\
\hline & \multirow{2}{*}{$\begin{array}{l}\text { Perimysiales } \\
\text { Bindegewebe }\end{array}$} & \multirow[t]{2}{*}{ Ja/nein } & Nicht erkennbar & 0 \\
\hline & & & Erkennbar & 1 \\
\hline
\end{tabular}




\begin{tabular}{|c|c|c|c|c|}
\hline Färbung & Feature & Erfassung & Befund & Endwert \\
\hline \multirow{5}{*}{$\begin{array}{l}\text { PAS, ORO, } \\
\text { (MAD) }\end{array}$} & \multirow[t]{5}{*}{ Gehalt } & \multirow[t]{5}{*}{ Rel. Einheiten } & Keine Anfärbung & 0 \\
\hline & & & Geringer Gehalt & 1 \\
\hline & & & Normaler Gehalt & 2 \\
\hline & & & Hoher Gehalt & 3 \\
\hline & & & $\begin{array}{l}\text { Pathologische Ab-lagerungen / } \\
\text { Vermehrung }\end{array}$ & 4 \\
\hline \multirow[t]{5}{*}{ PAS } & \multirow{5}{*}{$\begin{array}{l}\text { Ablagerungen in den } \\
\text { Muskelfasern }\end{array}$} & \multirow[t]{5}{*}{ Faserzahl } & Keine & 0 \\
\hline & & & Bis $1 / 10 \mathrm{PF} ;<1 \%$ & 1 \\
\hline & & & $1-2 / 10 \mathrm{PF} ; 1 \%$ & 2 \\
\hline & & & $>2-10 / 10 \mathrm{PF} ;>1 \%$ bis $5 \%$ & 3 \\
\hline & & & $>10 / 10 \mathrm{PF} ;>5 \%$ & 4 \\
\hline \multirow[t]{6}{*}{ ORO } & \multirow[t]{4}{*}{ Fettzellen endomysial } & \multirow[t]{4}{*}{ Lokalisation } & Einzelne im Bindegewebe & 1 \\
\hline & & & Einzelne im Muskel & 2 \\
\hline & & & Kleine Gruppen im Muskel & 3 \\
\hline & & & Weitgehender fettiger Umbau & 4 \\
\hline & \multirow[t]{2}{*}{ Fettzellen perimysial } & \multirow[t]{2}{*}{ Ja/nein } & Nicht vorhanden & 0 \\
\hline & & & Vorhanden & 1 \\
\hline \multirow{15}{*}{ Trichrom } & \multirow{5}{*}{ „ragged red“-Fasern } & \multirow{5}{*}{ Fasern / LPF } & Keine & 0 \\
\hline & & & Bis 1/10 PF & 1 \\
\hline & & & $1-2 / 10 \mathrm{PF}$ & 2 \\
\hline & & & $>2-5 / 10 \mathrm{PF}$ & 3 \\
\hline & & & $>5 / 10 \mathrm{PF}$ & 4 \\
\hline & \multirow{5}{*}{$\begin{array}{l}\text { Subsarkolemmale } \\
\text { Ablagerungen }\end{array}$} & \multirow[t]{5}{*}{ Fasern / LPF } & Keine & 0 \\
\hline & & & Bis $1 / 10 \mathrm{PF}$ & 1 \\
\hline & & & $1-2 / 10 \mathrm{PF}$ & 2 \\
\hline & & & $>2-5 / 10 \mathrm{PF}$ & 3 \\
\hline & & & $>5 / 10 \mathrm{PF}$ & 4 \\
\hline & \multirow[t]{5}{*}{ Rimmed vacuoles } & \multirow[t]{5}{*}{ Fasern / LPF } & Keine & 0 \\
\hline & & & Bis 1/10 PF & 1 \\
\hline & & & $1-2 / 10 \mathrm{PF}$ & 2 \\
\hline & & & $>2-5 / 10 \mathrm{PF}$ & 3 \\
\hline & & & $>5 / 10 \mathrm{PF}$ & 4 \\
\hline \multirow{5}{*}{ COX-SDH } & \multirow{5}{*}{$\begin{array}{l}\text { Quotient neg./pos. } \\
\text { Fasern }\end{array}$} & Fasern / LPF & Keine & 0 \\
\hline & & & Bis $1 / 10 \mathrm{PF}$ & 1 \\
\hline & & & $1-2 / 10 \mathrm{PF}$ & 2 \\
\hline & & & $>2-5 / 10 \mathrm{PF}$ & 3 \\
\hline & & & $>5 / 10 \mathrm{PF}$ & 4 \\
\hline COX-SDH; & Strukturalterationen & Fasern / LPF & Keine & 0 \\
\hline $\mathrm{SDH} ; \mathrm{COX}$; & & & Bis 1/10 PF & 1 \\
\hline $\mathrm{NADH}$ & & & $1-2 / 10 \mathrm{PF}$ & 2 \\
\hline MAG & & & $>2-5 / 10 \mathrm{PF}$ & 3 \\
\hline & & & $>5 / 10 \mathrm{PF}$ & 4 \\
\hline NADH; & Typisierbarkeit der & Ja, nein, & Nicht möglich & 0 \\
\hline MAG; & Fasern & fraglich & Schwierig; fraglich & 0,5 \\
\hline ATPasen & & & Möglich & 1 \\
\hline $\begin{array}{l}\text { NADH; } \\
\text { MAG; }\end{array}$ & $\begin{array}{l}\text { Verhältnis Typ I zu } \\
\text { Typ II }\end{array}$ & Typ I : Typ II & $\begin{array}{l}\text { Zahlenwert = Typ I - Typ II; } \\
\text { wenn I = II }\end{array}$ & 0 \\
\hline ATPasen & & & Wenn I > II & $>0$ \\
\hline & & & Wenn I < II & $<0$ \\
\hline $\mathrm{NADH} ;$ & Atrophie eines & Atrophe Fasern & Keine & 0 \\
\hline $\begin{array}{l}\text { MAG; } \\
\text { ATPasen }\end{array}$ & Fasertyps & $\begin{array}{l}\text { Typ I oder Typ } \\
\text { II }\end{array}$ & Vorhanden & 1 \\
\hline MAG & Reziprozität zu NADH & Ja, nein, & Nicht möglich & 0 \\
\hline & & fraglich & Schwierig; fraglich & 0,5 \\
\hline & & & Möglich & 1 \\
\hline
\end{tabular}




\begin{tabular}{|c|c|c|c|c|}
\hline Färbung & Feature & Erfassung & Befund & Endwert \\
\hline \multirow[t]{20}{*}{ SP } & \multirow{5}{*}{$\begin{array}{l}\text { Reaktivität in den } \\
\text { Fasern }\end{array}$} & \multirow[t]{5}{*}{ Semiquantitativ } & Keine Anfärbung & 0 \\
\hline & & & $\begin{array}{l}\text { Geringe Anfärbung (Lipofuszin } \\
\text { in normalem Ausmaß) }\end{array}$ & 1 \\
\hline & & & Mäßige Vermehrung & 2 \\
\hline & & & Deutliche Vermehrung & 3 \\
\hline & & & $\begin{array}{l}\text { Starke Vermehrung (Streaming, } \\
\text { Vakuolen) }\end{array}$ & 4 \\
\hline & \multirow{5}{*}{$\begin{array}{l}\text { Makrophagen im } \\
\text { Bindegewebe }\end{array}$} & \multirow[t]{5}{*}{ Semiquantitativ } & Keine & 0 \\
\hline & & & Vereinzelt & 1 \\
\hline & & & Mehrere Makrophagen & 2 \\
\hline & & & Viele Makrophagen & 3 \\
\hline & & & Deutliche Infiltrate mit Konfluenz & 4 \\
\hline & \multirow[t]{5}{*}{ Fasernekrosen } & \multirow[t]{5}{*}{ Nekrosen / LPF } & Keine & 0 \\
\hline & & & Bis 1/10 PF & 1 \\
\hline & & & $1-2 / 10 \mathrm{PF}$ & 2 \\
\hline & & & $>2-5 / 10 \mathrm{PF}$ & 3 \\
\hline & & & $>5 / 10 \mathrm{PF}$ & 4 \\
\hline & \multirow{5}{*}{$\begin{array}{l}\text { Typische } \\
\text { feingranuläre } \\
\text { Zeichnungsvermehrun } \\
\text { g in den Fasern } \\
\text { (Streaming) }\end{array}$} & \multirow[t]{5}{*}{$\%$ der Fasern } & Keine & 0 \\
\hline & & & $<1 \%$ & 1 \\
\hline & & & $1-2 \%$ & 2 \\
\hline & & & $>2-5 \%$ & 3 \\
\hline & & & $>5 \%$ & 4 \\
\hline \multirow[t]{5}{*}{ ATPasen } & \multirow{3}{*}{$\begin{array}{l}\text { Gruppierung der } \\
\text { Fasertypen }\end{array}$} & \multirow{3}{*}{$\begin{array}{l}\text { Ja, nein, } \\
\text { fraglich }\end{array}$} & Nicht möglich & 0 \\
\hline & & & Schwierig; fraglich & 0,5 \\
\hline & & & Möglich & 1 \\
\hline & \multirow[t]{2}{*}{ Strukturalterationen } & \multirow[t]{2}{*}{ Ja / nein } & Keine & 0 \\
\hline & & & Vorhanden & 1 \\
\hline
\end{tabular}

\subsubsection{Semidünnschnittpräparate}

Die Auswertung der Semidünnschnittpräparate erfolgt am Lichtmikroskop. Die nachfolgend benannten morphologischen Veränderungen werden an den gefärbten Semidünnschnitten semiquantitativ ausgewertet. Für diese Auswertung wurde als Skala eine Einteilung in Stufen von 0 bis 4 vorgenommen. 0 entspricht dem Fehlen, 1 einzelnen, 2 wenigen, 3 etlichen und 4 vielen der untersuchten Veränderungen. Ausgewertet wurde jeweils die volle Querschnittsfläche der Semidünnschnittpräparate. Alle zur Verfügung stehenden Blöcke wurden in die Untersuchung einbezogen. Die erkennbaren Kerne wurden nach der Chromatinstruktur, der Erscheinung der Membran und ihrer Lage beurteilt. Die Zahl der Fasern mit internalisiert gelegenen Kernen wurde semiquantitativ bewertet. Bei der Beurteilung der Binnenstruktur der Muskelfasern wurde insbesondere auf Unterbrechungen der Querstreifung und deren Lage im Zentrum oder am Rand der Fasern geachtet. Die Bewertung der Anzahl bezieht sich auf die Zahl der Läsionen pro Faser. Bewertet wurde darüber hinaus, ob sich regional kompakte Verdichtungen nachweisen lassen, die in ihrer Struktur als „Rod“-ähnlich beschrieben werden können. Hierbei wurde die Unterscheidung in feine und grobe „Rods“ nach morphologischem Aspekt unternommen. Die Zahl von lysosomalen Ablagerungen (z.B. myelinartige Körperchen) wurde semiquantitativ beurteilt. 
Auch subsarkolemmale Aggregate wurden semiquantitativ erfasst. Der Gehalt an Speicherfetten wurde als 1 = gering, 2 = feintropfig, 3 = mitteltropfig und $4=$ grobtropfig bewertet. Fettzellen wurden erfasst mit einer Skala von 1 = einzelne Zellen im Bindegewebe, 2 = einzelne Zellen im Muskel, 3 = Gruppen von Fettzellen im Muskel und $4=$ fettiger Umbau des Muskels. Das einsprossende Bindegewebe wird mit $1=$ beginnende Einsprossung, 2 = deutliche Einsprossung von Bindegewebe, 3 = Ummauerung nahezu aller Fasern und $4=$ weitgehender Ersatz durch Bindegewebe bewertet. Die Kapillaren werden in ihrer Erscheinung nach augenfälligen Veränderungen beurteilt. Einige Veränderungen wurden als einfache Befunde notiert.

\subsubsection{Elektronenmikroskopie}

Die Ultradünnschnittpräparate wurden aus den Kunstharzpräparaten angefertigt. Die Auswahl erfolgte anhand der verfügbaren Materialien. Die Zutrimmung des Materials erfolgte ggf. anhand der betroffenen Areale, um eine möglichst klare Beurteilbarkeit der Läsionen zu erreichen. Bei den Kontrollfällen wurde aufgrund des Fehlens von im Semidünnschnitt identifizierbaren Läsionen eine orientierende Beurteilung am Elektronenmikroskop durchgeführt, in der alle sonst beurteilten Strukturen aufgenommen wurden. Grundsätzlich wurden Zellmembranen, Zellkerne, Mitochondrien, Myofibrillenstruktur und mögliche erkennbare Veränderungen beurteilt. 


\section{Ergebnisse}

\subsection{Lichtmikroskopischer Befund der Kamptokormiefälle}

Einleitung zu den Kamptokormiebiopsien

Insgesamt standen zur Auswertung 14 Fälle zur Verfügung, von denen ein Fall ein morphologisch nur teilweise zu verwerten war, da etliche Enzymreaktionen aufgrund starker Artefakte nicht sicher zu bewerten waren. Ein weiterer Fall war in Teilbereichen nicht auszuwerten, da das zur Verfügung stehende Material zu gering war, um alle gewünschten Aspekt zu beleuchten. Einzelfärbungen waren in einzelnen Fällen trotz Wiederholung nicht sicher zu verwerten, daher ergeben sich in einzelnen Aspekten abweichende Zahlen der verwerteten Fälle. Je nach Fall standen eine oder mehrere gefrorene Biopsieproben zur Verfügung. Die gemachten Befunde beziehen sich hierbei auf den jeweils diagnostisch am besten auszuwertenden Block. Im Prinzip finden sich die nachfolgend beschriebenen Befunde in jedem Block je Fall, sodass durch die Auswahl keine Beeinflussung der Ergebnisse erkennbar ist. Ausschlaggebend für die Auswahl des Blockes waren Größe (möglich repräsentativer Überblick), Erhaltungszustand (Gefrierartefakte), Orientierung der Muskelfasern zur Schnittfläche (Queranschnitt der Fasern wird angestrebt) und Inhalt der Biopsie (möglichst hoher Muskelanteil, da teilweise viel Bindegewebe enthalten ist). Befunde

Für die orientierende Bewertung der Schnittpräparate kommt die HE-Färbung zum Einsatz. In der Untersuchung der Kamptokormiefälle zeigen alle 14 untersuchten Fälle eine mäßiggradige bis starke Variation des Kaliberspektrums. Diese Kalibervariation kann als unimodale Variation charakterisiert werden. Der semiquantitativ bestimmte Variationsindex liegt bei 3,5 im Durchschnitt. Das entspricht einem mittleren Faserndurchmesser in der softwaregestützten Vermessung von im Schnitt 68,7 $\mu \mathrm{m}$. Dabei liegt der kleinste Faserdurchmesser dann bei 4,6 $\mu \mathrm{m}$ und der größte bei 193,1 $\mu \mathrm{m}$ (Grafik III). Die in der Standardliteratur genannten (Schröder 1982) Werte variieren für Frauen zwischen 45 und $60 \mu \mathrm{m}$ und für Männer zwischen 60 und $75 \mu \mathrm{m}$. Zwischen etwa 0,1 und $10 \%$ der Fasern erscheinen dabei atroph, wobei mit Ausnahme von zwei Fällen die Zahl rundlich atropher Fasern die Zahl angulär atropher Faser deutlich überwiegt. Nur sieben der Fälle weisen überhaupt einzelne angulär atrophe Fasern auf. Sehr auffällig ist, dass alle Fälle maximal atrophe Fasern in Form so genannter Kernsäcke aufweisen. Das Spektrum reicht hierbei von 0,15 bis zu 4 Kernsäcke auf ein Gesichtsfeld bei 200facher Vergrößerung (Medium Powerfield, MPF), wobei im Mittel 1,04 Kernsäcke pro Feld zu finden sind. 
Grafik III: Faserdurchmesser

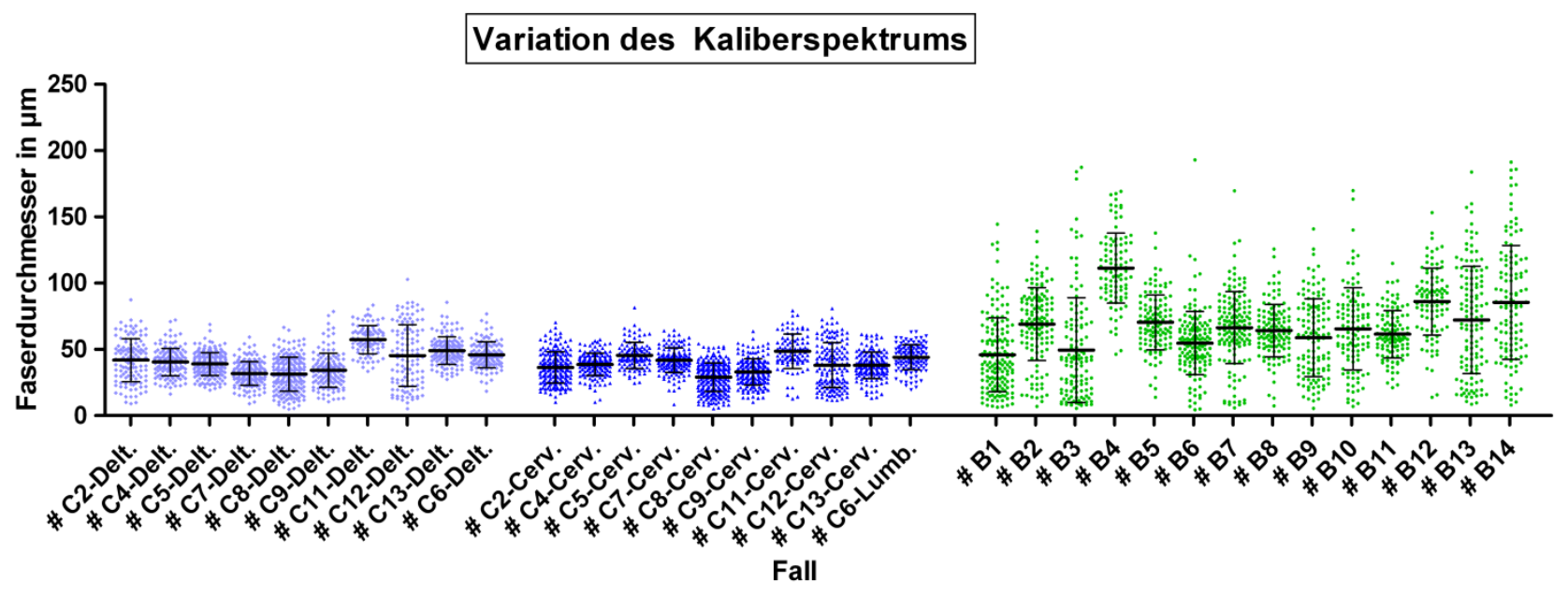

Die Zahl internalisiert gelegener Zellkerne in den Muskelfasern ist in zwei der Fälle mit jeweils fünf Prozent grenzwertig und in den übrigen Fällen teils deutlich erhöht. Bis zu 65 \% der Muskelfasern lassen internalisiert gelegene Kerne erkennen, wobei der Durchschnitt bei rund $30 \%$ liegt.

Alle 13 auswertbaren Fälle zeigten Aufsplitterungen einzelner Muskelfasern, so genannte „Splittings“. Die Anzahl reicht von 0,08 bis 2,25 „Splittings“ pro MPF, der Mittelwert liegt bei 0,96 ,Splittings“ pro MPF.

In keinem der untersuchten Fälle konnten morphologisch nennenswerte Infiltrate aus Lymphozyten oder Monozyten identifiziert werden. Nennenswert heißt in diesem Zusammenhang, dass einzelne Lymphozyten vorkommen können, aber eine relevante eigenständige Infiltration durch Lymphozyten oder Makrophagen nicht erkennbar ist. Der Fall, der in seinem ursprünglichen Befund als entzündlich verändert angesehen wurde, lässt in der Tat einzelne Lymphozyten erkennen, aber ein eigenständiger entzündlicher Prozess ist in den weiteren zusätzlichen Untersuchungen (Immunhistochemie) nicht zu erkennen gewesen. Elf der 14 Fälle lassen hypertrophe Fasern erkennen, die eine Invagination ihres Zytoplasmas, teilweise mit Verwindung der sarkoplasmatischen Strukturen ineinander aufweisen. Diese Fasern erinnern am ehesten an die in der Literatur bekannten „Whorled fibers“. In der EvG-Färbung wird vor allem der endomysiale Gehalt von kollagenem Bindegewebe beurteilt. Dabei lassen alle untersuchten Fälle eine endomysiale Vermehrung des Bindegewebes erkennen. Der Befund reicht vom beginnenden Einsprossen von Bindegewebsfasern in die Randbereiche der Faszikel (vier Fälle) bis zum hochgradigen fibrotischen Umbau, bei dem jede Faser von Bindegewebe ummauert ist (vier Fälle). Perimysiales Bindegewebe ist ebenfalls in allen Fällen nachzuweisen. Es handelt sich dabei um zellarmes, kollagenfaserreiches Bindegewebe (ortsständiges Bindegewebe). 
Für die nachfolgend beschriebenen Befunde war einer der Fälle leider nicht auswertbar, daher wird nicht mehr von 14, sondern von 13 Fällen gesprochen.

Der Glycogengehalt stellt sich in der PAS-Reaktion als fein verteilter normaler Gehalt dar. Drei der Fälle lassen verdichtet erscheinende Ablagerungen in Form subsarkolemmaler Kappen oder in Form granulärer Strukturen erkennen.

Der Gehalt an Neutralfetten in den Muskelfasern (ORO-Färbung) lässt in den Fällen einen geringen, teils auch vermindert (sieben Fälle) erscheinenden Gehalt erkennen. Endomysial gelegene Fettzellen finden sich in allen 13 Fällen. Bei sechs dieser Fälle beschränkt sich das Vorkommen auf die schmalen bindegewebigen Septen, die die Faszikel untergliedern. In den anderen sieben Fällen finden sich jeweils auch einzelne Fettzellen zwischen den Muskelfasern in den Faszikeln selbst. Angrenzend an die Faszikel der Muskulatur finden sich in neun der Fälle Gruppen reifzelligen Fettgewebes.

Keiner der untersuchten Fälle weist einen Mangel an Myoadenylatdeaminase auf. Mit der Trichromfärbung lassen sich in fünf der Fälle so genannte „ragged red“-Fasern erkennen, wobei nur 12 Fälle sicher zu bewerten waren. Die Anzahl reicht dabei von 0,12 bis zu 2 Fasern LPF. Daraus ergibt sich ein Durchschnitt von 0,67 „,ragged red“-Fasern pro LPF in den betroffenen Fällen bzw. 0,3 „ragged red“-Fasern referenziert auf die Zahl der untersuchten Fälle. Sieben Fälle zeigen keine solchen „ragged red“'-Fasern. Ebenfalls fünf Fälle lassen eine deutliche subsarkolemmale fuchsinophile Zeichnungsvermehrung erkennen. Drei dieser Fälle stimmen mit den Fällen überein, die „,ragged red“-Fasern aufweisen. Die Zahl betroffener Fasern reicht von zwei bis zu 70 Fasern pro LPF, wobei der Durchschnitt der betroffenen Fälle rechnerisch bei 23,4 Fasern pro LPF liegt. Sieben Fälle lassen keine vermehrte fuchsinophile Zeichnung erkennen. Nur drei der Fälle lassen einzelne geränderte Vakuolen, so genannte „rimmed vacuoles“, erkennen. Die Frequenz des Auftretens liegt dabei zwischen 0,5 und 0,1 Vakuolen pro MPF.

In 12 von 13 Fällen finden sich in der kombinierten COX / SDH-Reaktion COX-defiziente Fasern. Der Gehalt reicht dabei von 0,08 bis zu 17 Fasern pro LPF. Damit liegt der Durchschnitt bei 1,98 Fasern pro LPF. Darüber hinaus erkennt man in dieser Färbung in zwölf Fällen zentrale Strukturdefekte, in denen sich keine Ablagerung des Substrates erkennen lässt. Diese Veränderung lassen sich in 0,5 bis $40 \%$ der Muskelfasern nachweisen.

Durchschnittlich haben somit 12,2 \% der Fasern diese zentralen Strukturaufhebungen. Betrachtet man die COX oder die SDH-Reaktion als Monofärbungen, ergibt sich ein entsprechendes Bild. 
Die NADH-Reaktion ist die klassische Färbung zur Darstellung des sarkoplasmatischen Retikulums und somit besonders geeignet zur Beurteilung von strukturellen Veränderungen einer Muskelfaser. In den hier gemachten Analysen finden sich in zwölf Fällen die bereits erwähnten Strukturdefekte in den Muskelfasern, wobei zwischen 1 und etwa 25 \% der Fasern betroffen sind. Das entspricht einem Durchschnittswert von 7,54 \% der Fasern. Es handelt sich dabei um teils im Zentrum, teils aber auch randlich in der Muskelfaser befindliche Auslöschungen der Substratablagerungen. Diese sind relativ scharf begrenzt, ohne dass sie jedoch im Randbereich durch eine Verdichtung besonders demarkiert wären. Die Form imponiert im Wesentlichen homogen oval. Es findet sich nicht der ausgefranste oder mehrfach gelappte Aspekt von Mottenfraßfasern. Bei quer angeschnittenen Fasern ist teilweise mehr als die Hälfte des Faserdurchmessers betroffen. Bei längs angeschnittenen Fasern erstrecken sich die Veränderungen über weite Strecken der Fasern. Die Fasertypisierung erscheint in der NADH-Reaktion oftmals schwierig und gelingt in fünf Fällen nicht. In der Auswertung der Fasertypen zeigt sich ein heterogenes Bild. Vier Fälle zeigen eine leichte bis massive Typ-II-Fasertypenprädominanz, zwei Fälle eine leicht- bzw. hochgradige Typ-I-Fasertypenprädominanz und zwei Fälle erscheinen weitgehend paritätisch verteilt.

In der MAG-Reaktion lassen sich die Fasern mit einer Ausnahme immer typisieren. Acht Fälle ließen sich in ihrer Reziprozität der Fasertypisierung zur NADH-Reaktion beurteilen, wobei fünf Fälle reziprok, drei nicht reziprok waren. Die Strukturdefekte sind in elf Fällen nachweisbar.

Die saure Phosphatasereaktion wird zum Nachweis von Makrophagen und lysosomalen Strukturen genutzt. In den hier untersuchten Fällen fällt in 12 Fällen eine deutliche feingranulär erscheinende Vermehrung positiv reagierender Strukturen im Zentrum oder Randbereich etlicher Fasern auf. Ein Fall zeigt wiederholt keinerlei Reaktivität in der Färbung, sodass Zweifel an der Integrität der Biopsie bestehen. Die Substratablagerung passt in Form und Verteilung zu den zuvor beschriebenen Strukturauslöschungen in den oxidativen Fermentfärbungen. Dieser Eindruck lässt sich in Doppelfärbungen einzelner Fälle (SP / NADH, SP / SDH und SP / COX) bestätigen.

Das Färbesignal erscheint einem Sandsturm ähnlich fein verteilt und ist damit different von den globulären Strukturen, die sich als Lipofuszin identifizieren lassen. Auch die groben Strukturen, die sich im Rahmen vakuolärer Myopathien nachweisen lassen sind anders gestaltet, da sie wesentlich gröber erscheinen. Zwischen 0,5 und $40 \%$ der Fasern zeigen diese Veränderungen, der Durchschnitt liegt bei 20,1 \%. In immerhin acht der Fälle lassen sich 
vereinzelte Einzelfasernekrosen nachweisen. Dabei finden sich zwischen 0,17 und einer Nekrose pro LPF, im Schnitt 0,37 Nekrosen pro LPF in den betroffenen Fällen. Diffus verteilte Makrophagen lassen sich teils in geringer, teils in deutlicher Anzahl nachweisen. Die eigentliche Einteilung in die jeweiligen Fasertypen erfolgt anhand der ATPase-Reaktion bei unterschiedlichen $\mathrm{pH}-$ Werten. Im vorliegenden Untersuchungsgut gestaltet sich die Bewertung schwierig und es lassen sich bei $\mathrm{pH}-$ Wert 4,4 acht, bei den $\mathrm{pH}-$ Werten 4,7 und 10,4 jeweils sieben Fälle typisieren. Insgesamt sind daher acht Fälle typisierbar, da sich alle Fälle komplett überschneiden. Von den Fällen weisen vier Fälle eine hochgradige und ein Fall eine deutliche Typ-I-Fasertypenprädominanz auf. Zwei Fälle zeigen ein ausgeglichenes Verhältnis der Fasertypen. Nur ein Fall zeigt ein diskretes Überwiegen der Typ-II-Fasern. Die beschriebenen Strukturdefekte lassen sich auch in den ATPasen nachvollziehen. Bei ATPase pH-Wert 4,4 zeigen neun von zehn, bei ATPase $\mathrm{pH}$-Wert 4,7 acht von elf und bei ATPase pH-Wert 10,4 vier von sieben Fällen die Strukturdefekte.

Grafik IV: Typische Strukturläsionen

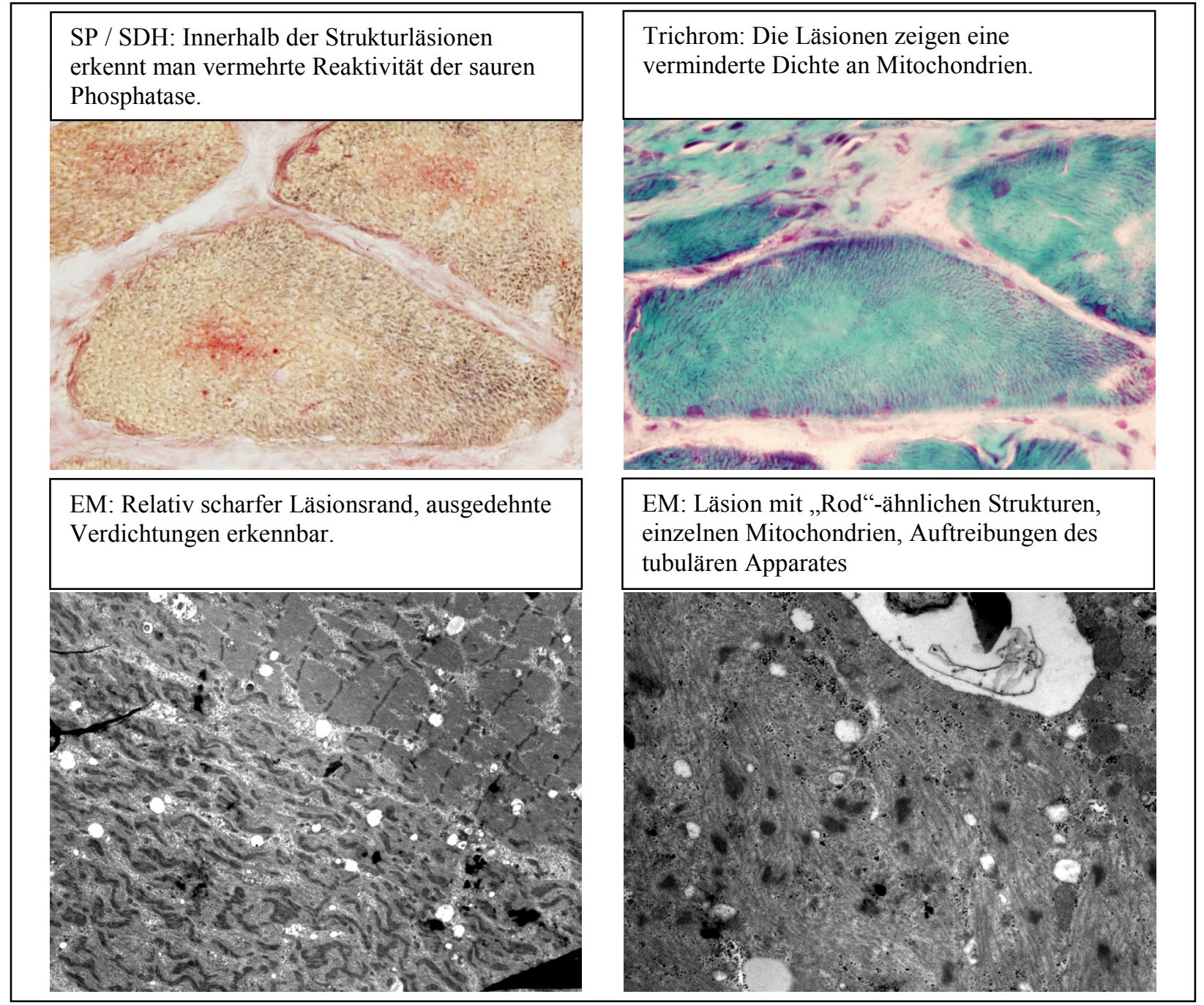


In den folgenden Grafiken (V-VII) werden die zuvor beschriebenen Veränderungen nach ihrer Bedeutung zusammengefasst graphisch dargestellt.

Die Balken markieren den Mittelwert und die jeweilige (einfache) Standardabweichung. Jeder Fall wird durch einen Punkt markiert. In der Legende ist zu erkennen, auf welche Ordinate sich die jeweiligen Werte beziehen.

Tabelle X fasst die wesentlichen Befunde und die klinischen Parameter zusammen.

Grafik V: Myopathische Veränderungen

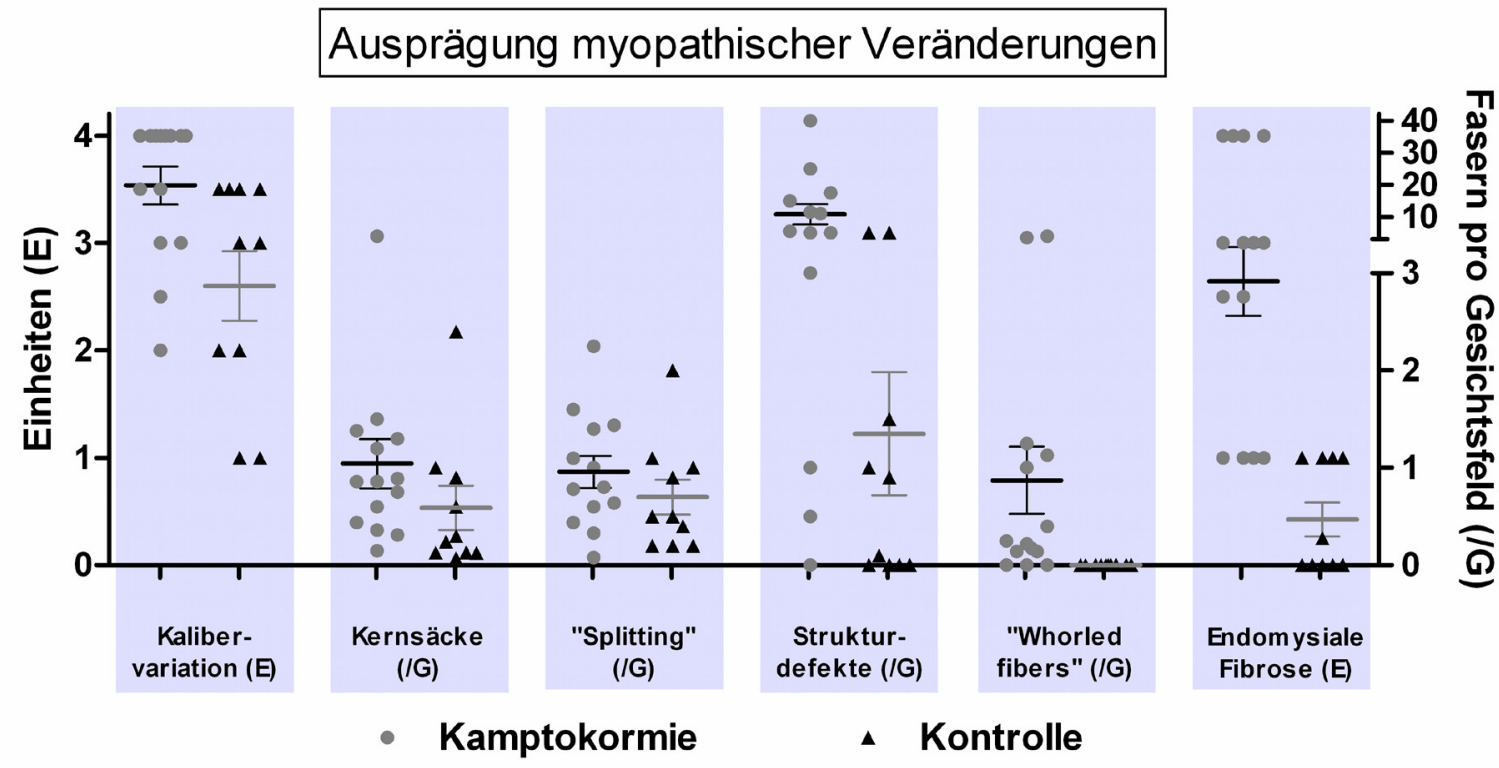

Grafik VI: Mitochondriale Veränderungen

Zeichen mitochondrialer Schädigung

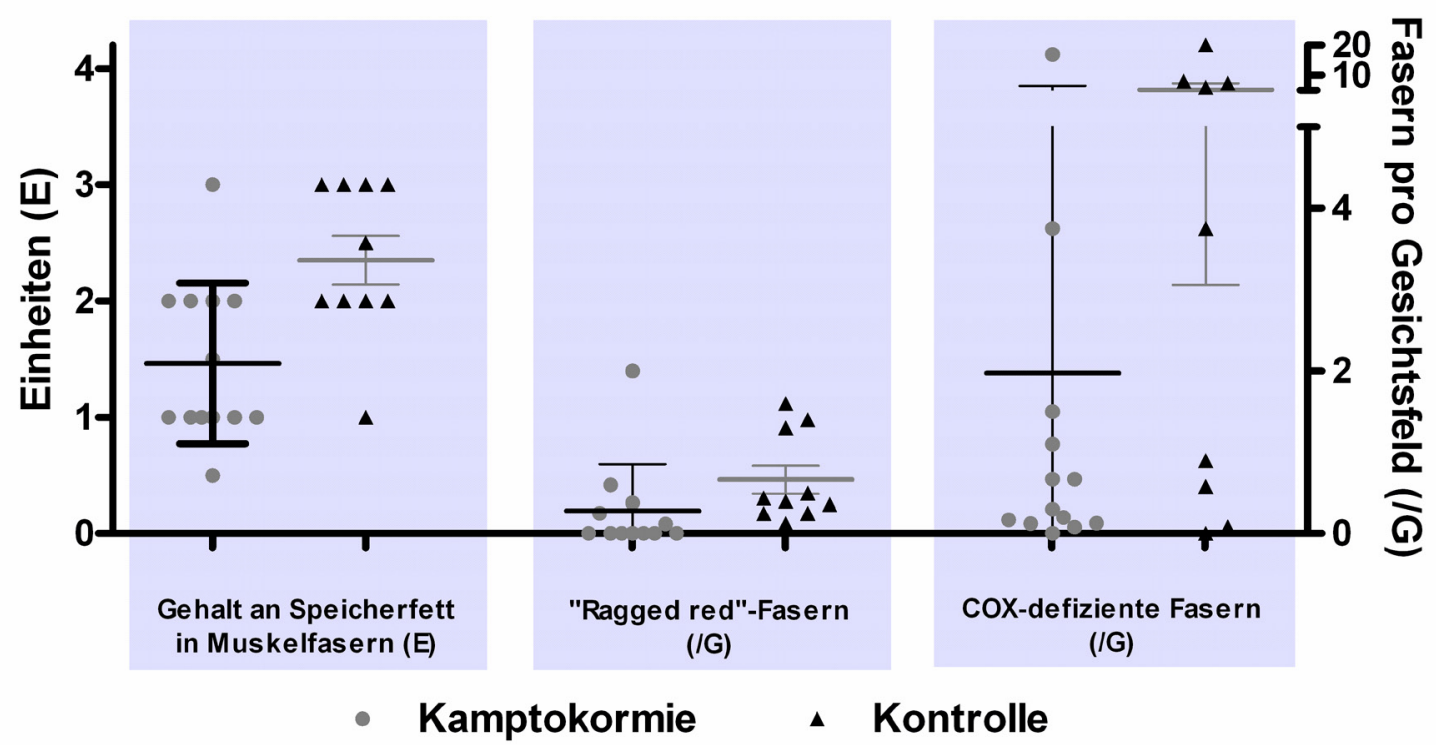


Grafik VII: Zeichen muskulärer Reorganisation

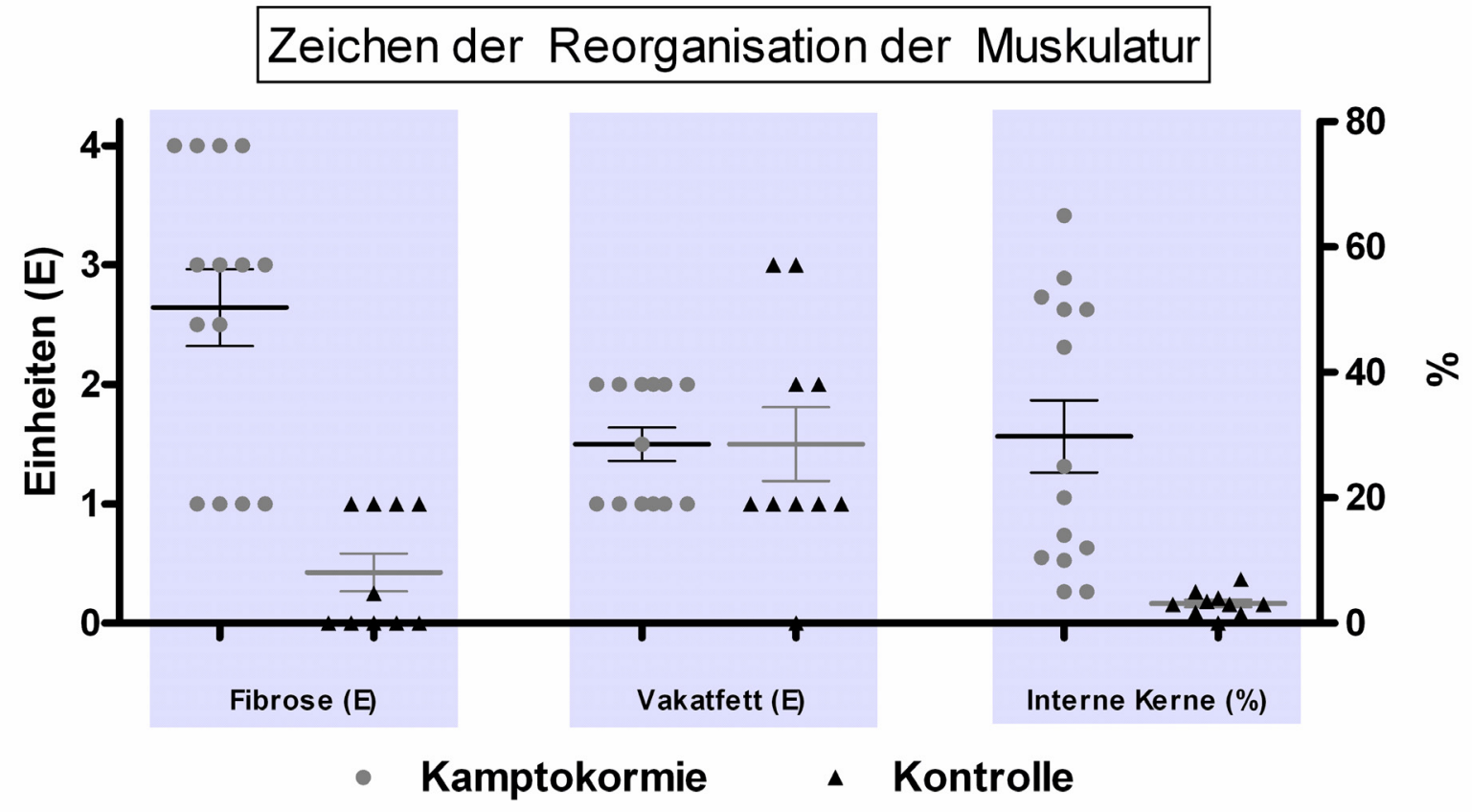

\subsection{Lichtmikroskopischer Befund der Kontrollfälle}

Einleitung zu den Kontrollgruppenergebnissen

Da Muskeln je nach anatomischer Lage aber gewisse Eigenheiten aufweisen können, war ein Kontrollkollektiv von Rückenmuskeln notwendig, welches sich nicht unter den Routinebiopsien des diagnostischen Eingangsmaterials befindet. Als Kontrollgruppe wurde daher initial ein Kollektiv von 13 zufällig ausgewählten Verstorbenen gewählt, von denen im Rahmen der Autopsie Proben der Rückenmuskulatur zur Untersuchung entnommen wurden. Diese Biopsien entstammten vorwiegend der zervikalen, in einigen Fällen auch der lumbalen Rückenmuskulatur. Als Referenz lagen von den jeweiligen Fällen auch noch Proben des M. deltoideus vor. Da es sich beim M. Parkinson um eine neurodegenerative Erkrankung handelt, war die Überlegung, eine neurodegenerative Erkrankung in der Kontrollgruppe möglichst auszuschließen. Um eine dahingehend ausgewählte Kontrollgruppe zu erhalten, in der ein möglicher Effekt durch eine zuvor nicht erkannte neurodegenerative Erkrankung möglichst ausgeschlossen ist, wurden die gewählten Fälle im Rahmen dieser Arbeit einem Demenzscreening mittels der PET-blot Methode unterzogen. Mit den Antikörpern 4B12 und LB509 wurde nach pathologischen Ablagerungen von $\alpha$-Synuklein, mit 6E10 nach $\beta$-Amyloid und mittels AT8 nach pathologischen Ablagerungen von Tauprotein gesucht.

Mit dem Screening konnten drei der Fälle als wegen deutlicher neurodegenerativer Veränderungen wenig geeignet identifiziert werden. Diese Fälle zeigten einen CERAD-Score $\mathrm{C}$ beziehungsweise ein Braak-Stadium, welches größer als III ist (siehe Tabelle XI). Diese Befunde könnten die Muskelhistologie der Kontrollpatienten beeinflussen, wenn es sich um 
einen übergeordneten Prozess im Rahmen einer neurodegenerativen Erkrankung handelt, der charakteristische morphologische Veränderungen mit sich bringt. Demgegenüber fanden sich keine Veränderungen, die auf eine mit $\alpha$-Synuklein assoziierte Pathologie hinweisen würden. Befunde

Nachfolgend werden die Befunde der untersuchten Kontrollmuskeln beschrieben, die bei Autopsien gewonnen wurden. Einander gegenübergestellt werden dabei Proben der Rückenmuskulatur jeweils den korrespondierenden Proben der sonst als Standard geltenden Muskulatur des M. deltoideus.

Die HE-Färbung zeigt in allen Fällen eine leichte, teils auch deutliche Variation des Kaliberspektrums der Muskelfasern. Diese Variation ist in einigen Fällen als eher bimodal, in anderen Fällen als unimodal zu beschreiben. Der durchschnittliche semiquantitativ ermittelte Variationsindex liegt für die lumbale Rückenmuskulatur bei 3,1. Für die zervikale

Rückenmuskulatur liegt er bei 2,61. Die gesamten Rückenmuskelproben liegen im Schnitt bei 2,79 und die Deltoidmuskulatur bei 2,6 (referenziert auf die zervikalen Rückenmuskeln bei 2,78, auf die lumbale bei 2,6). Anhand der analogen Bewertungsskala scheint der Unterschied zu den Kamptokormien recht moderat, was in der Codierung des zugrunde liegenden

Befundes liegt. In der Vermessung wird deutlich, wie viel stärker ausgeprägt die Variation der Faserdurchmesser in den Fällen der Kamptokormie ist.

Fünf Deltoidproben zeigen angulär atrophe Fasern, wobei in zwei Fällen mehr als 5 \% (bis zu $10 \%$ ) angulär atrophe Fasern zu finden sind. Bei den Rückenmuskeln zeigt sich zervikal und lumbal ein vergleichbares Bild. Bei Fällen mit hohen Zahlen angulär atropher Fasern findet sich dies in den Rückenmuskeln wieder. Unter den zervikalen Proben fallen fünf Fälle, unter den lumbalen vier Fälle auf, von denen jeweils zwei 5 \% oder mehr atrophe Fasern aufweisen. Abgerundet atrophe Fasern finden sich in jeweils vier der Deltoidproben, der zervikalen und der lumbalen Proben. Die Zahl der gerundet atrophen Fasern ist in der Mehrzahl der Fälle geringer, als die angulär atropher Fasern, wobei in einem Fall auch $20 \%$ gerundet atrophe Fasern zu erkennen sind. Maximal atrophe Fasern in Form so genannter Kernsäcke finden sich in acht der zehn Deltoidproben und in sämtlichen Rückenmuskelproben. Die Werte reichen hierbei von 0,07 bis 2,71 Fasern / MPF für Deltoidproben (MW: 0,48), von 0,07 bis 1,4 Fasern / MPF für zervikale (MW: 0,55) und 0,125 bis 2,4 Fasern / MPF für lumbale Proben (MW: 0,68).

Internalisiert gelegene Zellkerne finden sich in allen untersuchten Kontrollfällen. Allerdings wird der allgemein akzeptierte Wert von mehr als $5 \%$ als Kriterium für einen pathologischen Befund nur in fünf Deltoidproben, in zwei zervikalen und einer lumbalen Proben 
überschritten. Die Durchschnittswerte liegen dabei für die Deltoidproben bei 7,35 \%, für die zervikalen Proben bei 3,87 \% und für die lumbalen Proben bei 3,5 \%.

„Splittings“ finden sich ebenfalls in sämtlichen Proben. Zwischen 0,4 und 2,125 Fasern / MPF $(Ø: 1,24)$ zeigen in den Deltoidproben ein solches Splitting. In der Gruppe der

Rückenmuskelproben zeigen 0,2 bis 3 Fasern / MPF (Ø: 0,91) der zervikalen und 0,2 bis 1,1 Fasern / MPF (Ø: 0,56) der lumbalen Proben dieses Splitting.

Infiltrate lymphomononukleärer Zellen finden sich in vier der Fälle. Darunter findet sich ein Fall, der in allen drei Proben entzündliche Infiltrate aufweist. Bei den anderen handelt es sich um Infiltrate in nur einem Biopsieort. Nur bei dem Fall, in dem alle Biopsieorte betroffen sind, handelt es sich um deutliche Infiltrate, die klar an einen eigenständigen entzündlichen Prozess denken lassen. Torquierte Muskelfasern, die an „Whorled fibers“ erinnern, finden sich in keinem der Kontrollfälle.

In der EvG-Färbung zeigen acht der Deltoidproben eine diskrete bis leichte endomysiale Bindegewebsvermehrung. Unter den lumbalen Proben findet man in zwei Fällen eine leichte, unter den zervikalen Proben in fünf Fällen eine leichte und in einem Fall eine mäßiggradige Vermehrung endomysialen Bindegewebes. Die jeweils übrigen Fälle lassen kein endomysial gelegenes kollagenes Bindegewebe erkennen. Perimysiales Bindegewebe kommt in neun Deltoidproben, in sieben von neun zervikalen und in vier von sechs lumbalen Proben zur Darstellung.

Die PAS Färbung zur Darstellung des Glycogengehaltes der Muskelfasern verläuft in allen Kontrollfällen eher schwach. Kompakte Verdichtungen finden sich in drei von zehn Deltoidproben, in sieben der zervikalen und fünf der lumbalen Proben. Die betroffenen Deltoidproben weisen teils nur einzelne, teils auch zahlreiche Fasern mit Ablagerungen auf. Bei den Rückenmuskelproben weisen die zervikalen Biopsien einzelne bis etliche, bei den lumbalen Proben, je nach Fall, einzelne bis zahlreiche betroffene Fasern auf. Der Fall mit zahlreichen von Ablagerungen betroffenen Fasern weist diese in beiden beprobten Höhen auf. Die ORO Färbung zeigt in mehreren untersuchten Fällen eine geringe bis durchschnittliche feintropfige Speicherfettverteilung. Je Gruppe fallen drei Fälle, unter den lumbalen Proben auch vier Fälle mit kräftiger Fettspeicherung auf, die aber noch regelhaft feintropfig erscheint. Die semiquantitativ ermittelten Werte lassen tendenziell einen höheren Fettgehalt in den Proben aus dem Rücken verglichen mit dem Deltoid erkennen. Die Mittelwerte liegen für die Deltoidgruppe bei 2,15, für die zervikale Muskulatur bei 2,22 und für die lumbale Muskulatur bei 2,8, gemessen in relativen Einheiten. Sieben der Deltoidproben lassen einzelne Fettzellen in den Bindegewebssepten erkennen, zwei der Fälle auch einzelne Fettzellen im 
Muskelfaszikel selbst. Bei den zervikalen Proben zeigen fünf Fälle Fettzellen in den Septen, vier Fälle auch einzelne Fettzellen in den Muskelfaszikeln und ein Fall etliche Fettzellen in den Faszikeln. Lumbal zeigt eine Probe keine Fettzellen, zwei Proben Fettzellen in den Septen und zwei Proben bereits kleine Gruppen von Fettzellen in den Muskelfaszikeln. Angrenzend an das Muskelgewebe findet man bei drei der Deltoidproben, bei sieben der zervikalen und bei einer der lumbalen Rückenmuskelproben reifzelliges Fettgewebe.

Ein Mangel an Myoadenylatdeaminase findet sich in keinem der Kontrollfälle. Als Zeichen vermehrter Akkumulation von Mitochondrien finden sich in acht der Deltoidproben, in acht von neun zervikalen sowie in allen lumbalen Rückenproben „,ragged red“-Fasern. Die Zahl der, ,ragged red“-Fasern liegt in den Proben des Deltoid zwischen 0,05 und 0,5 Fasern / LPF bei einem Mittelwert von 0,2 Fasern / LPF in sämtlichen Deltoidproben. In der zervikalen Rückenmuskulatur finden sich im Schnitt 0,67 Fasern / LPF, wobei die Bandbreite von 0,14 bis zu 1,6 Fasern / LPF reicht. In der lumbalen Muskulatur findet man im Schnitt 0,48 Fasern / LPF bei einer Streuung zwischen 0,125 und 1,4 Fasern / LPF. Dabei fällt in der longitudinalen Betrachtung der Fälle auf, das in vier von fünf Fällen die zervikale Probe am meisten, in einem Fall die lumbale Probe am meisten „ragged red“-Fasern enthalten. Die zervikalen Proben weisen in sieben Fällen mehr, in einem Fall gleich viele und in einem Fall weniger ,ragged red“-Fasern als die Deltoidproben auf. Eine subsarkolemmale Zeichnungsvermehrung findet sich in sechs der Deltoidproben, in sieben der zervikalen und drei der lumbalen Rückenmuskelproben. Dabei reichen die Werte bei den Deltoidproben von 0,07 bis zu 30 Fasern / LPF, bei den zervikalen Proben von 0,07 bis 1 Fasern / LPF und bei den lumbalen Proben von 0,29 bis zu 20 Fasern / LPF. Geränderte Vakuolen (,rimmed vacuoles“) finden sich in geringer Anzahl in drei der Deltoidproben, drei der zervikalen und zwei der lumbalen Proben. Die Zahl der betroffenen Fasern beläuft sich jeweils auf 0,05 bis 0,2 Fasern / MPF.

Es ließen sich nur neun der Deltoidproben in der COX / SDH-Färbung sicher auswerten, wobei sieben davon COX-defiziente Fasern zeigten. Die Werte reichen dabei von 0,07 bis 8,2 Fasern / LPF bei einem Mittelwert der auswertbaren Proben von 1,58 Fasern / LPF. Bei den zervikalen Proben waren sieben von neun Fällen sicher auszuwerten. Es konnten zwischen 0,3 und 8 Fasern / LPF als defizient identifiziert werden, der Mittelwert lag bei 4,11 Fasern / LPF. In der Gruppe der lumbalen Proben zeigten fünf der sechs Fälle defiziente Fasern mit einer Anzahl zwischen 0,58 und 20 Fasern / LPF, wobei der Mittelwert hier bei 6,07 Fasern / LPF lag. Bereits die Durchschnittswerte zeigen die Tendenz, dass die Rückenmuskeln mehr COXdefiziente Fasern aufweisen. In der Einzelfallbetrachtung (Longitudinalauswertung) erkennt 
man, dass die sechs verwertbaren Fälle in den zervikalen Proben immer mehr defiziente Fasern, als in den Deltoidproben aufweisen. Bei den lumbalen Proben weisen fünf Proben mehr, eine weniger defiziente Fasern als die Deltoidprobe auf. Beim Vergleich zervikaler und lumbaler Proben findet man dreimal in den lumbalen, einmal in der zervikalen Probe mehr COX-defiziente Fasern. Die bei den Kamptokormiefällen beschriebenen Strukturdefekte erkennt man in keiner der Deltoidproben. Vier der zervikalen und zwei der lumbalen Proben weisen derartige Defekte in geringer Zahl auf. Bei den zervikalen Proben finden sich in 0,1 bis $5 \%$ der Fälle Strukturdefekte, bei den lumbalen in 1 bis $2 \%$ der Fälle.

Die hierfür klassischerweise herangezogene NADH Färbung zeigt vereinzelte Strukturdefekte in drei der Deltoidproben, in zwei der zervikalen und vier der lumbalen Proben. Dabei handelt es sich um 0,1 bzw. 0,5\% betroffene Fasern in den Deltoidproben. Bei den Rückenmuskeln finden sich zervikal 0,1 bzw. $5 \%$ betroffene Fasern und lumbal zwischen 0,5 und $1 \%$ betroffene Fasern. Alle Biopsien lassen eine gute Typisierbarkeit der Muskelfasern erkennen. In den Deltoidproben zeigen vier Fälle ein ausgeglichenes Verhältnis der Fasertypen, drei eine leichte Prädominanz des Typs I und drei eine leichte bis deutliche Prädominanz des Typs II. Die zervikalen Proben stellen sich relativ ausgeglichen dar, wobei zwei Fälle eine leichte Dominanz des Typs II, ein Fall eine leichte Prädominanz des Typs I zeigen. Lumbal weisen drei der fünf Fälle eine leicht bis mäßige Typ-I-Faserprädominanz auf. Das Verhältnis der Prädominanz beträgt in den Kontrollfällen maximal 1: 5 .

Die MAG Reaktion zeigt nur in einer zervikalen und einer lumbalen Proben einzelne Strukturdefekte. Die Typisierbarkeit ist gegeben. Neun der Deltoidproben zeigen ein reziprokes Verhältnis zur NADH Reaktion, eine nicht. Acht der zervikalen Rückenmuskelproben und vier der lumbalen Proben zeigen die erhaltene Reziprozität der Anfärbbarkeit der Fasertypen in Relation zur NADH Reaktion.

In der sauren Phosphatasereaktion zeigen vier der Deltoidproben einen geringen, drei einen mäßigen und drei einen vermehrten Gehalt der Muskelfasern. Bei den zervikalen Proben zeigen zwei einen geringen, fünf einen mäßigen und zwei einen vermehrten Gehalt positiv markierter Strukturen. Die lumbalen Proben zeigen in drei Fällen einen geringen, in einem Fall eine mäßigen und in zwei Fällen einen vermehrten Gehalt. Dieser Gehalt ist durch mehr oder minder grob markierte fuchsinophile Strukturen gekennzeichnet, die diffus in den Muskelfasern nachzuweisen sind. Eine unter den Biopsien beschriebene feine sandsturmähnliche Ablagerung findet sich in $0,1 \%$ der Fasern einer Deltoidprobe. Bei den zervikalen Rückenmuskelproben findet man diese Veränderung in 0,1 \% der Fasern in drei Fällen, in $0,5 \%$ bzw. 2 \% der Fasern in jeweils einem weiteren Fall. Unter den lumbalen 
Proben findet sich ein Fall, der in 0,1 \% der Fasern diese speziellen Ablagerungsformen zeigt. Ein weiterer Fall zeigt in $4 \%$ der Fasern Ablagerungen, die ähnlich sind. Fünf der Deltoidproben weisen Einzelfasernekrosen auf, wobei Werte zwischen 0,083 und 1,57 Nekrosen / LPF erreicht werden. Fünf der zervikalen Proben weisen ebenfalls Einzelfasernekrosen mit Werten zwischen 0,2 und 0,9 Nekrosen / LPF auf. In den lumbalen Proben zeigen zwei Fälle 0,13 bzw. 0,33 Nekrosen / LPF. Einzelne Makrophagen in geringer bis etwas erhöhter Zahl fanden sich in allen Proben. Es fallen drei Proben hierbei durch einen deutlich vermehrten Gehalt an Makrophagen in der Deltoid- und der zervikalen Biopsie auf, wobei es sich immer um die gleiche Fälle handelt. Einer dieser Fälle zeigt auch die deutlichen entzündlichen Infiltrate, ein weiterer zumindest lymphomononukläre Infiltrate in geringerer Dichte. Einer dieser Fälle sticht auch in der lumbalen Probe hervor.

Die Beurteilung der Fasertypen in den ATPase Reaktionen verlief an den Proben bei den pHWerten 4,4 und 10,4 ohne Probleme, lediglich bei pH-Wert 4,7 gelang nicht immer die Typisierbarkeit. Hierbei zeigten fünf der Deltoidproben ein weitgehend ausgeglichenes, teilweise von Faszikel zu Faszikel etwas veränderliches Verhältnis der Fasertypen. Zwei der Deltoidbiopsien zeigen eine leichte Typ-I-Prädominanz (1:2), ein Fall eine mäßige Typ-IPrädominanz (1:3) und zwei Fälle eine deutliche Prädominanz des Typs I (1:4 und mehr). Unter den zervikalen Proben finden sich vier Fälle mit einer überwiegend paritätischen Verteilung der Fasertypen. Drei Fälle zeigen eine leichte, zwei Fälle eine mäßige Prädominanz des Fasertyps I. Bei den lumbalen Proben findet man zwei ausgeglichen verteilte Fälle. Daneben zeigen je zwei Fälle eine mäßige, bzw. eine deutliche (1:4) Prädominanz des Fasertyps I. Mit Ausnahme zweier Fälle unter den Deltoidproben und zweier Fälle unter den zervikalen Proben finden sich immer einzelne oder wenige atrophe Fasern des Typs I. Demgegenüber fallen deutliche Zahlen atropher Typ-II-Fasern in etlichen der Fälle auf. Vier der Deltoid- und jeweils drei der Rückenmuskelproben zeigen eine starke / subtotale Typ-II-Faseratrophie, wobei ein Fall in allen drei Proben betroffen ist. Vier der Deltoid- und drei der zervikalen Proben zeigen noch eine deutliche Zahl atropher Typ-IIFasern. Nur eine der Deltoid- und zwei der zervikalen bzw. zwei der lumbalen Proben zeigen keine oder eher wenige atrophe Fasern vom Typ II. In den nachfolgenden Grafiken (VIII und IX) werden die hier gemachten Aussagen grafisch dargestellt. Dabei wird einmal (VIII) Muskelgewebe des M. deltoideus mit Gewebe paraspinaler Muskulatur (gemischt lumbal und zervikal) verglichen. In Grafik IX werden die Höhen paraspinaler Muskulatur verglichen. 
Grafik VIII: Vergleich von Deltoid und paraspinaler Muskulatur in der Kontrollgruppe

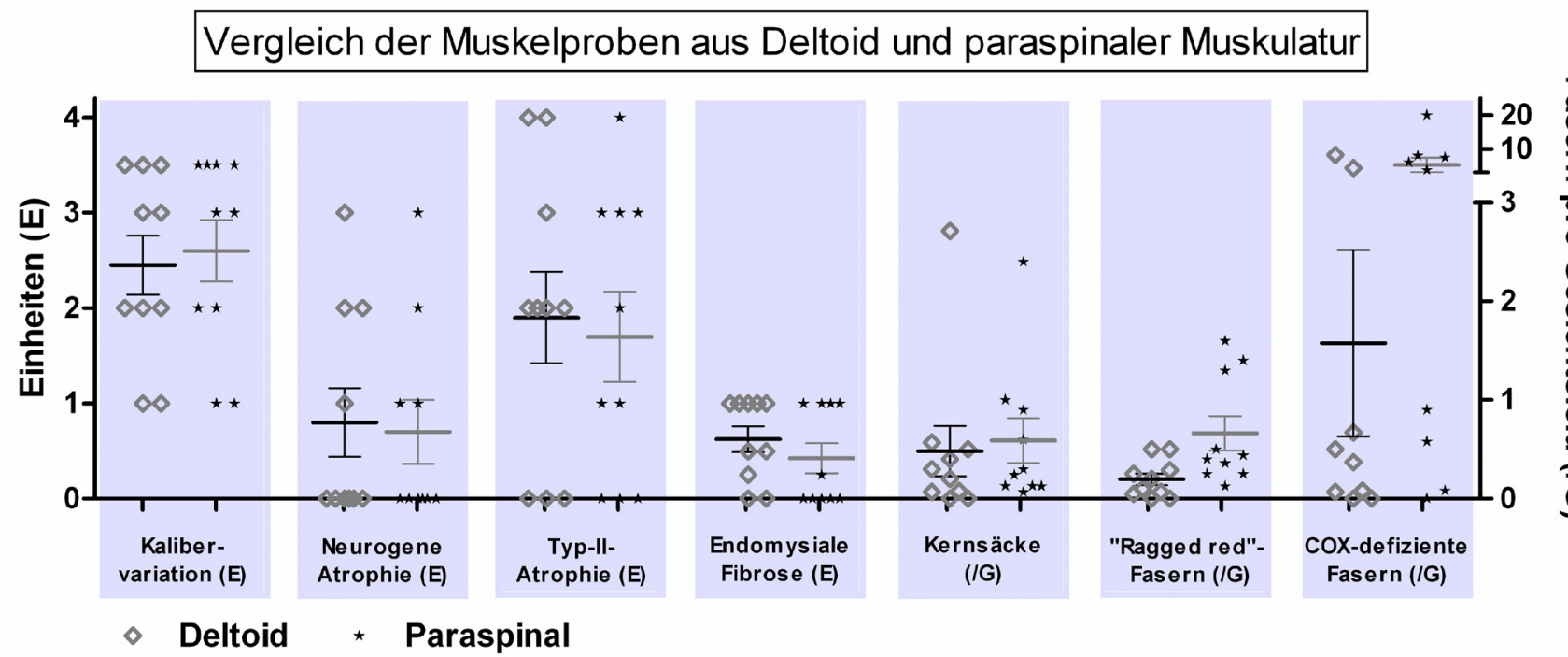

Die Balken markieren wieder Mittelwert und Standardabweichung. Außerdem findet sich in der Tabelle XI unter dem Punkt „Muskelbefund“ eine Zusammenfassung des Gesamtbefundes des jeweiligen Falls, wie sie in einem neuropathologischen Befund gemacht würde.

Grafik IX: Vergleich unterschiedlicher Entnahmehöhen bei paraspinaler Muskulatur

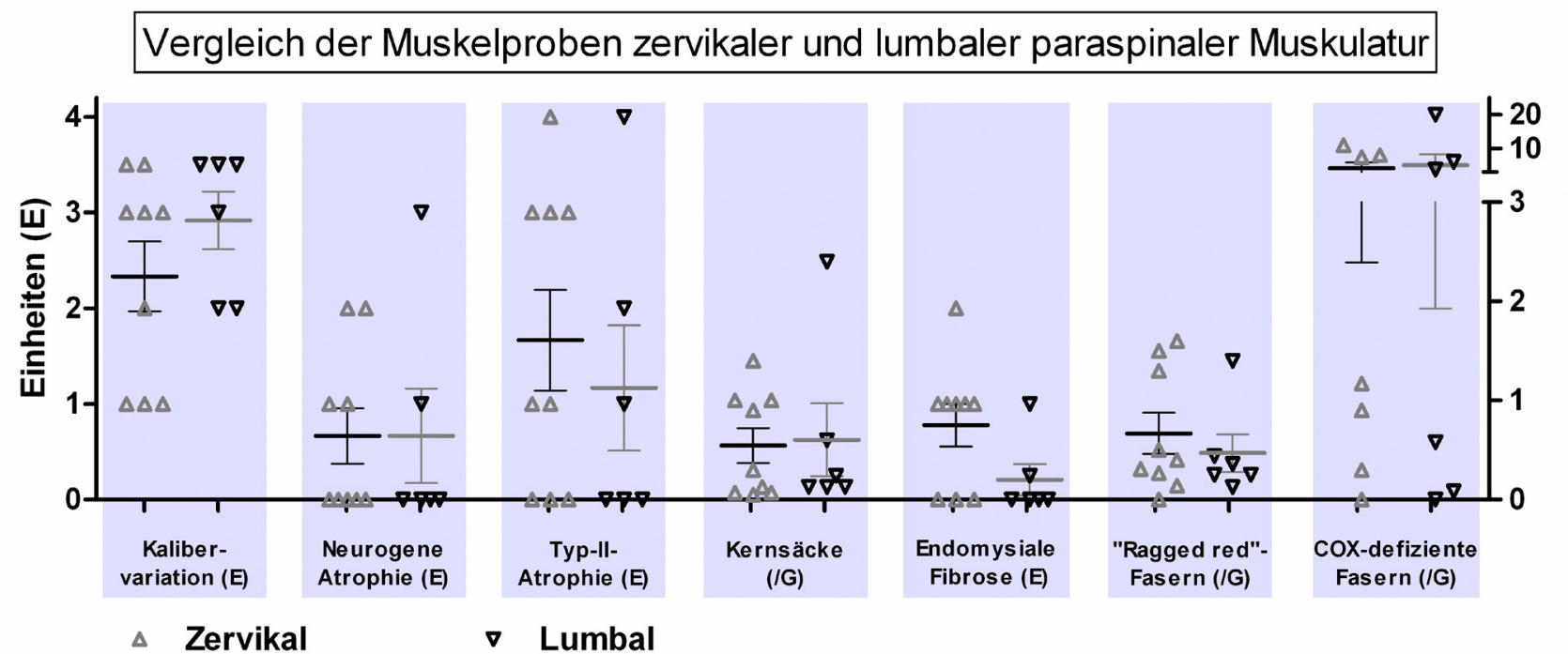

\subsection{Immunhistochemische Befunde der Kamptokormiefälle}

In elf der Kamptokormiefälle untersuchten wir immunhistochemisch die Expression von

Desmin, weil irreguläre Ablagerungen auf eine myofibrilläre Myopathie (MFM) hinweisen

könnten. Hierbei wird Desmin sowohl auf dem Sarkolemm, wie auch sarkoplasmatisch 
detektiert. Zwei Fälle zeigen hierbei Verdichtungen, die als Ablagerungen gewertet werden können. Alle übrigen Fälle sind frei von irregulären Massenablagerungen.

Zur immunhistochemischen Darstellung der Verteilung der Mitochondrien wurde der Marker Prohibitin verwendet. Mit Hilfe dieses Markers lassen zehn der elf untersuchten Fälle subsarkolemmale Zeichnungsvermehrung erkennen, die zischen ein und $40 \%$ der Fasern betrifft. Klar abgrenzbare „ragged-red“-Fasern finden sich nur in zwei Fällen und in geringer Zahl von bis zu einem Prozent.

Eine immunhistochemische Fasertypisierung konnte mittels SERCA-1 (färbt Typ-II-Fasern an) durchgeführt werden. Hierbei kann in der Hälfte der zehn untersuchten Fälle eine starke Typ-I-Fasertypenprädominanz gefunden werden. Zwei der Fälle weisen ein diskretes bzw. leichtes Überwiegen vom Fasertyp II auf. Zwei Fälle weisen eine paritätische Verteilung der Fasertypen ohne Prädominanz eines Typs auf. In einem der Fälle wurden zwei unterschiedliche Biopsien ausgewertet, wobei die eine Biopsie ein ausgeglichenes Verhältnis, die andere ein leichtes Überwiegen von Typ-II-Fasern zeigt.

Die untersuchte Expression des MHC-I-Komplexes auf den Muskelfasern konnte in zehn der elf Fälle ausgewertet werden. In allen auswertbaren Fällen fand sich eine regelhafte starke Expression im Bereich der Kapillarwände. Eine Aufregulierung auf einzelnen Muskelfasern konnte in zwei Fällen gefunden werden, wobei jeweils nur singuläre Fasern betroffen waren. Von einem Fall konnten zwei Biopsien ausgewertet werden, von denen eine singuläre Fasern mit diskreter Aufregulation zeigte.

Die Expression des Markers CD56 (neuronal cell adhesion molecule, N-CAM) wurde an zehn Fällen untersucht. Sämtliche Fälle zeigten positiv markierte Fasern, bei denen sich sowohl membranständig, als auch vermindert sarkoplasmatisch ein Signal finden ließ. Es finden sich zwischen 0,75 und $40 \%$ betroffene Muskelfasern, im Durchschnitt 13,9\% der Fasern positiv markiert.

Exemplarisch wurden mit dem Marker LB509 zur Detektion von $\alpha$-Synuklein vier der Fälle gefärbt, in denen mein ein membranbetontes Färbemuster erkennt. Das Sarkoplasmatische Netzwerk reagiert nur gering. In zwei der Fälle kommen kompakte Ablagerungen zur Darstellung, die immunreaktiv sind. Die Zellkerne werden nicht markiert.

Zusätzlich wurde der Marker pSer129 zur Suche nach an Position 129 phosphoryliertem $\alpha$ Synuklein eingesetzt, mit dem neun Fälle gefärbt wurden. Sieben dieser Fälle konnten ausgewertet werden. Die Muskelfasern zeigen keine klar zuzuordnende Anfärbung. In allen Fällen werden die Wände kapillärer Blutgefäße markiert. In drei der Fälle lässt sich ein im Bereich der Kernmembran der Muskelfasern lokalisiertes Färbesignal erkennen. 
Mit dem Marker $\alpha \beta$-Crystallin wurden zehn Fälle untersucht, von denen neun zu verwerten waren. Drei der Fälle lassen hierbei Ablagerungen erkennen, ein weiterer Fall zeigt ein uneindeutiges Muster bei wiederholter Färbung. Die Muskelfasern selbst reagieren schwach mit dem Antikörper. Ablagerungen stellen sich als kompakte ovaloide Strukturen innerhalb der Muskelfasern dar.

Der Marker LDB-3 (positiv bei ZASP-assoziierten MFM) zeigt ein leichtes, am ehesten als sarkoplasmatisch imponierendes Muster ohne kompakte Ablagerungen.

Ubiquitin und p62 sind zwei Marker zur Darstellung ubiquitinylierter Proteine. In der p62Färbung stellen sich in allen vier untersuchten Fällen feine, eher globulär wirkende Ablagerungen in Muskelfasern dar. Der Marker Ubiquitin liefert keine positiv markierten Strukturen in den drei untersuchten Fällen. Diese Fälle sind deckungsgleich mit den Fällen, die mit p62 gefärbt wurden.

Der Antikörper AT8 zum Nachweis von Tauprotein konnte in zwei von neun untersuchten Fällen positiv markierte Strukturen nachweisen, wobei in einem Fall lediglich im Bindegewebe befindliche Strukturen markiert worden sind. In einem Fall finden sich kompakte, bis maximal ein Viertel des Zelldurchmessers große Strukturen in den Fasern angefärbt. Die Muskelfasern selbst zeigen keine oder lediglich eine sehr schwache membranständige Reaktion.

Die Färbungen mit dem gegen Prionprotein gerichteten Antikörper 3F4 lassen in den sechs gefärbten Fällen nur in einem Fall positiv markierte rundliche bis oval Strukturen im Bindegewebe erkennen. Die Muskelfasern selbst zeigen keine spezifische Färbung. Mit den Antikörpern gegen $\alpha$-actinin und Filamin wurden zwei Fälle exemplarisch gefärbt, die keine pathologischen Ablagerungen erkennen ließen. Filamin färbt insbesondere Blutgefäße und muskelfasernahes Bindegewebe. Mit $\alpha$-actinin färben sich Sarkolemm und sarkoplasmatisches Retikulum an.

Mit einem Antikörper gegen Myotilin wurden vier Fälle untersucht. Die Muskelfasern zeigen eine sarkolemmal betonte und darüber hinaus schwache sarkoplasmatische Färbung. Ablagerungen oder Verdichtungen sind nicht nachzuweisen.

Der Marker Triadin, der ein Protein im Bereich der Triaden nachweisen soll, färbt die Muskelfasern der drei untersuchten Fälle sarkolemmal und im Bereich des sarkoplasmatischen Retikulums an. Auffällig ist ein relativ grobes, teils fokal verdichtet wirkendes Muster. 
Mit dem Marker Utrophin wurden zehn Fälle gefärbt, von denen zwei Fälle nicht auswertbar waren. Die übrigen Fälle lassen eine regelrechte Markierung der kapillären Blutgefäße erkennen. Positiv markierte Muskelfasern werden demgegenüber nicht markiert.

Mit dem Neurofilamentmarker SMI32 wurden zehn Fälle untersucht, von denen acht verwertbar waren. In keinem der Fälle konnten pathologische verdichtete Strukturen identifiziert werden. Die Muskelfasern selbst zeigten kein spezifisches Signal.

Der Antikörper APP detektiert das Betaamyloidvorläuferprotein. Es wurden sechs Fälle untersucht, von denen vier verwertbar waren. In einem Fall ließen sich kompakte Strukturen in Muskelfasern schwach markieren. Ein spezifisches Färbesignal fand sich in den Färbungen sonst nicht.

Zusammenfassend ergibt sich in den immunhistochemischen Untersuchungen kein Hinweis auf einen okkulten entzündlichen Prozess (MHC-I) und kein Hinweis auf eine Muskeldystrophie (Utrophin). Positiv markierte Ablagerungen für Desmin sind in einzelnen Fällen zu erkennen, aber kein generelles Phänomen. Andere Marker, die mit einer MFM assoziiert sein können, fanden sich in den untersuchten Fällen nicht. Somit ergibt sich kein Hinweis auf eine MFM als Basis der Kamptokormie. Da sich in Einzelfällen ubiquitinylierte Proteine nachweisen lassen (p62) und diese Fälle eine Ablagerung mehrerer unterschiedlicher Proteine aufweisen, ist eher von Ablagerungen im Rahmen des Faserunterganges / -umbaus auszugehen. Die Befunde der Fasertypisierung und der Mitochondriendarstellung mittels enzymatischer Färbungen konnten immunhistochemisch weitgehend nachvollzogen werden.

\subsection{Immunhistochemischer Befund der Kontrollfälle}

Die immunhistochemischen Untersuchungen wurden in Anteilen auch im Bereich der Kontrollfälle durchgeführt. Hierbei zeigt sich in den acht untersuchten Fällen, dass fünf Fälle ein ausgeglichenes, ein Fall ein etwas schwankendes Verhältnis und zwei Fälle ein leichtes Überwiegen des Fasertyps II zeigen. Zur Überprüfung des regulären Bildes wurden drei Kontrollfälle mit Antikörpern gegen Desmin gefärbt, in denen sich ein regelhaft verteiltes Signal auf der Zellmembran und dem sarkoplasmatischen Retikulum zeigt. Prohibitin stellt in sieben der acht untersuchten Fällen vereinzelte ,ragged red“-Fasern dar. Die Darstellung des MHC-I Komplexes zeigt in den acht untersuchten Fällen eine regelrechte Expression auf den Kapillaren. Ein Fall lässt eine Aufregulation auf Muskelfasern erkennen. Dieser Fall zeigt auch in der HE-Färbung einzelne lymphozytäre Infiltrate, was dieses Ergebnis validiert. Das neuronale Zelladhäsionsmolekül CD56 stellt in fünf der acht untersuchten Fälle eine Expression auf Muskelfasern dar. Auf eine ausführliche Untersuchung weiterer Marker wurde 
verzichtet, da diese eine absolute Aussagekraft besitzen und sich in den untersuchten Kamptokormiefällen keine Pathologie zeigte, sodass ein Vergleich von Kontrollgruppe und Kamptokormiekollektiv irrelevant erscheint.

\subsection{Befunde der Semidünnschnittpräparate}

\subsubsection{Befunde der Kamptokormiefälle}

Material für die Aufarbeitung als Kunstharzpräparat stand nur in zwölf Fällen zur Verfügung, da es von den Einsendern nicht immer mit zur Verfügung gestellt wurde und eine Präparation aus zuvor eingefrorenem Gewebe wenig sinnvoll ist. Zwei der Fälle waren trotz weitreichender Aufarbeitung mehrerer Kunstharzblöcke nur mit sehr großen Einschränkungen $\mathrm{zu}$ bearbeiten, da zu beurteilende Muskelfasern in einem Fall fast vollständig und im anderen Fall komplett fehlten. Da ein Fall nur Fett- und Bindegewebe zeigt, werden die nachfolgend gemachten Angaben auf elf Fälle bezogen. Die Beurteilung zielt auf die Identifizierung von Veränderungen der Struktur, insbesondere im Hinblick auf die lichtmikroskopisch gefundenen Veränderungen, ab.

Alle elf zu bewertenden Fälle zeigen Zellkerne mit erkennbarer Kernmembran, teils locker, teils kondensiert erscheinendem Chromatin und vielfach abgrenzbarem Nucleolus. Die Kerne erscheinen somit regelrecht. Die Mehrzahl der Fälle zeigt eine Internalisierung von Zellkernen. In der Untersuchung der sarkoplasmatischen Struktur sind sieben Fälle besonders gut zu beurteilen. In allen diesen Fällen finden sich Aufhebungen der normalen Querstreifung der Muskulatur. Vereinzelt besteht diese Aufhebung nur in einer sehr begrenzten Verbreiterung der Z-Bande mit häufig folgender Rasterverschiebung der Querstreifung. Teilweise sind die Läsionen aber so groß, dass sie den halben Durchmesser einer Faser betreffen. Dabei erscheint der Rand zur normalen Querstreifung relativ scharf definiert. Der Grund der Läsion erscheint hell, der Dichte nach Plasmabestandteilen oder der I-Bande in etwa entsprechend. Innerhalb der Läsionen sind in unterschiedlicher Dichte kompakte, scharf begrenzte dunkle Strukturen erkennbar. Diese sind rundlich-ovaloid, teils auch länglich gewellt und erinnern an „Rods“ oder zytoplasmatische Körperchen. Alle elf verwertbaren Fälle zeigen diese Ablagerungen mit relativ kleiner Größe. Einzelne Fälle weisen zusätzlich wesentlich größere, grobe dieser kompakten Strukturen auf. Als zusätzlicher Information ist hier gut zu erkennen, dass es in einigen Fasern offensichtlich mehrere Läsionen innerhalb einer Faser gibt. Einige Fälle weisen je Faser nur eine, ein Fall zwei und mehrere Fälle drei und mehr Läsionen in einzelnen Fasern auf. Etliche Fällen lassen neben zentral gelegenen Läsionen auch solche mit subsarkolemmaler Ausdehnung erkennen. Vier Fälle lassen klar 
vakuoläre Strukturen erkennen, deren Inhalt rundlichen dunklen Strukturen entspricht, die an „Myelinwhorls“ erinnern. Diese Veränderungen passen zu lysosomalen Strukturen. Der endomysiale Fettgehalt stellt sich in allen verwertbaren Fällen als gering und feintropfig verteilt dar. Ein Fall lässt in etlichen Fasern subsarkolemmale Akkumulate erkennen, die beispielsweise Glycogen oder Mitochondrien entsprechen können. Sieben Fälle zeigen Fettzellen im Muskel. Dabei zeigen vier Fälle einzelne Fettzellen im Faszikel, zwei Fälle Gruppen von Fettzellen im Faszikel und ein Fall einen fortgeschrittenen fettigen Umbau. Die gleichen sieben Fälle weisen vermehrt endomysiales Bindegewebe auf. Hierunter findet sich ein Fall mit beginnend einsprossendem Fett, vier Fälle mit deutlicher Einsprossung kräftigen Bindegewebes und zwei Fälle mit starker Ummauerung jeder einzelnen Muskelfaser. Zwei Fälle lassen degenerierende Fasern erkennen, die aufgeblähte und weitgehend zentralisierte Kerne sowie ein Auflösung der Querstreifung zeigen.

\subsubsection{Befunde der Kontrollfälle}

Von sechs der Autopsiefälle lagen Kunstharzblockpräparate vor. In allen Fällen lässt sich die Integrität der anatomischen Strukturen identifizieren, insbesondere ist die regelhafte Querstreifung nachvollziehbar. Die Zellkerne erscheinen in ihrer Struktur unauffällig und sind randlich gelegen. Drei der untersuchten Fälle weisen auch internalisiert gelegene Kerne auf, wobei ein Fall einige, die anderen beiden Fälle sehr selten einzelne interne Kerne zeigen. Fünf Fälle weisen einen kaum erkennbaren Fettgehalt auf. Ein Fall lässt feine Fettvakuolen, einem kräftigeren Fettgehalt entsprechend, erkennen. Eine deutliche Fettvermehrung zeigt keiner der Fälle. In einem Fall finden sich kleine Strukturunterbrechungen mit relativ scharfem Rand. Diese erscheinen rundlich und weisen im Zentrum eine inhomogene Struktur auf. Gegenüber den Kamptokormiefällen ist weder der wenig elektronendichte Grund zu erkennen, noch finden sich die „Rod“-ähnlichen Strukturen. Die in den Kamptokormiefällen beschriebenen Verdichtungen mit „Rod““-ähnlicher Struktur sind in keinem der Kontrollfälle zu finden. Lysosomale Strukturen oder Ablagerungen myelinähnlicher Körperchen sind nicht zu finden. Zwei der Fälle weisen verbreiterte subsarkolemmale Räume auf, in denen Verdichtungen zu erkennen sind. In einem Fall ist eine beginnende Einsprossung von Bindegewebsfasern zwischen die Muskelfasern zu erkennen. Die übrigen Fälle lassen keinerlei Vermehrung von Bindegewebe erkennen. Ein Fall zeigt einzelne Fettzellen in den perifaszikulären Septen, ein Fall auch einzelne Fettzellen im Muskelfaszikel selbst. Auffälligkeiten im Bereich der Kapillaren lassen sich in keinem der Fälle finden. Orientierend beurteilt, erscheint auch ihre Anzahl unauffällig. 


\subsection{Befunde der Elektronenmikroskopie}

\subsubsection{Befunde der Kamptokormiefälle}

Am Elektronenmikroskop konnten elf Kamptokormiefälle ausgewertet werden. Untersucht man die in den enzymatischen Färbungen und in den Semidünnschnittpräparaten erkennbaren Läsionen mit dem Elektronenmikroskop (Transmissionselektronenmikroskop; TEM) erkennt man im Randbereich ein scharfes Abbrechen der typischen Querstreifung. An die Stelle treten ungeordnete filamentäre Strukturen, in die eingebettet kompaktes elektronendichtes Material zu Darstellung kommt. Dieses ist seinerseits wieder scharf abgegrenzt und besitzt eine dichte, eher geordnet erscheinende filamentäre Struktur. Ein parakristalliner Aspekt ist hier nicht festzustellen. Die Form dieser Strukturen variiert, ist aber abgerundet und teils ovaloid. Eine radiäre Anordnung von lockeren Filamenten um diese dichten Strukturen erkennt man nicht. Wir beschreiben diese Strukturen als „Rod““-artig. Der Randbereich der gesamten Läsion lässt keine Verdichtung oder Umorientierung der Banden erkennen. Gut darstellbare Läsionen konnten elektronenmikroskopisch in mehreren Fällen ausgewertet werden. Dabei zeigen alle Läsionen die lockeren ungeordneten Fibrillen als Grund der Läsion und die „Rod“-ähnlichen Verdichtungen. Die Zahl der „Rod“-artigen Strukturen pro Läsion bzw. die Dichte ihrer Lagerung variiert. Darüber hinaus zeigen die Läsionen immer erhaltene Mitochondrien. Die Läsionen von drei der Fälle zeigen membranbegrenzte Strukturen mit nicht kontrastiertem oder vielgestaltigem Inhalt. Diese Strukturen passen zu Lysosomen. Drei der Fälle zeigen ungeordnet liegende Triadenstrukturen, die häufig auch zusammenhanglos in den Läsionen liegen. In fünf der untersuchten Fälle erkennt man im Muskel gut die Struktur der Cristae innerhalb der Mitochondrien. Interessanter Weise zeigt ein Fall parakristalline Einschlüsse in zumindest einem Mitochondrion. In den anderen Fällen scheinen Zahl, Form, Größe und Struktur der Cristae normal. Lysosomen lassen sich ebenfall in fünf der Fälle in den Muskelfasern selbst abgrenzen. Teilweise enthalten sie elektronendichte kugelige Strukturen, die „Myelin like bodies“ entsprechen. Auch Lipofuszin ist zu erkennen. Interessanter Weise sind innerhalb der Strukturalterationen kaum Lysosomen oder lysosomale Ablagerungen zu erkennen. In fünf der Fälle findet sich immer wiederkehrend eine Unterbrechung der normalen Querstreifung durch teil konfluierende Bereiche verbreiterter und verdichteter ZBanden, ein so genanntes „Z-Band-Streaming“ oder Z-Band-Strömen. Drei dieser Fälle zeigen dies sehr häufig, ein Fall noch an etlichen Stellen und ein Fall eher selten. In zwei Fällen waren zentralisiert gelegene Zellkerne erkennbar. Auffälligkeiten an Zellkernen, Chromatin oder Kernmembran wurden nicht erkannt. Auch das Sarkolemm erscheint in allen Fällen regelrecht. 


\subsubsection{Befunde der Kontrollfälle}

Von den zehn hier beschriebenen Kontrollfällen wurden fünf Fälle zur detaillierten elektronenmikroskopischen Auswertung herangezogen. Drei weitere Autopsiefälle zeigten ein vergleichbares Bild in der elektronenmikroskopischen Untersuchung.

In der elektronenmikroskopischen Auswertung erkennt man in allen Fällen ein regelrecht erhaltenes Muster der Banden. In drei von fünf Fällen finden sich fokale Aufhebungen der Querstreifung, ohne dass es zu Verdichtungen oder Unterbrechung der Faserrichtung kommt. Am ehesten entsprechen diese Areale Traktionsartefakten, die durch mechanische Zugwirkung auf den Muskel bei der Entnahme oder Präparation zurückzuführen sein dürften. Die bei den Kamptokormien auffindbaren Störungen des Strukturaufbaus fanden sich in keinem der untersuchten Fälle. Dementsprechend finden sich weder fibrilläre Ablagerungen, noch „Rod“-ähnliche Strukturen. Ein Z-Band-Strömen ist in keinem Fall zu finden. Im Bereich der Membran der Muskelfasern konnte keine Veränderung identifiziert werden. Die Zellkerne liegen in allen Fällen in randlicher Lage. Vier Fälle lassen eine regelrechte, mit Poren besetzte Kernmembran erkennen. In einem Fall erscheint die Kernmembran verdickt und elektronendicht. Die Doppelstruktur ist nicht zu erkennen. Das Kernchromatin ist in allen Fällen unauffällig mit verdichteten und lockeren Anteilen. Die Mitochondrien zeigen in zwei Fällen eine leichte, in einem Fall eine mittlere und in zwei Fällen eine starke Schwellung. Diese führt zur Vergrößerung und Abrundung dieser Organellen. Die Cristaestruktur ist mit zunehmender Schwellung der Mitochondrien stärker aufgehoben und fehlt bei starker Schwellung völlig. Parakristalline Einschlüsse können in keinem Fall identifiziert werden. Die meisten Fälle weisen eine sehr homogene Verteilung der Mitochondrien auf. In einem Fall finden sich etwas mehr Mitochondrien, so dass sie teilweise in kleinen Gruppen zwischen den Fibrillenbündeln liegen. Drei der fünf Kontrollfälle zeigen membranbegrenzte Strukturen mit elektronendichtem Inhalt, Lysosomen entsprechend. In diesen Fällen sind auch deutliche Ablagerungen von Lipopigmenten („Lipofuszin“) zu erkennen. Der Gehalt an erkennbaren Lipidtropfen in den Fasern variiert etwas und es finden sich Fälle mit sehr geringer bis kräftiger Speicherung. Vergrößerte Fetttröpfchen oder eine deutlich vermehrte Anzahl sind in keinem Fall zu erkennen. Die bei einigen Kamptokormiefällen auffindbaren ungeordnet liegenden Triaden sind in keinem der Fälle zu finden. 


\subsection{PET-blot- und Tissue-blot-Analyse des Gewebes}

\subsubsection{Untersuchungen am Paraffinmaterial}

Sieben Kamptokormiefälle wurden untersucht. Hierzu wurden als Primärantikörper jeweils die gegen $\alpha$-Synuklein gerichteten Antikörper LB509, Syn211 und Syn-1/42 eingesetzt. Die Darstellung mit LB509 lässt eine diffuse flächige Färbung der Muskelfasern und des Bindegewebes erkennen. Es ist keine Orientierung an anatomischen Strukturen erkennbar. Ein nachvollziehbares Ablagerungsmuster, wie für $\alpha$-Synuklein aus anderen Regionen des Körpers bekannt, ist nicht erkennbar. Die Färbung wird als Hintergrundreaktion angesehen. Weder der Marker Syn211, noch der Marker Syn-1/42 zeigen irgendein Farbsignal.

Der Versuch wurde mit den Antikörpern LB509 und pSer87 wiederholt, wobei der Schritt der Vorbehandlung mit Guanidiniumisothiocyanat $(\mathrm{GdnSCN})$ in unterschiedlicher Konzentration von $0,5 \mathrm{M}, 1 \mathrm{M}, 2 \mathrm{M}$ und $3 \mathrm{M}$ variiert wurde. Als Vergleich wurde hierbei eine Membran der in Formalin fixierten Autopsiemuskulatur mitgeführt. Es konnte weder in der Kontrolle, noch in den Kamptokormiefällen ein spezifisches Färbesignal identifiziert werden. Im Gegensatz zu den in Glutaraldehyd fixierten Kamptokormiefällen zeigte die in Formalin fixierte Kontrolle kein unspezifisches Signal. Das zuvor beschriebene unspezifische Reaktionsverhalten zeigte sich unabhängig von der Konzentration des eingesetzten GdnSCN und von der Wahl des jeweiligen Antikörpers in den Kamptokormiefällen.

\subsubsection{Untersuchungen am Gefriermaterial mittels „,Tissueblot“-Technik}

Nachdem in den Untersuchungen am Paraffinmaterial kein Nachweis eines spezifischen Signals gelungen war, wurde in Analogie die Untersuchung des Gefriermaterials begonnen. In einem ersten Durchgang wurden zwei exemplarisch ausgewählte Fälle einander gegenüber gestellt. Der Nachweis von $\alpha$-Synuklein erfolgte über die Marker LB509 und pSer87. Zuerst erfolgte die Untersuchung ohne enzymatischen Verdau im Vergleich mit einem enzymatischen Verdau. Hierbei zeigt sich bei Verzicht auf einen Verdau ein kräftiges Färbesignal in beiden Fällen. Es werden rundliche und längliche Strukturen zwischen den Muskelfasern markiert. Diese Signale erinnern an feine Nervenfasern oder Kapillaren, wobei die Anzahl geringer als die zu erwartende Kapillardichte erscheint, aber mehr Strukturen nachweist, als mit Neurofilamentmarkern als Nerven erkannt werden. Teilweise finden sich auch kappenähnliche Signale an einzelnen Muskelfasern. Morphologisch könnten diesen Strukturen neuromuskuläre Junktionen (NMJ) entsprechen. Die Muskelfasern selbst zeigen keinerlei Signale. Eine unspezifische Färbung des Bindegewebes ist ebenfalls nicht zu erkennen. Die beschriebene Signalverteilung entspricht sich in der Untersuchung mit den 
jeweils unterschiedlichen Primärantikörpern. Wird vor der Antikörperinkubation mit Proteinase K (PK, $10 \mu \mathrm{g} / \mathrm{ml}, 120 \mathrm{~min}$.) oder einer Kombination aus Collagenase A (2,5mg/ml, $30 \mathrm{~min}$.) und PK (10 $\mu \mathrm{g} / \mathrm{ml}, 90 \mathrm{~min}$.) verdaut, ist keinerlei Reaktionsprodukt im Gewebe mehr zu detektieren. Das Gewebe als solches ist noch erhalten. Dieser Befund ist ebenfalls mit beiden Antikörpern zu finden. Der alleinige Verdau mit Collagenase A (2,5mg/ml, 30 min.) lässt die zuvor beschriebenen Signale in deutlich abgeschwächter Form erkennen (Untersuchung nur mit LB509). In einem weiteren Durchgang wurde ein Verdau mit Protease $(200 \mu \mathrm{g} / \mathrm{ml}, 45 \mathrm{~min}$.) vorgenommen, der in der Untersuchung mit LB509 kein Signal erbrachte.

Folglich war der Verzicht auf den Verdau der erste Ansatz, mit dem nun unterschiedliche Erkrankungen miteinander verglichen werden sollten. So wurden vier Autopsiemuskeln, fünf Kamptokormiemuskeln und zwei andere Muskelbiopsien miteinander verglichen. Dabei weisen alle untersuchten Fälle die zuvor beschriebene Verteilung des Signals im Bereich von feinsten Nervenästen oder Kapillaren auf. In den Autopsiefällen und einem der Kamptokormiefälle sind vereinzelte Kappen, passend z.B. zu NMJ zu finden. In einer Kontrollbiopsie und einem Kamptokormiefall lassen sich flächig markierte Muskelfasern erkennen. Hierbei entsprechen sich jeweils die Färbemuster der Primärantikörper LB509 und pSer87.

Um zu klären, inwieweit ein Verzicht auf den Verdau ein spezifisches Antikörpersignal behindert wurde zum Vergleich ein Durchgang mit den Antikörpern pSyn64 und LB509 (gegen $\alpha$-Synuklein) dem Antikörper Aktin gegenübergestellt. Die beiden gegen $\alpha$-Synuklein gerichteten Antikörper zeigten das bekannte Färbemuster in den zwei untersuchten Kamptokormiefällen und den beiden Autopsieproben. LB509 erwies sich hierbei als intensiver in seinem Signal. Klar erkennbar war in der LB509-Färbung aber auch eine Markierung von Blutgefäßen unterschiedlichen Kalibers. Ein völlig anderes Signal konnte mit Aktin erzeugt werden. Die Muskelfasern weisen hier ein feines eher helles Signal in homogener Verteilung auf. Somit ist die Färbung als spezifisch dem Primärkorper zuzuordnen anzusehen.

Um jetzt den Einfluss unterschiedlicher Enzyme auf mögliche Aggregate von $\alpha$-Synuklein zu untersuchen wurden je zwei Kamptokormiefälle mit zwei Autopsiefällen verglichen. Die Untersuchung erfolgte mit den Antikörpern LB509 und pSer87. Bei stärker verringerter Konzentration von PK mit $5 \mu \mathrm{g} / \mathrm{ml}$ für $30 \mathrm{~min}$. zeigt sich ein unvermindert starkes Signal in den Kamptokormien wie in den Kontrollen. Eine Steigerung der Konzentration auf $10 \mu \mathrm{g} / \mathrm{ml}$ bei gleicher Inkubationszeit führt in beiden Gruppen zu einem leichten Verlust des Signals. 
Ein Verdau mit im Vergleich zum ersten Durchgang verminderten Konzentration und verkürzter Einwirkzeit brachte für Collagenase A (1,5mg/ml, $30 \mathrm{~min}$.) und Protease $(100 \mu \mathrm{g} / \mathrm{ml}, 30 \mathrm{~min}$.) ein kräftiges Signal wie zuvor beschrieben. Hierbei fallen die Signale bei der Detektion mit pSer87 geringfügig schwächer als mit LB509 aus. Geringfügig schwächer reagiert die eine Kontrolle beim Proteaseverdau, die andere ist nicht verwertbar. Ein klarer Unterschied ist aber nicht zu erkennen. Die Enzyme Thermolysin (1,5mg/ml, $15 \mathrm{~min}$.) und Subtilisin $(250 \mu \mathrm{g} / \mathrm{ml}, 15 \mathrm{~min}$.) zeigen keinen Einfluss auf die Stärke der Signale. Der Verdau mit Trypsin $(500 \mu \mathrm{g} / \mathrm{ml}, 15 \mathrm{~min}$.) führt zu einer deutlichen Reduktion der Signale, wobei Kamptokormien und Kontrollen gleichermaßen betroffen sind. In einem weiteren Durchgang werden noch weitere Verdauprotokolle getestet. Als Antikörper wird LB509 eingesetzt. Zwei Kamptokormien werden mit einer anderen Biopsie und einer Autopsie verglichen. Ohne Vorbehandlung zeigen alle Proben die beschriebenen kräftigen Signale. Die Kombination

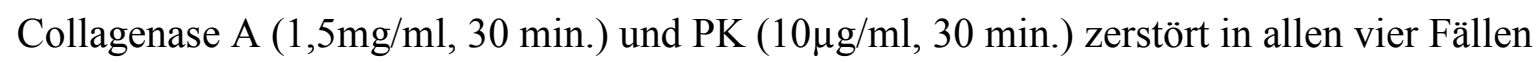
die Signale komplett. Ein verstärkter PK-Verdau ( $20 \mu \mathrm{g} / \mathrm{ml}$, bzw. $30 \mu \mathrm{g} / \mathrm{ml}$, jeweils $30 \mathrm{~min}$.) lässt etwa gleichstark abgeschwächte Signale in allen vier Proben erkennen. Die Kombination von Collagenase A (1,5mg/ml, $30 \mathrm{~min}$.) und Protease (10 $\mu \mathrm{g} / \mathrm{ml}, 30 \mathrm{~min}$.) zerstört alle Signale. Ein Verdau mit Protease bei $150 \mu \mathrm{g} / \mathrm{ml}$ für $30 \mathrm{~min}$. lässt in allen vier Proben ein leicht abgeschwächtes Signal erkennen. Die Steigerung auf $200 \mu \mathrm{g} / \mathrm{ml}$ zeigt keinen wesentlichen Effekt. Erst bei $300 \mu \mathrm{g} / \mathrm{ml}$ erkennt man eine stärkere Reduktion, allerdings auch alle Fälle betreffend. Der Verdau mit Papain zeigt in allen vier Fällen eine unspezifisch variierende Reduktion der Signale. Behandlung mit Pepsin reduziert in allen vier Fällen das Signal, wobei es sich auch morphologisch stark verändert, sodass nur noch feine Punkte übrig bleiben. Um den Einfluß weiterer Primärantikörper auszutesten wurden zwei weitere Antikörper gegen $\alpha$-Synuklein (pSer129 und 4B12) an Kontrollen ausprobiert. Einmal wurden nur mit Isopropanol und einmal mit PFA fixiert. Der gegen pathologisch phosphoryliertes $\alpha$ Synuklein gerichtete Antikörper pSer129 zeigt bei PFA-Fixierung markierte Blutgefäßstrukturen. Nach Fixierung mit Isopropanol ist kein Signal nachzuweisen. 4B12 zeigt in keiner der Fixierungen ein Signal. Einen Eindruck über die Ergebnisse des „Tissue-blot“ vermittelt die Grafik X.

Zusammenfassend bleibt somit festzuhalten, dass mittels „Tissue-blot“ unterVerwendung verschiedener Antikörper ein eindeutiges Signal für $\alpha$-Synuklein gewonnen werden konnte. Eine Verwendung anderer Primärantikörper zeigt andere markierte Strukturen, sodass es sich um ein spezifisches Signal handelt. Dieses Signal zeigt im enzymatischen Verdau mittels unterschiedlicher Proteasen und Collagenase unter keiner der untersuchten Bedingungen 
einen Stabilitätsunterschied der Signale gegenüber der Kontrolle. Es sind keine PK-resistenten Ablagerungen zu finden. Folglich wurde nur physiologisches $\alpha$-Synuklein nachgewiesen. Der Nachweis gelingt auf Strukturen, die morphologisch an Nervenfasern oder Kapillaren erinnern.

Grafik X: Illustration der „Tissue-blot“-Analyse

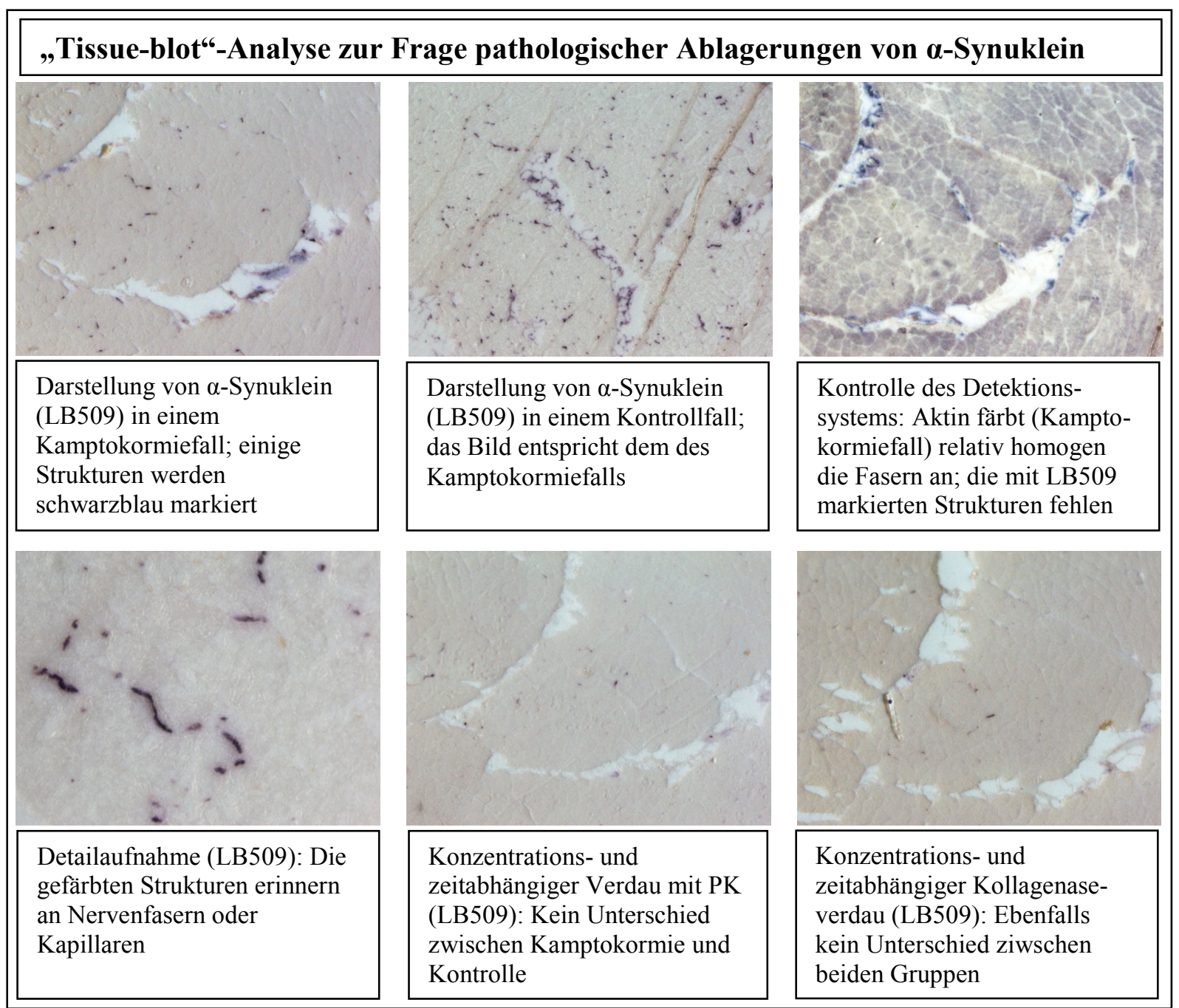

\subsection{Neurodegenerationsstaging mittels PET-blot}

Von dreizehn Autopsiefällen stand Muskelgewebe zur Verfügung. Um eine Beeinträchtigung der Kontrollgruppe durch das Vorliegen einer neurodegenerativen Erkrankung im untersuchten Kollektiv zu vermeiden wurde von den zur Verfügung stehenden Fällen ein Screening mittels PET-blot durchgeführt. Hierbei wurde nach Ablagerungen von $\beta$-Amyloid, Tauprotein und $\alpha$-Synuklein gesucht. Hierzu wurden je Fall drei typische Hirnregionen untersucht: Das Mittelhirn mit der Substantia nigra, der Hippokampus mit dem Ammonshorn und der frontale Cortex. 
Die Darstellung von $\alpha$-Synuklein mit den Markern LB509 und 4B12 konnte in keinem der Fälle ein pathologisches Ablagerungsmuster identifizieren. Es konnten weder kompakte Ablagerungen in Form von Lewy-Körperchen, noch ein synaptisches Ablagerungsmuster gefunden werden. Man findet in der Darstellung mit 4B12 ein leichtes diffuses Hintergrundsignal, was in der Darstellung mit LB509 weitgehend fehlt. Dieses ist keiner anatomischen Struktur zuzuordnen und somit ein unspezifischer Hintergrund.

Anders sehen die Untersuchungen mit dem Marker 6E10 zum Nachweis von $\beta$-Amyloid aus. Es finden sich in sechs Fällen Ablagerungen in Form diffuser und kompakter seniler Plaques im Kortex des Hippokampus und der frontalen Hirnregionen. Aus der Zahl der neuritischen Plaques im Frontalhirn lässt sich in drei Fällen ein Stadium CERAD-Score C ermitteln. Die drei übrigen Fälle weisen einen CERAD-Score B auf.

Die Untersuchung mit Hilfe des gegen Tauprotein gerichteten Antikörpers AT8 wurden intraneuronale „Tangles“ in fünf der Fälle nachgewiesen. In vier dieser Fälle waren die „Tangles“ nicht nur auf den Hippokampus beschränkt, sondern auch in den frontalen Hirngewebsproben nachzuweisen. In der Auswertung der Verteilung und Dichte ergibt sich somit in drei Fällen ein Braak-Stadium III, in einem Fall ein Stadium IV und in einem Fall ein Stadium V. Die Fälle mit den Stadien IV und V entsprechen jeweils zwei der Fälle mit einem CERAD-Score C. Der dritte Fall mit einem CERAD-Score C lässt keine sichere Ablagerung von Tauprotein erkennen. Ein Fall mit einem Braak-Stadium III lässt keine Ablagerung von $\beta$-Amyloid erkennen.

Weiterer Befund der Untersuchung mit dem Antikörper 6E10 ist der Nachweis einer zerebralen Amyloidangiopathie (CAA) in vier der untersuchten Fälle. Nur einer dieser Fälle entspricht einem der hohen CERAD- bzw. Braak-Stadien. Alle betroffenen Fälle weisen hierbei eine Beteiligung der Meningen (Arachnoidea) und der oberen Rindenschichten (Stratum I-III) auf. In zwei Fällen sind alle Rindenschichten (Stratum I-VI) betroffen. Eine Beteiligung der Blutgefäße der weißen Substanz ist in keinem der Fälle zu beobachten. Die Ergebnisse finden sich zusammengefasst in Tabelle IX. 


\section{Diskussion}

\subsection{Eignung postmortaler Gewebeproben als Kontrollgewebe}

Letztendlich ist aus den hier gemachten Untersuchungen bereits klar erkennbar, dass postmortale Gewebeproben sowohl enzymhistochemisch, als auch elektronenmikroskopisch auszuwerten sind. In der Literatur finden sich zahlreiche Beispiele dafür, wobei an dieser Stelle eine Veröffentlichung von H.H.Goebel et al. angeführt werden soll (Goebel et al. 1975). In dieser ist klar zu erkennen, dass eine elektronenmikroskopische Auswertung gut möglich ist, selbst wenn feine lysosomale Strukturen nachgewiesen werden müssen. Insbesondere die fibrillären Strukturen sind gut erhalten. Gewisse Artefakte finden sich im Zusammenhalt der Strukturen und in der Morphologie der Mitochondrien. Dies deckt sich auch mit den hier gemachten Untersuchungen. Wenn enzymatische Untersuchungen nicht mehr funktionieren, werden keine Färbesignale mehr produziert. Das ist bei den hier untersuchten Fällen nicht zu erkennen. In den elektronenmikroskopischen Aufnahmen lassen sich die kontraktilen Elemente, die Zell- und Kernmembranen, wie auch die Organellen gut abgrenzen. Nicht selten lassen die Mitochondrien Zeichen der Schwellung und eine Ruptur der Cristae erkennen, was als erster Hinweis autolytischer Veränderungen angesehen werden kann. Eine Beeinträchtigung der hier gemachten Analysen ist aber nicht zu erkennen.

\subsection{Die Befunde stehen in einer Reihe mit denen einiger anderer Gruppen}

Das hier beschriebene Muster einer Erkrankung aus neuropathologischer Sicht lässt sich unter anderem in der Publikation von Delisle et al. (1993) in Zügen wieder finden. Delisle et al. finden als herausragendes Charakteristikum einen massiven fibrotischen Umbau, der nach ihrer Studie nicht mit der Dauer der Erkrankung korreliert ist. Als weiteres Kriterium finden sie die von uns beschriebenen Strukturveränderungen, die sie als Targetoidveränderungen beschreiben. Allerdings finden sie diese auch in ihrer Kontrollgruppe, bei der es sich um Patienten handelt, die gemäß der klinischen Beschreibung am ehesten eine neurogene Schädigung erwarten ließen. Auch die von uns beschriebenen Schwierigkeiten bei der Fasertypisierung mit Hilfe der ATPasen werden hier thematisiert. Auffällig sei in den beurteilbaren Fällen eine Typ-I-Prädominanz sowie eine Typ-II-Atrophie.

Elektronenmikroskopisch werden alterierte Mitochondrien, jedoch ohne parakristalline Einschlüsse beschrieben. Auch die von uns gefundenen Z-Band-Strömungen und „Rod“Strukturen werden benannt. Ähnlich wie wir sehen die Autoren die Zeichen des Umbaus und 
der Strukturauffälligkeiten als entscheidende Veränderungen, die aber ätiologisch nicht weiter eingeordnet werden. Parallel zu unserer Einschätzung sehen die Autoren in vereinzelten lymphozytären Infiltraten oder mitochondrialen Veränderungen keinen wegweisenden Befund. Sie sind aus unserer Sicht als eine Variation des allgemeinen Spektrums zu sehen, die auch aus der Standarddiagnostik der Muskulatur bekannt sind. Einzelne „ragged red“-Fasern machen keine Mitochondriopathie, schütter nachweisbare Lymphozyten bedeuten keine Entzündung und eine leichte Variation des Kaliberspektrums bedeutet keine Myopathie. In der Studie von Spuler et al. (2009) wird, wie in den hier gemachten Ausführungen, ein myopathisches Bild gefunden. Auch die Studie von Gdynia et al. (2009) zeigt prinzipiell ein myopathisches Schädigungsbild.

\subsection{Andere Gruppen wiederum kommen zu anderer Einschätzung des Bildes}

Die im vorigen Abschnitt genannte Studie von Gdynia et al. (Gdynia et al. 2009) beschreibt eine Untersuchung von 19 Muskelbiopsien bei Kamptokormie im Rahmen eines M. Parkinson, die zu einer Einteilung der Befunde in drei Gruppen kommt: Nekrotisierende Myopathie, entzündliche Myopathie und Myopathie mit mitochondrialen Veränderungen werden unterschieden. Bezogen auf unsere Daten bleibt festzuhalten, dass keiner der Fälle klar abgrenzbare entzündliche Infiltrate zeigt und auch die immunhistochemische Expression des MHC-I-Komplexes auf den Muskelfasern keinen Hinweis auf einen entzündlichen Prozess liefert. Auch wir finden Muskelfasern mit Zeichen einer mitochondrialen Akkumulation und Hinweisen auf eine gestörte Funktion der Mitochondrien (COX-defiziente Fasern). Allerdings erscheinen diese Veränderungen gegenüber der Kontrollgruppe nicht vermehrt. Daraus kann man folgern, dass es sich um ein altersentsprechendes Phänomen handelt. Dieses alterskorrelierte Vorkommen von Fasern mit Mitochondrienvermehrung ist weithin bekannt. Gdynia et al. zeigen auch biochemisch Hinweise auf eine mitochondriale Defizienz. Hierbei ist aber zu bedenken, dass es einerseits keine Normwerte für die paraspinale Muskulatur im höheren Alter gibt und andererseits eine vermehrte Anzahl von Fasern mit mitochondrialen Veränderungen in der Regel auch biochemisch Veränderungen in den mitochondrialen Marker zeigen wird. Spuler et al. (2009) ordnen ihre Befunde als MFM ein. Diese Einordnung kann in den eigenen Untersuchungen nicht bestätigt werden.

\subsection{Eine immer wiederkehrende Diskussion: Was ist die Kamptokormie?}

Sieht man die bestehende Literatur durch, fällt auf, dass es immer wieder um die Frage der Muskelerschlaffung / -erkrankung der Rückenmuskulatur in Abgrenzung von der 
Hyperkontraktion der Antagonisten geht (Jankovic 2010). Hierbei fällt zum einen auf, dass teilweise die Begriffe falsch verwandt werden oder aneinander vorbei diskutiert zu werden scheint. Ein myopathischer Befund der Rückenmuskulatur muss nicht zwangsläufig bedeuten, dass ein anderer Muskel unbeteiligt ist. Wichtig ist sicherlich in erster Linie, dass zum einen die verminderte Funktion der Mm. erectores spinae, zum anderen ein vermehrter Tonus der Antagonisten (M. psoas, M. rectus abdominis) prinzipiell als Erklärung für die Erkrankung in Frage kommen. Ersterer Befund würde sich durch einen Schaden im Rückenmuskel (Myopathie, Myositis, neurogener Schaden) erklären lassen. Letzterer würde zu einer Dystonie ggf. mit axialer Ausprägung passen. Die muskulären Befunde sowohl in der klinischen Untersuchung (EMG, MRT); (Holler et al. 2003; Margraf et al. 2010), wie auch in der pathologischen Untersuchung (Gdynia et al. 2009; Margraf et al. 2010; Spuler et al. 2009) lassen an einer Veränderung der Rückenmuskeln keinen Zweifel. Damit stellt sich aus meiner Sicht in erster Linie die Frage, welche Rolle am ganzen Geschehen die Antagonisten noch haben können. Jankovic (Jankovic 2010) argumentiert hierzu, dass einige Autoren einen Effekt der Injektion mit Botulinumtoxin in die Abdominalmuskulatur finden können. Außer Acht gelassen wird dabei aber, dass die Kamptokormie in liegender Position sofort wieder verschwindet. Nun könnte man von einer rein lagebedingten Dystonie ausgehen. Aber auch im Stehen bei deutlicher Kamptokormie ist diese passiv relativ leicht zu überwinden (Patienten heben den Kopf mit Hilfe einer Hand unter dem Kinn oder richten sich an einer Wand auf). Die beschriebene Wirksamkeit „,sensorischer Tricks“ (Gerton et al. 2010) allerdings würde zu einer Dystonie passen. Hierbei wäre aber noch die Frage zu klären, welcher Muskel dann dyston ist. In Frage kämen unter anderem Der M. psoas und die Bauchmuskelgruppe.

In den Fällen, in denen eine Entzündung im Bereich der Rückenmuskulatur gefunden werden konnte (Bahnof 1999; Charpentier et al. 2005; Delcey et al. 2002; Dominick et al. 2006; Hachulla 2001), finden sich immer wieder Beschreibungen der deutlichen Besserung der Symptomatik bei antiinflammatorischer Therapie. Wenngleich es sich bei diesen Fällen mit einer entzündlichen Genese in der Regel nicht um Parkinsonpatienten handelt, so zeigt sich zumindest der Hinweis, dass der lokale entzündliche Prozess im Rücken dieses Krankheitsbild hervorbringen kann und somit eine isolierte Schädigung im Rücken als Auslöser für eine Kamptokormie ausreichend ist. 


\subsection{Kamptokormie findet sich als Spätsymptom des M. Parkinson}

Ruth Djaldetti et al. (Djaldetti et al.1999) beschrieben als eine der ersten Gruppen explizit die Assoziation zwischen Kamptokormie und M. Parkinson. Kamptokormie als Symptom findet sich schon in den Originalbeschreibungen von James Parkinson. Bereits Parkinson beschreibt eine Symptomatik, die später von Djaldetti et al. (Djaldetti et al. 2004) als „,bent knee“Syndrom und als „Tiptoeing“ bezeichnet werden. Auffällig ist insbesondere zwischen „,bent spine“- und „bent knee“-Syndrom die bestehende Ähnlichkeit im Erscheinungsbild. Die betroffenen Muskelgruppen erscheinen versteift und es kommt zu einer abnormen Anwinkelung im Bereich der Gelenke. Bei passiver Bewegung kann aber die normale gestreckte Position ohne Probleme erreicht werden. Bei diesen Symptomen handelt es sich offensichtlich um Symptome der Spätphase der Erkrankung, die beim „bent knee“-Syndrom oft mit einer dementiellen Entwicklung einhergehen. Zu diskutieren ist in diesem Zusammenhang, ob möglicherweise beiden bzw. allen drei Phänomenen der gleiche Pathomechanismus zugrunde liegt. Interessant wären in diesem Zusammenhang natürlich die Analyse der betroffenen Beinmuskulatur und der Vergleich der Befunde mit den hier gemachten Befunden. Sollte sich ein entsprechendes Bild wieder finden, würde dies die gemeinsame Genese wahrscheinlich erscheinen lassen.

\subsection{Entspricht das Bild einer „Exercise myopathy"?}

Fridén et al. (1983) haben in den 1980er Jahren untersucht, ob es ein morphologisches Korrelat für den Muskelkater nach schwerer Belastung gibt. In ihren an Freiwilligen beschriebenen Befunden zeigen sie in einem deutlichen Teil der Muskelfasern Z-BandStrömen und teilweise auch Unterbrechungen des Fibrillenmusters. Lichtmikroskopisch sind die Befunde nur am Semidünnschnitt zu finden, wobei nur wenige Färbungen durchgeführt worden sind. Das dort dargestellte Z-Band-Strömen differiert in seiner Form nach von dem in den Kamptokormiefällen von uns gefundenen Strömen. Auch die Läsionen erscheinen weniger ungeordnet als in den von uns untersuchten Fällen. Die von uns beschriebenen „Rod“-ähnlichen Strukturen werden nicht gefunden. Bei diesem Vergleich ist natürlich zu beachten, dass der schädigende Mechanismus nur über kurze Zeit (30 min.) eingewirkt hat. In den Kamptokormiefällen wäre von einer wesentlich längeren Kontraktion auszugehen. Interessant ist in den Untersuchungen von Fridén et al. (Friden et al. 1983; Friden und Lieber 2001), dass insbesondere Typ-II-Fasern betroffen sind. Wir finden in unseren Untersuchungen in mehreren Fällen eine Hypotrophie und einen deutlichen Verlust von Typ-II-Fasern. 


\subsection{Helfen die Therapieansätze bei der Einordnung des Krankheitsbildes?}

Therapieansätze sind prinzipiell je nach Erfolg oder Misserfolg ein wichtiger mechanistischer Ansatzpunkt für ätiologische Überlegungen. Der gewisse Erfolg von Orthesen beruht selbstverständlich auf der rein mechanischen Fixierung einer aufrechten Position. Bei durch psychische Probleme verursachter Kamptokormie ist erklärlich, dass psychotherapeutische Ansätze helfen können. In diesem Zusammenhang ist auch eine simple erfolgreiche Therapie durch Tragen eines Rucksacks interessant, bei der die Autoren einen guten Dauereffekt beschreiben (Gerton et al. 2010). Sie diskutieren als Funktion ein rein mechanisches Gegengewicht und / oder eine taktile Stimulation. Letzterer Aspekt wäre natürlich interessant, da sich hieraus die Frage ergibt, ob eine rein sensible Stimulation eine Kamptokormie positiv beeinflussen kann. Es gibt einzelne Beschreibungen eines positiven Einflusses taktiler Reize auf die Symptomatik (Holler et al. 2003). Daraus ließe sich ableiten, dass eine Form der sensorischen Neuropathie für das Geschehen verantwortlich sein könnte. Bei einem Erfolg einer reinen Stimulustherapie ist nach Definition immer auch an eine Dystonie zu denken. Erfolge und Misserfolge werden bei der tiefen Hirnstimulation berichtet. Dies könnte an der Lokalisation der Elektroden liegen. Da zumindest ein Teil der Patienten profitiert, ist von einer echten Korrelation des M. Parkinson mit der Kamptokormie auszugehen.

\subsection{Welche Rückschlüsse erlauben die neuropathologischen Befunde?}

Aus den hier vorgestellten neuropathologischen Untersuchungen lassen sich einige Schlüsse ziehen. In erster Linie bleibt festzuhalten, dass sich ein einheitliches Schädigungsbild darstellen lässt, welches als myopathisch zu beschreiben ist. Hierbei ist die erhöhte Kalibervariation durch die Atrophie von Muskelfasern auf der einen Seite und die kompensatorische Hypertrophie durch Fibrillenvermehrung auf der anderen Seite zu erklären. Diese Hypertrophie durch Vermehrung kontraktiler Elemente führt zu Umstrukturierungsprozessen innerhalb der Muskelfaser, im Zuge derer immer wieder Kerne nach zentral verlagert werden. Die Fibrose und der Ersatz von Muskelfasern durch Fettzellen sind letztlich Zeichen der Defektheilung mit inadäquatem Umbau des Muskels.

\subsubsection{Vermehrte Aktivität der sauren Phosphatase}

Die Literatur behandelt den Befund der sauren Phosphatasereaktion nur selten und dann fast ausschließlich in Zusammenhang mit Glycogenosen bzw. vakuolären Myopathien. Dabei ist das Signal deutlich vermehrt und außerhalb von der ,physiologischen“ perinukleären Lagerung (Schröder et al.1982) zu finden. Es stellen sich zahlreiche unterschiedlich große 
rund bis ovale Strukturen dar, die als Äquivalent von Lysosomen angesehen werden. Dieser Befund entspricht morphologisch in keiner Weise dem hier gefundenen fein verteilten Ablagerungsmuster innerhalb von Muskelfasern. J.M. Schröder beschreibt in seinem diagnostischen Standardwerk (Schröder et al. 1982), dass sich in gesunden Muskelfasern eine Beschränkung der Aktivität der sauren Phosphatase auf die perinukleären Zonen, das endomysiale Bindegewebe (Septen) und die Muskelspindeln findet. Bei erkrankten Muskelfasern findet sich ein ,reicher“ Gehalt an saurer Phosphatase, der sich am stärksten auf degenerierende und basophile Fasern bezieht. Basophile Fasern werden als regenerierende Fasern interpretiert, die vermehrt saure Phosphatase aufweisen, was als Vermehrung von Lysosomen gewertet wird. Diese lysosomale Vermehrung wird als Zeichen des Wachstums und der Differenzierung gewertet, wobei die Lysosomen den Austausch zwischen Kern und Zytoplasma erleichtern bzw. ermöglichen und als wichtiger Partner in der Proteinbiosynthese teilnehmen (Neerunjun und Dubowitz 1977). Allgemein führt Schröder an, dass eine vermehrte Reaktion des Enzyms im Rahmen der „fokalen Degradation“ (Schroder und Adams 1968) zu finden sei. Eine offensichtlich ähnliche Verteilung der Reaktivität beschreibt H.H. Goebel (Goebel et al. 1975) im Rahmen der Muskelbiopsien bei neuronaler Zeroidlipofuszinose (NCL). Hier finden sich als Hintergrund zahlreiche Lysosomen mit pathologischen Einschlüssen, nicht aber die von uns beschriebenen Strukturveränderungen. Zusammenfassend gibt es somit keine morphologische Beschreibung der hier gefundenen Veränderung in der Literatur.

\subsubsection{Strukturläsionen - nicht spezifisch, aber recht charakteristisch}

In den Fällen der Kamptokormie finden sich charakteristische Aufhebungen der normalen Binnenstruktur der Muskelfasern. Diese liegen häufig zentral, teils aber auch am Rand der Muskelfasern. Pro Fasern können eine oder mehrere Läsionen vorliegen. Die Form ist rund bis oval und überwiegend homogen geformt. Somit entsprechen sie nicht den klassischen Mottenfraßveränderungen. Eher ähneln sie den Targetoidläsionen, wobei diese eher zentral liegen. Gegen eine echte Targetläsion spricht das Fehlen der zentralen Verdichtungen mit Zielscheibenaspekt. Der Rand der jeweiligen Läsionen ist relativ scharf begrenzt, nicht jedoch verdichtet, wie dies bei klassischen Core-Läsionen beschrieben wird. Am besten lassen sich die Veränderungen in den oxidativen Enzymen, insbesondere in der SDH und COX Reaktion, nachvollziehen. Auch in der NADH-Reaktion ist in der Regel eine solche Läsion nachvollziehbar. In den ATPasen lassen sich die Läsionen ebenfalls erkennen. 


\subsubsection{Prädominanz des Fasertyps I durch Atrophie des Fasertyps II}

In den untersuchten Fällen fällt in der deutlichen Mehrzahl der Fälle eine Prädominanz des Fasertyps I auf, die nicht selten nahezu einer Uniformität entspricht. Physiologisch findet man im Rückenmuskel ein Verhältnis von Typ-I- zu Typ-II-Fasern von zwischen rund 60:40 und 55:45 (Johnson et al. 1973). In unserem Kontrollkollektiv fanden sich ähnliche Werte, sodass auch bei den Rückenmuskeln offensichtlich im Normalfall keine vollständig andere Verteilung der Fasertypen vorliegt. Umso erstaunlicher, dass in den Kamptokormiefällen häufig eine deutliche Prädominanz des Fasertyps I auffällt. Diese besteht offensichtlich nicht primär, sondern entsteht durch eine starke Atrophie der Fasern des Typs II mit nachfolgender zahlenmäßiger Reduktion dieser Fasern. Dieses Phänomen erklärt auch die Schwierigkeiten, die in der Auswertung der Fasertypisierung mittels der ATPasen-Reaktionen auftraten. In diesen Reaktionen sind Kapillaren erkennbar, so dass atrophe Fasern teilweise von diesen nicht zu unterscheiden sind. Besteht nun nahezu eine Uniformität, bleibt häufig unklar, ob die Reaktion überhaupt funktioniert hat. Durch immunhistochemische Fasertypisierung mittels SERCA-1 und Reaktion von NADH und MAG konnte letztlich aber der Befund gesichert werden. Ursachen einer erworbenen Prädominanz des Fasertyps I sind verschieden. In Untersuchungen zur Alterung des M. vastus medialis fanden Scelsi et al. (1984) eine zunehmende Atrophie der Fasern des Typs II und nachfolgend eine Reduktion ihrer Anzahl. Da als weitere Veränderungen Targetoidfasern und eine Tendenz zur Fasertypengruppierung beschrieben werden, wobei myopathische Zeichen überwiegend fehlen, ist die bloße Alterung hier als Ursache nicht abzunehmen. Auch Speicherfettvakuolen seien vermehrt, wobei in den untersuchten Kamptokormiefällen gerade das Gegenteil der Fall ist. Die beschriebene vermehrte lysosomale Zeichnung wäre zumindest in der sauren Phosphatasereaktion nachzuvollziehen. Als diagnostisch wichtiges Kriterium dient die Prädominanz des Typs I vor allem bei der „Central-core“- und „Multicore“-Erkrankung. Insgesamt ist die Betrachtung unter dem Begriff einer Typ-I-Prädominanz wenig zielführend, da die Literatur hier wenig zu berichten vermag. Blickt man von der anderen Seite, nämlich der Atrophie mit nachfolgendem Verlust des Fasertyps II auf diesen Befund, finden sich in der Literatur unterschiedliche Ursachen, die zu diesem Befund führen können. Zum einen werden Kollagenosen angeführt. Auch eine Erhöhung des Kortisonspiegels, therapeutisch oder krankheitsbedingt (M. Cushing), wird angeführt. Eine Kortisontherapie der hier untersuchten Fälle wird nicht berichtet. Edström et al. (Edstrom 1970) berichten über eine Typ-II-Atrophie im Rahmen des M. Parkinson sowie bei Pyramidenbahnläsionen. Inaktivität, Immobilisation und Kachexie werden angeführt, sind aber in den hier untersuchten Fällen als solche nicht zu 
beschreiben und fallen damit als Gründe weg. Die in der Literatur berichtete Anorexia nervosa besteht in den untersuchten Fällen ebenso wenig, wie sich Hinweise auf eine Myasthenia gravis finden. Sicherlich wäre ein myasthenes Schädigungsgeschehen im Rahmen neoplastischer Veränderungen (Lambert-Eaton-Syndrom) denkbar und nur bedingt sicher auszuschließen, aber das relativ häufige gemeinsame Auftreten von Kamptokormie und M. Parkinson spricht sicherlich dagegen, dass es sich immer um paraneoplastische Veränderungen handelt. Explizit wird auch ein Karzinoid erwähnt, was sicherlich in der zuvor geschilderten Sichtweise eingeordnet werden kann (Swash 1998). Unter den muskeleigenen Erkrankungen wird die Myopathie mit tubulären Aggregaten beschrieben (Engel et al. 1970). Wichtig ist sicherlich, dass die Atrophie des Fasertyps II im Rahmen einer Hypothyreose beschrieben wird, wobei mit zunehmender Schwere des endokrinen Mangelzustandes auch ein zunehmender Verlust der Typ-II-Fasern einherginge, der wiederum von einem zunehmenden Verlust der Kraft begleitet sei (McKeran et al. 1975; McKeran et al. 1980). Auch der primäre Hyperparathyreoidismus wird als Auslöser beschrieben. Hinweise auf derartige endokrine Störungen werden uns nicht berichtet. Weitere Erkrankungen mit Angabe einer Typ-II-Faseratrophie sind Hämophilie und Tetanie.

\subsubsection{Schwache Zeichnung der Fasern für Glycogen und Fett}

Wenn man die Aussagen der Standardliteratur (Schröder et al. 1982) zugrunde legt, müsste im (vorzeitig) gealterten Muskel vermehrt Fett gespeichert werden. Die untersuchten

Kamptokormiefälle zeigen demgegenüber eine geringe Fettspeicherung, obwohl die Reaktion erkennbar funktioniert hat. Auch in den Semidünnschnitten und in der Elektronenmikroskopie finden sich keine Hinweise auf eine vermehrte Fettspeicherung. Alle Fälle lassen in der PASReaktion eine eher schwache Anfärbung erkennen und zeigen keine pathologischen Ablagerungen. Insgesamt sind diese Befunde sicherlich mit Zurückhaltung zu interpretieren, da sie immer auch eine Veränderung nach Biopsienahme darstellen könnten, aber möglicherweise sind sie auch als Zeichen einer Verminderung der Energiesubstrate zu sehen. Dies wäre damit auch als Zeichen der Erschöpfung oder auch der verminderten Versorgung zu diskutieren. Wichtig ist sicherlich auch, dass bei Störungen der mitochondrialen Funktion häufig vermehrt Speicherfette in den Muskelfasern nachweisbar sind. Damit ergeben sich auch aus der Fettfärbung keine Hinweise auf eine Mitochondriopathie. Auch Störungen des Carnitinstoffwechsels sind somit weitgehend ausgeschlossen. 


\subsection{Kamptokormie - Eine Mitochondriopathie der paraspinalen Muskulatur?}

In der Literatur finden sich immer wieder Fallbeschreibungen, die die Kamptokormie als Mitochondriopathie einordnen. Zugrunde liegt diesen Einschätzungen der Befund eines myopathisch veränderten Muskels mit Vorkommen von „,ragged red“-Fasern.

Myopathologisch werden zur Klärung der Frage des Vorliegens einer Mitochondriopathie mehrere Befunde einer Muskelbiopsie hinzugezogen: Das vermehrt Vorkommen von „ragged red“-Fasern (Trichromfärbung), eine vermehrt Zahl COX-defizienter Fasern (COX oder COX-SDH-Färbung) und pathologische parakristalline Einschlüsse in Mitochondrien in der Elektronenmikroskopie. Indirekt kann auch die vermehrte Speicherung von Neutralfetten in den Muskelfasern (ORO-Färbung) auf einen gestörten Energiemetabolismus hinweisen. „Ragged red“-Fasern sind in der Trichromfärbung fuchsinophil durchzogene Muskelfasern, was als Ausdruck einer vermehrten Ansammlung von Mitochondrien gesehen wird. Diese Akkumulation von Mitochondrien findet sich typischerweise im Rahmen einer Mitochondriopathie, jedoch auch als allgemeines Schädigungszeichen einer Muskelfaser. „Ragged red“-Fasern finden sich, wie auch COX-defiziente Fasern in einer mit dem zunehmenden Alter des Probanden zunehmenden Anzahl im Muskel. Unsere Untersuchungen haben gezeigt, dass sich in der Rückenmuskulatur tendenziell mehr „,ragged red“-Fasern, als im jeweiligen M. deltoideus finden. Vergleicht man nun die Rückenmuskelproben der Kontrollen mit denen der Kamptokormiefälle, erkennt man, dass bei den Kamptokormiefällen sogar weniger „ragged red“-Fasern zu finden sind. Ein vermehrtes Vorkommen von „ragged red“-Fasern gegenüber einer Kontrollgruppe wäre aber erst ein Hinweis in Richtung einer Mitochondriopathie. Beim Vorkommen von COX-defizienten Fasern findet sich beim Vergleich der Patientengruppen ein analoger Befund. Damit ergibt sich auch hieraus kein Hinweis auf eine vermehrte funktionelle Störung der Atmungskette in der Gruppe der Kamptokormiepatienten. Letztlich konnte in der elektronenmikroskopischen Untersuchung nur in einem Fall ein parakristalliner mitochondrialer Einschluss gefunden werden. Parakristalline Einschlüsse in Mitochondrien sind nicht spezifisch, werden aber gehäuft bei Mitochondriopathien gefunden. In Struktur, Größe und Aufbau der Cristae erscheinen die Mitochondrien unauffällig. Zusammenfassend ergibt sich somit weder in den enzymatischen Färbungen, noch in der Elektronenmikroskopie der Hinweis auf eine Mitochondriopathie. Im medizinischen Sprachgebrauch kann diese somit natürlich nicht ausgeschlossen werden, aber aktiv finden sich hierfür keine Hinweise. 


\subsection{Die Frage nach der entzündlichen Genese der Kamptokormie}

Klinisch war der Grund für die Entnahme der Biopsien, dass sich bildgebend im MRT Hinweise auf einen entzündlichen Prozess fanden. Ein entzündlicher Prozess ließe eine mögliche therapeutische Strategie erkennen, die aber nicht ohne Risiken wäre und somit auf einer gesicherten Diagnose fußen sollte. In der Literatur finden sich immer wieder Beschreibungen eines entzündlichen Prozesses als Auslöser der Kamptokormie. In den entnommenen Biopsien sahen wir in keinem der Fälle nennenswerte Vorkommen von Leukozyten. Immunhistochemisch lassen sich in einzelnen Fällen vereinzelt schütter eingestreute Lymphozyten erkennen, die aber als unspezifische reaktive Veränderung zu werten sind. Manchmal lässt der stark vermehrte Bindegewebsgehalt eine vermehrte Zellularität durch entzündliche Infiltrate vermuten, was aber immunhistochemisch ausgeschlossen werden konnte. In der Literatur wird darauf hingewiesen, dass entzündliche Prozesse häufig ein fokales Geschehen sind. Damit könnten sie der Aufarbeitung leicht entgehen. Allerdings wird im Rahmen der entzündlichen Prozesse auf einem Großteil der Muskelfasern der MHC-I-Komplex aufreguliert. Dieses kann immunhistochemisch nachgewiesen werden und dient somit zur Absicherung der Diagnose. In den untersuchten Kamptokormiefällen findet sich in keinem der Fälle eine solche Aufregulation. Die Färbung ist in sich validiert, da der MHC-I-Komplex regelhaft in den Kapillaren nachzuweisen ist und somit immer eine Referenzfärbung vorhanden ist. Auch Einzelfasernekrosen sind nur vereinzelt zu finden. Ebenso wenig sind diffus vermehrt Makrophagen nachweisbar. Dieser morphologische Befund wird in der sauren Phosphatasereaktion bestätigt. Zusammenfassend ließen sich in keinem der untersuchten Fälle Zeichen einer Entzündung feststellen.

\subsection{Minderversorgung mit Blut - Ein möglicher Auslöser?}

In den hier untersuchten Fällen der Kamptokormie findet sich keine sicher abgrenzbare Verminderung der Anzahl der Kapillaren. Allerdings erkennt man immer wieder eine inhomogene Verteilung in der Dichte der Kapillaren. Folglich ergibt sich kein Hinweis darauf, dass ein starker Verlust von Kapillaren zu einer verminderten Blutversorgung des Muskels führt. Allerdings werden in der Literatur unterschiedliche Formen der Minderversorgung mit Blut beschrieben. Bei Unterbrechung der arteriellen Blutversorgung muss in der Regel ein Verschluss größerer Gefäße vorliegen, da ansonsten die gute Kollateralversorgung die Muskulatur ausreichend gut versorgt. Bild eines solchen arteriellen Verschlusses ist eine Nekrose der Muskelfasern, ein Bild, das in den vorliegenden Untersuchungen nicht zu finden ist. Interessanterweise findet man bei einem isolierten 
Verschluss der venösen Versorgung keine Nekrosen, sondern in erster Linie eine zunehmende Fibrosierung der Muskulatur. Diese Mechanismen der Schädigung werden beispielsweise beim angeborenen Torticollis und auch bei der Volkmannschen Kontraktur diskutiert. Nimmt man nun an, dass nicht ein thrombembolischer Verschluss der Venen vorliegt, sondern eine chronische Drosselung, wären hier in erster Linie zwei Wege in dieser Richtung denkbar: Zum einen könnte ein vermehrter Tonus der Rückenmuskeln zu einer chronischen Verschlechterung der venösen Drainage führen, die dann zu Veränderungen führen kann. Zum anderen kann eine Veränderung der Wandstruktur der Kapillaren, beispielsweise durch eine Verdickung der Basalmembran, zu einer zunehmenden Diffusionsstrecke und somit zu einem verminderten Stoffaustausch führen. Auf jeden Fall findet sich in den hier untersuchten Fällen immer wieder durch eine Vermehrung von Bindegewebe zwischen Muskelfaser und Kapillare eine nachvollziehbare Vergrößerung der Diffusionsstrecke.

\subsection{Kamptokormie - Erkrankung oder Symptom?}

Sowohl die in der Einleitung erwähnte Breite der Fallbeschreibungen einer Kamptokormie, wie auch die unterschiedlichen pathologischen Analysen der Biopsien lassen die Frage aufkommen, ob die Kamptokormie als solche ein eigenes Krankheitsbild oder möglicherweise ein sehr spezielles Symptom im Rahmen einer oder mehrerer Gruppen von Erkrankungen ist. Die zum Teil genaue Beschreibung unterschiedlicher Erkrankungen mit Auftreten einer Kamptokormie spricht dafür, dass sie tatsächlich im Rahmen etlicher, teils offensichtlich sogar recht heterogener Erkrankungen auftreten kann. Für diese These und auch eine deutliche Heterogenität der auslösenden Erkrankungen spricht auch, dass deutlich unterschiedliche Therapieansätze Erfolge verbuchen konnten, in anders gelagerten Fällen jedoch versagen. Wenn es sich also um heterogene Auslöser eines klinisch einheitlichen Symptoms handelt, erscheint es umso wichtiger, das morphologische, mit einer Biopsie gesicherte Korrelat möglichst genau zu beschreiben. Diese Beschreibung ist letztlich für die unterschiedlichen Grunderkrankungen separiert anzustreben, da sich aus dem Vergleich der verschiedenen Gruppen wichtige Hinweise ergeben können. In dieser Studie wird ein Kollektiv von Parkinsonpatienten mit einer Kamptokormie untersucht und ein einheitliches Schädigungsmuster in unterschiedlich starker Ausprägung beschrieben. Dabei fällt auf, das sich immer wieder in einzelnen Fällen Veränderungen finden, die den Blick in eine bestimmte Richtung lenken könnten. So finden sich in einzelnen Fällen mehr „,ragged red“-Fasern, als in den anderen Fällen. Der Rückschluss auf eine Mitochondriopathie wäre allerdings sehr kurz gedacht, da die übrigen Fälle dies nicht aufweisen. Das um diese Art von Variabilität (zum 
Beispiel durch individuelle Variation erklärbare Veränderungen) bereinigte Bild kann Hinweise auf einen gemeinsamen Prozess der Schädigung liefern. Insbesondere die recht ungewöhnlichen Strukturläsionen sind hier sicherlich als wichtiger Punkt anzusehen. Über eine solche Gemeinsamkeit könnte, wenn diese auch in den Kamptokormiefällen mit anderer Grunderkrankung gefunden werden kann, möglicherweise ein gemeinsamer Schädigungsmechanismus identifiziert werden. Dies wäre auch bei sehr heterogenen Schädigungsprozessen dankbar. Geht man von einer dysbalancierten Innervation aus, bei der bestimmte Afferenzen (und Efferenzen) mehr als andere geschädigt sind, könnte es zur Fehlsteuerung der Muskeln kommen. Diese könnte sich in einem vermehrten oder auch verminderten Muskeltonus, aber auch in anderen Störungen der Steuerung der Kontraktion äußern. Durch Dauer und Ausmaß der Schädigung wäre das unterschiedlich starke Schädigungsbild erklärbar. Eine solche Fehlsteuerung ist durch eine Schädigung im Bereich der innervierenden Fasern durchaus vorstellbar. Eine solche Schädigung innervierender Fasern kann auf unterschiedlichem Weg passieren, beispielsweise durch Ablagerungen und Transportstörungen im Rahmen neurodegenerativer Erkrankungen, oder aber auch durch entzündliche Prozesse im Bereich der Nervenfasern. Auch Störungen des Metabolismus, beispielsweise durch eine Störung der mitochondrialen Funktion, sind gut vorstellbar. Auch die psychogenen Formen wären hierbei unterzubringen, sei es durch gestörte Willkürinnervation oder durch Vorliegen einer organischen Erkrankung als Ursache der psychischen Störung. So wird in der Erforschung der Depressionen beispielsweise über die Rolle von $\alpha$-Synuklein diskutiert. Die Unterbringung der Gruppe der genetischen Myopathien erscheint schwieriger bei einem solchen Erklärungsansatz. Allerdings ist natürlich nachzuvollziehen, ob es sich um eine Störung eines reinen Strukturproteins handelt, oder ob möglicherweise auch eine Störung der Signalübertragung oder -ausbreitung resultieren könnte. Letztendlich sind diese Überlegungen natürlich daran gebunden, dass den jeweiligen Kamptokormiefällen das gleiche Schädigungsbild zugrunde liegt. Gewisse Hinweise darauf ergeben sich aus der Literatur, wobei bisher die klar morphologische Beschreibung der Fälle in der Regel unterblieben ist.

\subsection{Kamptokormie - (K)ein Fall für $\alpha$-Synuklein?}

In der Untersuchung unserer These, dass $\alpha$-Synuklein eine Rolle bei der Entstehung der Kamptokormie spielen könnte, ist uns im Rahmen dieser Arbeit kein Beweis dieser These gelungen. Innerhalb der Muskelbiopsien wurde von uns auch mit sensitiven Methoden kein Hinweis auf pathologische Ablagerungen von $\alpha$-Synuklein gefunden. Damit finden wir 
zumindest im Bereich der Muskelfasern keinen Hinweis auf eine Rolle des Proteins im Rahmen der Kamptokormie. Einschränkend ist an dieser Stelle aber darauf zu verweisen, dass die NMJ und die Muskelspindeln in den untersuchten Fällen in der Regel in den Biopsien nicht oder nur auf einzelnen Schnittpräparaten zu erkennen waren und folglich nicht bewertet werden konnten. Somit findet sich kein aktiver Hinweis auf eine Rolle von $\alpha$-Synuklein, aber diese Rolle kann durchaus weiter diskutiert werden. So könnten Ablagerungen in afferenten und efferenten Fasern, den neuromuskulären Junktionen oder den Muskelspindeln ebenso eine Rolle spielen, wie synaptische Ablagerungen im Bereich der Spinalganglien oder der zentralnervösen Verschaltungen. Nicht zuletzt muss auch die Imbalance zwischen dopaminergem und cholinergem System mit Betonung des cholinergen Systems immer auch als Faktor in Erwägung gezogen werden. Dieser Faktor wäre als Modulator des Muskeltonus und damit in der Folge der Muskelveränderungen denkbar. Zu dem Aspekt der Ablagerungen an unterschiedlichen Stationen lässt sich ein besonderes Augenmerk auf zukünftige Studien an Autopsiefällen legen. 


\section{Zusammenfassung}

Mit den hier gemachten Untersuchungen lässt sich ein klares Bild der neuropathologisch feststellbaren Veränderungen gewinnen. Somit kann man aus den zuvor beschriebenen Befunden ein Diagnostikschema entwerfen, an dem zukünftige Diagnosen überprüft werden können. Zum einen kann dieses die Basis für die Untersuchung von Kamptokormiefällen im Rahmen anderer Erkrankungen sein, zum anderen muss dieses Schema in der prospektiven Anwendung zeigen, wie solide es ist. Wichtig ist auch die gelungene Abgrenzung gegen viele der in der Literatur diskutierten Aspekte (Inflammation, Mitochondriopathie etc.), die ätiopathologisch diskutiert worden sind. In dieser Studie konnte bisher kein Zusammenhang der gefundenen Veränderungen oder der klinischen Symptomatik mit einer pathologischen Ablagerung von $\alpha$-Synuklein-Aggregaten im Bereich des Muskels gefunden werden. Damit ist aber eine mögliche Bedeutung von $\alpha$-Synuklein bei der Kamptokormie nicht ausgeschlossen, da sie auch in Form von Ablagerungen an Muskelspindeln, Endplatten, Synapsen der afferenten und efferenten Bahnen und im ZNS bestehen könnte. Diese Strukturen standen hier nicht für eine Untersuchung zur Verfügung. 
Grafik XI: Neuropathologische Diagnosekriterien Kamptokormie

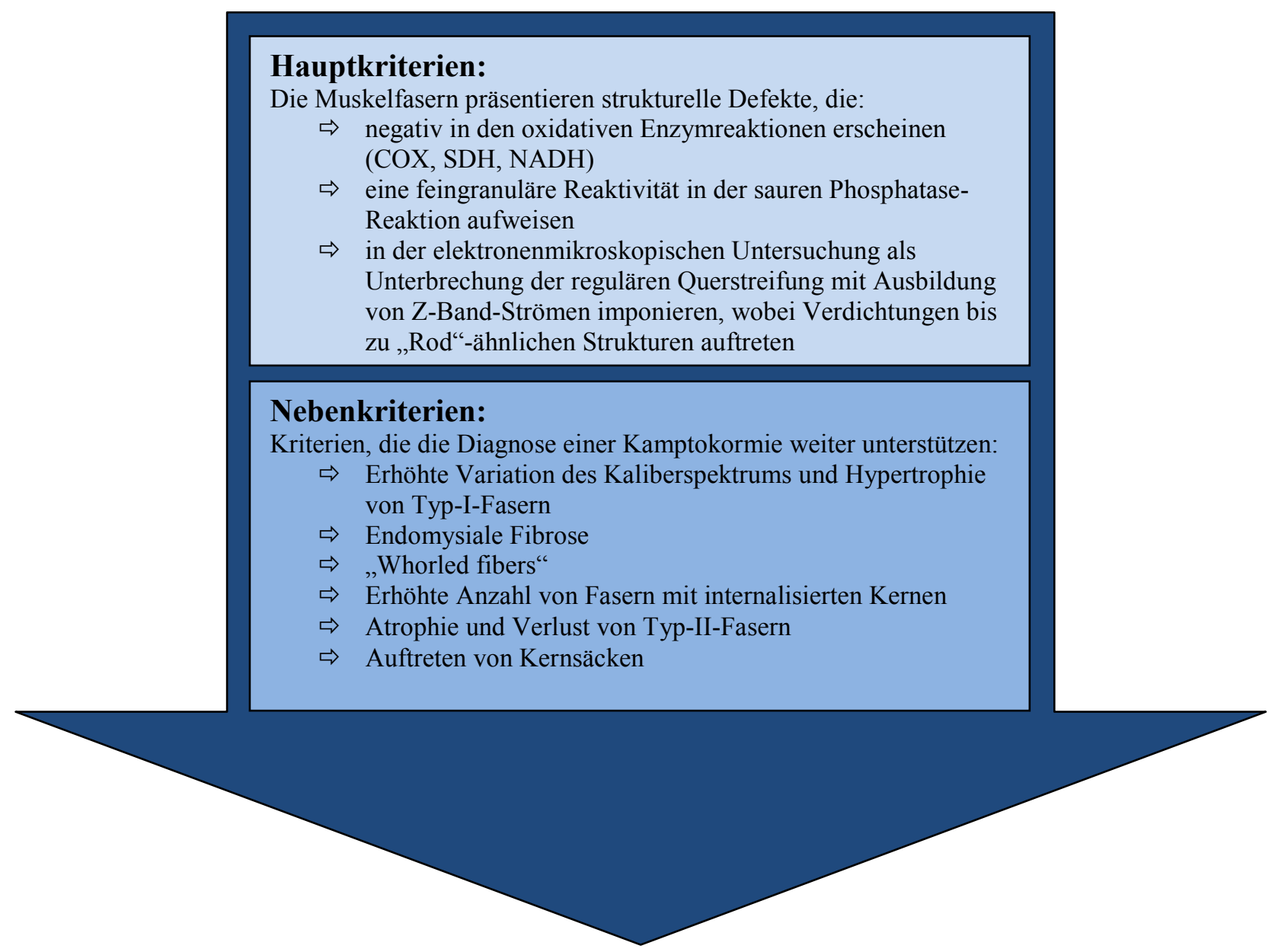

Diagnosevorschlag: Skelettmuskulatur mit myopathischen Veränderungen, vom Bild mit dem Befund einer Kamptokormie vereinbar 
Grafik XII: Illustration der Hauptkriterien

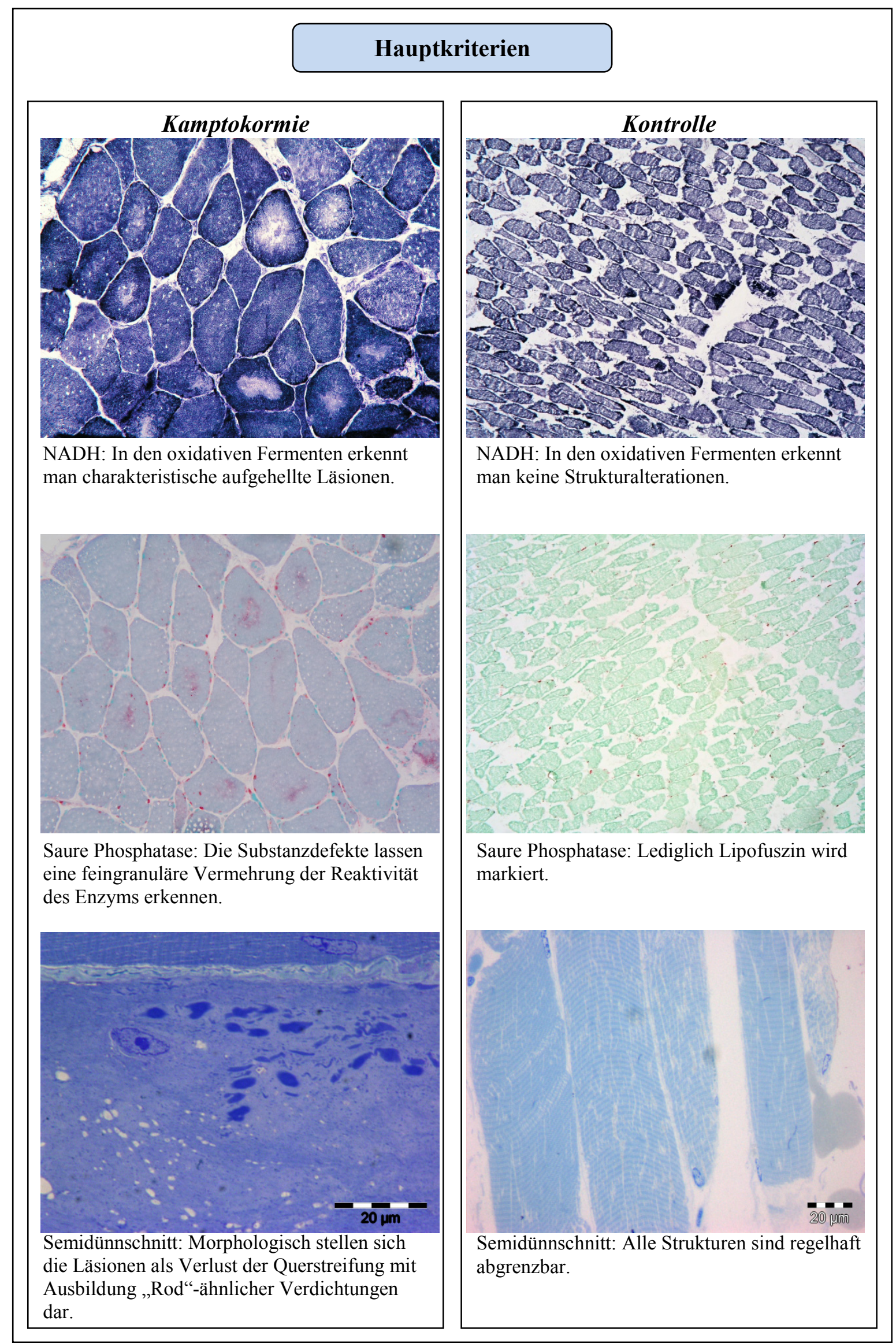


Grafik XIII: Illustration der Nebenkriterien

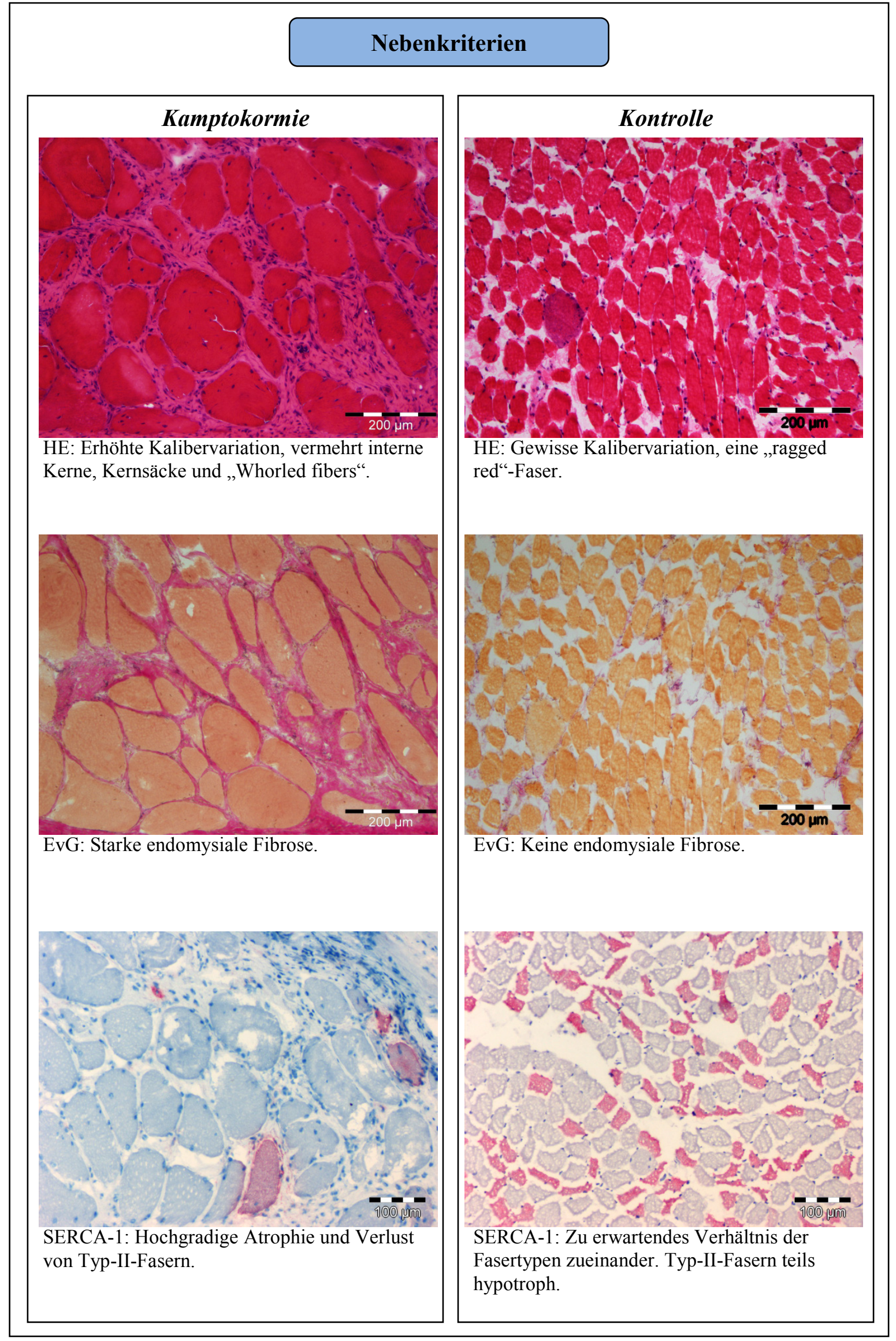


Tabelle X: Übersicht über die Kamptokormiefälle

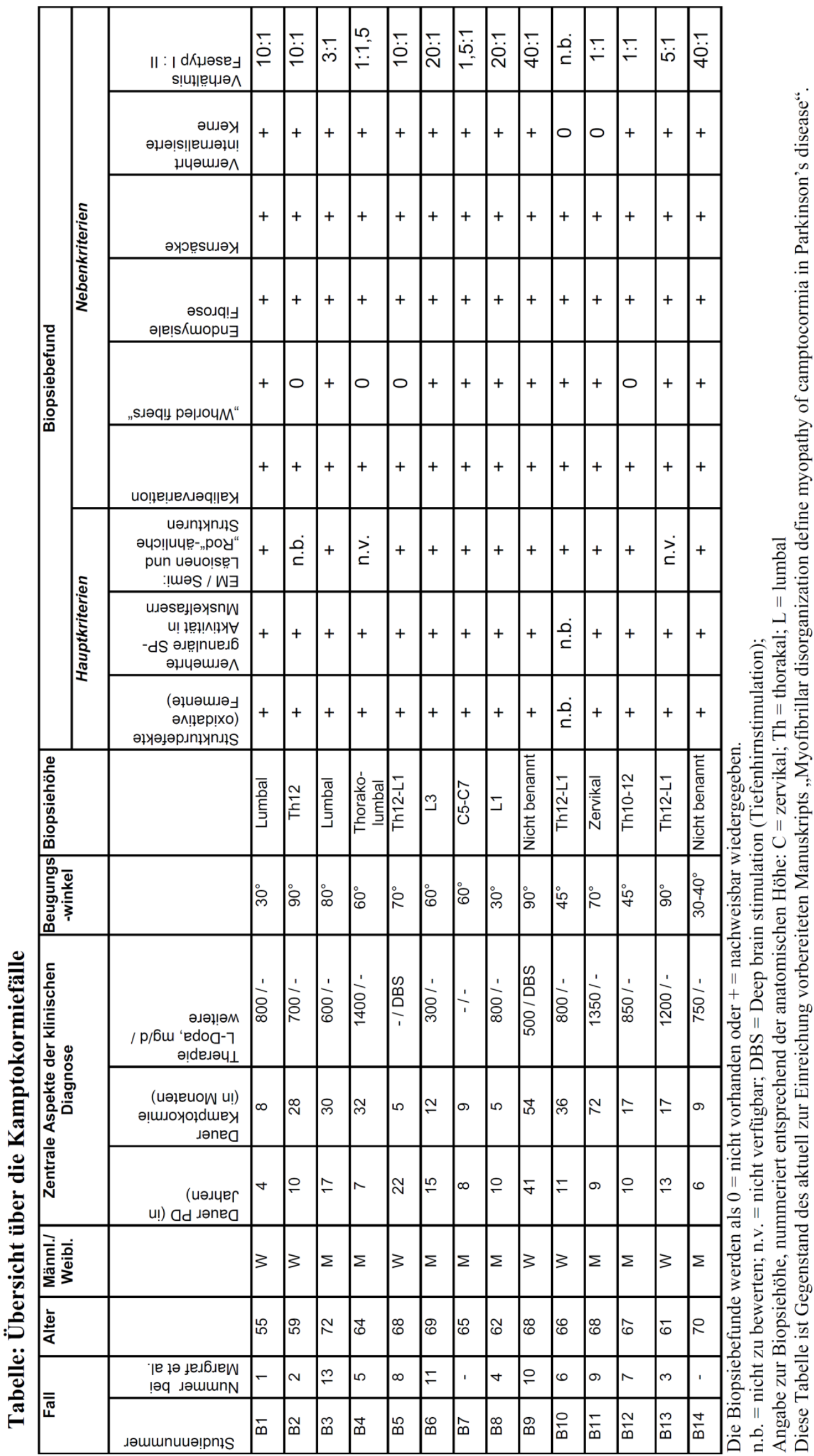


Tabelle XI: Übersicht über die Kontrollfälle

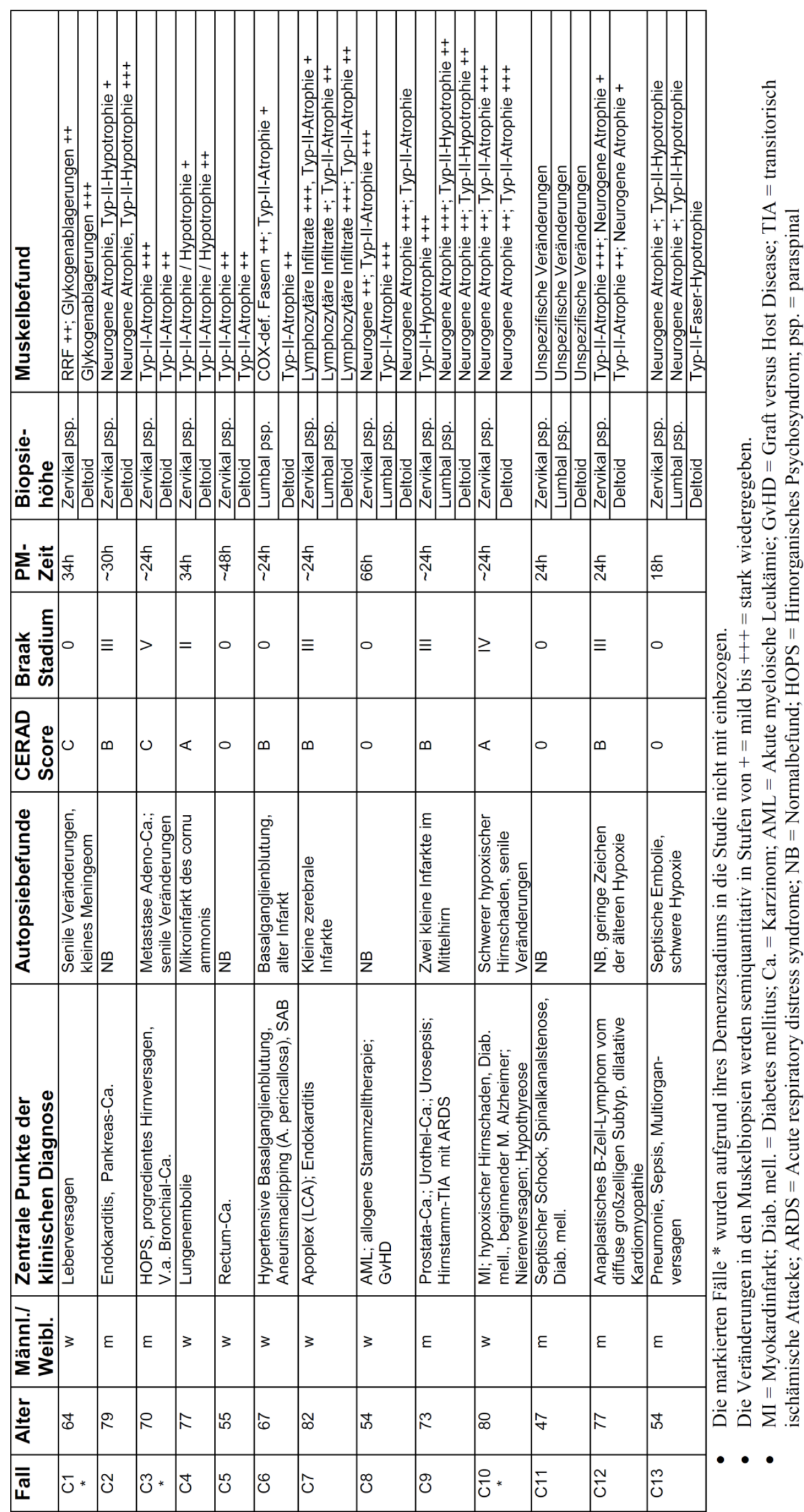




\section{$\underline{\text { Tabellenverzeichnis }}$}

Tabelle I: Literaturangaben mit den Berichten einer Kamptokormie $\quad 16$

Tabelle II: Kamptokormiescore gemäß Margraf et al. (2010) 19

Tabelle III: Therapieansätze gemäß Literatur $\quad 22$

Tabelle IV: Diagnosen der neuropathologischen Befunde 26

$\begin{array}{ll}\text { Tabelle V: Angaben aus den neuropathologischen Befunden } & 27\end{array}$

$\begin{array}{ll}\text { Tabelle VI: Verwendete Substanzen } & 28\end{array}$

Tabelle VII: Verwendete Geräte $\quad 29$

Tabelle VIII: Verwendete Antikörper 38

Tabelle IX: Auswertungsaspekte der Enzymfärbungen 51

Tabelle X: Übersicht der Kamptokormiefälle $\quad 97$

Tabelle XI: Übersicht der Kontrollfälle 98

\section{Abbildungsverzeichnis}

$\begin{array}{ll}\text { Grafik I: Klinische Diagnosekriterien des Parkinsonsyndroms } & 08\end{array}$

Grafik II: Neuropathologische Kriterien 09

Grafik III: Faserdurchmesser $\quad 56$

Grafik IV: Typische Strukturläsionen $\quad 59$

$\begin{array}{ll}\text { Grafik V: Myopathische Veränderungen } & 60\end{array}$

$\begin{array}{ll}\text { Grafik VI: Mitochondriale Veränderungen } & 60\end{array}$

$\begin{array}{ll}\text { Grafik VII: Zeichen muskulärer Regeneration } & 61\end{array}$

Grafik VIII: Vergleich Deltoid und paraspinale Muskulatur in der

$\begin{array}{ll}\text { Kontrollgruppe } & 67\end{array}$

Grafik IX: Vergleich unterschiedlicher Entnahmehöhen bei paraspinaler

$\begin{array}{ll}\text { Muskulatur } & 67\end{array}$

$\begin{array}{ll}\text { Grafik X: Illustration der „Tissue-blot“-Analyse } & 78\end{array}$

Grafik XI: Neuropathologische Diagnosekriterien Kamptokormie 94

Grafik XII: Illustration der Hauptkriterien 95

$\begin{array}{ll}\text { Grafik XIII: Illustration der Nebenkriterien } & 96\end{array}$ 


\section{Literaturverzeichnis}

1. Abdulhadi HM, Kerrigan DC (1996): Camptocormia: a biomechanical analysis. A case report. Am J Phys Med Rehabil 포, 310-313

2. Abe K, Uchida Y, Kawano N (2009): Camptocormia in Parkinson's disease. Mov Disord 24, 397

3. Alafuzoff I, Ince PG, Arzberger T, Al Sarraj S, Bell J, Bodi I, Bogdanovic N, Bugiani O, Ferrer I, Gelpi E et al. (2009): Staging/typing of Lewy body related alpha-synuclein pathology: a study of the BrainNet Europe Consortium. Acta Neuropathol $\underline{117}, 635-652$

4. Amin A, Casey ATH, Etherington G (2004): Is there a role for surgery in the management of dropped head syndrome? Br J Neurosurg $\underline{18}$, 289-293

5. Ashour R, Jankovic J (2006): Joint and skeletal deformities in Parkinson's disease, multiple system atrophy, and progressive supranuclear palsy. Mov Disord 21, 1856-1863

6. Askmark H, Eeg-Olofsson K, Johansson A, Nilsson P, Olsson Y, Aquilonius S (2001): Parkinsonism and neck extensor myopathy: a new syndrome or coincidental findings? Arch Neurol 58, 232-237

7. Azher SN, Jankovic J (2005): Camptocormia: pathogenesis, classification, and response to therapy. Neurology $\underline{65}, 355-359$

8. Bahnof R (1999): The dropped head syndrome: rehabilitation of cervical focal myositis. Disabil Rehabil 21, 563-565

9. Ballenger JC (1976): A case of camptocormia occurring in psychotherapy. J Nerv Ment Dis 162 , 291-294

10. Beekman R, Tijssen CC, Visser LH, Schellens RL (2002): Dropped head as the presenting symptom of primary hyperparathyroidism. J Neurol $\underline{249}, 1738-1739$

11. Bloch F, Houeto JL, Tezenas du MS, Bonneville F, Etchepare F, Welter ML, Rivaud-Pechoux S, Hahn-Barma V, Maisonobe T, Behar C et al. (2006):

Parkinson's disease with camptocormia. J Neurol Neurosurg Psychiatry $\underline{77,}$ 12231228

12. Bonneville F, Bloch F, Kurys E, du Montcel ST, Welter ML, Bonnet AM, Agid Y, Dormont D, Houeto JL (2008): Camptocormia and Parkinson's disease: MR imaging. Eur Radiol 18, 1710-1719

13. Bouzgarou E, Dupeyron A, Castelnovo G, Boudousq V, Collombier L, Labauge P, Pelissier J (2007): Camptocormia disclosing Parkinson's disease. Ann Readapt Med Phys $\underline{50}$, 55-59 
14. Braak H, Alafuzoff I, Arzberger T, Kretzschmar H, Del Tredici K (2006a): Staging of Alzheimer disease-associated neurofibrillary pathology using paraffin sections and immunocytochemistry. Acta Neuropathol 112, 389-404

15. Braak H, Bohl JR, Muller CM, Rub U, De Vos RAI, Del Tredici K (2006b): Stanley Fahn Lecture 2005: The staging procedure for the inclusion body pathology associated with sporadic Parkinson's disease reconsidered. Mov Disord $\underline{21}, 2042-2051$

16. Braak H, de Vos RA, Bohl J, Del Tredici K (2006c): Gastric alpha-synuclein immunoreactive inclusions in Meissner's and Auerbach's plexuses in cases staged for Parkinson's disease-related brain pathology. Neurosci Lett 396, 67-72

17. Brodie BC: Pathological and Surgical Observations on the Disease of the Joints. Longman, London 1818

18. Brodie BC: Lecture illustrative of certain local nervous affections. Longman, London 1837

19. Brucki S, Nitrini R (2008): Camptocormia in Alzheimer's disease: an association? Mov Disord 23, 156-157

20. Buchman VL, Hunter HJ, Pinon LG, Thompson J, Privalova EM, Ninkina NN, Davies AM (1998): Persyn, a member of the synuclein family, has a distinct pattern of expression in the developing nervous system. J Neurosci $\underline{18}$, 9335-9341

21. Capelle HH, Schrader C, Blahak C, Kinfe TM, Fogel W, Baezner H, Krauss JK (2010): Deep brain stimulation for camptocormia in dystonia and Parkinson's disease. Mov Disord 25, 460

22. Charpentier P, Dauphin A, Stojkovic T, Cotten A, Hurtevent JF, Maurage CA, Thevenon A, Destee A, Defebvre L (2005): Parkinson's disease, progressive lumbar kyphosis and focal paraspinal myositis. Rev Neurol (Paris) 161 , 459-463

23. Clayton DF, George JM (1998): The synucleins: a family of proteins involved in synaptic function, plasticity, neurodegeneration and disease. Trends Neurosci 21 , 249-254

24. Colosimo C, Salvatori FM (2009): Injection of the iliopsoas muscle with botulinum toxin in camptocormia. Mov Disord 24, 316-317

25. Coons AH, Kaplan MH, Deane HW (1950): The Histochemical Detection of Antigens. J Natl Cancer Inst $\underline{10}$, 1344-1345

26. Cuervo AM, Wong ESP, Martinez-Vicente M (2010): Protein Degradation, Aggregation, and Misfolding. Mov Disord 25, S49-S54

27. D'Amelio M, Di BN, Ragonese P, Daniele O, Brighina F, Fierro B, Savettieri G (2007): Dropped head as an unusual presenting sign of myasthenia gravis. Neurol Sci 28, 104-106

28. D'Amico A, Haliloglu G, Richard P, Talim B, Maugenre S, Ferreiro A, Guicheney P, Menditto I, Benedetti S, Bertini E et al. (2005): Two patients with 'Dropped 
head syndrome' due to mutations in LMNA or SEPN1 genes. Neuromuscul Disord $\underline{15}, 521-524$

29. Danik M, Champagne D, Petit-Turcotte C, Beffert U, Poirier J (1999): Brain lipoprotein metabolism and its relation to neurodegenerative disease. Crit Rev Neurobiol $\underline{13}, 357-407$

30. Delcey V, Hachulla E, Michon-Pasturel U, Queyrel V, Hatron PY, Boutry N, Lemaitre V, Vanhille P, Serratrice J, Disdier P et al. (2002): Camptocormia: a sign of axial myopathy. Report of 7 cases. Rev Med Interne 23, 144-154

31. Delisle MB, Laroche M, Dupont H, Rochaix P, Rumeau JL (1993):

Morphological analyses of paraspinal muscles: comparison of progressive lumbar kyphosis (camptocormia) and narrowing of lumbar canal by disc protrusions. Neuromuscul Disord $\underline{3}, 579-582$

32. Del Tredici K, Hawkes CH, Ghebremedhin E, Braak H (2010): Lewy pathology in the submandibular gland of individuals with incidental Lewy body disease and sporadic Parkinson's disease. Acta Neuropathol $\underline{119}$, 703-713

33. De Seze MP, Creuze A, de SM, Mazaux JM (2008): An orthosis and physiotherapy programme for camptocormia: a prospective case study. J Rehabil Med. $\underline{40}, 761-765$

34. Diaz-Guzman J, Nunez-Enamorado N, Ruiz-Jimenez J, Garcia E, Diez-Torres I, Ricoy-Campo JR (2006): Parkinsonism and Camptocormia with focal spinal myopathy: case report and responsiveness to treatment. Rev.Neurol. $\underline{43}, 466-469$

35. Diederich NJ, Goebel HH, Dooms G, Bumb A, Huber F, Kompoliti K, Meinck HM (2006): Camptocormia associated with focal myositis in multiple-system atrophy. Mov Disord 21, 390-394

36. Diener HC, Putzki N (Hrsg.): Leitlinien für Diagnostik und Therapie in der Neurologie, 4. Auflage; Georg-Thieme Verlag, Stuttgart 2008

37. Djaldetti R, Melamed E (2006): Camptocormia in Parkinson's disease: new insights. J Neurol Neurosurg Psychiatry $\underline{77}, 1205$

38. Djaldetti R, Mosberg-Galili R, Sroka H, Merims D, Melamed E (1999):

Camptocormia (bent spine) in patients with Parkinson's disease-characterization and possible pathogenesis of an unusual phenomenon. Mov Disord 14, 443-447

39. Djaldetti R, Hellmann M, Melamed E (2004): Bent knees and tiptoeing: late manifestations of end-stage Parkinson's disease. Mov Disord 19, 1325-1328

40. Dominick J, Sheean G, Schleimer J, Wixom C (2006): Response of the dropped head/bent spine syndrome to treatment with intravenous immunoglobulin. Muscle Nerve $\underline{33}, 824-826$

41. Dubowitz V, Sewry CA: Muscle Biopsy - A Practical Approach, 3. Auflage; Saunders, Elsevier, Philadelphia 2007 
42. Duman I, Baklaci K, Tan AK, Kalyon TA (2008): Unusual case of camptocormia triggered by lumbar-disc herniation. Clin Rheumatol 27, 525-527

43. Dupeyron A, Stober N, Gelis A, Castelnovo G, Labauge P, Pelissier J (2010): Painful camptocormia: the relevance of shaking your patient's hand. Eur Spine J $\underline{19}, 87-90$

44. Earle H (1815): Reply to the review of Mr Bayton's essay on the cure of crooked spine. Edinburgh Med Surg J 11, 35-51.

45. Edstrom L (1970): Selective Changes in the Sizes of Red and White Muscle Fibres in Upper Motor Lesions and Parkinsonism. J Neurol Sci 11, 537-550

46. Eliezer D, Kutluay E, Bussell R Jr., Browne G (2001): Conformational properties of alpha-synuclein in its free and lipid-associated states. J Mol Biol $\underline{307,}$, 10611073

47. Engel WK, Bishop DW, Cunningham GG (1970): Tubular aggregates in type II muscle fibers: ultrastructural and histochemical correlation. J Ultrastruct Res $\underline{31}$, 507-525

48. Eriksson O, Eriksson A, Ringqvist M, Thornell LE (1980): The reliability of histochemical fibre typing of human necropsy muscles. Histochemistry $\underline{65}, 193-$ 205

49. Errea JM, Ara JR, Aibar C, Pedro-Cuesta J (1999): Prevalence of Parkinson's disease in Lower Aragon, Spain. Mov Disord 14, 596-604

50. Fahn S, Elton R., Members of UPDRS Development Committee: The unified Parkinson's disease rating scale; in: Recent Development in Parkinson's Disease; Fahn S, Marsden CD, Caine DB, Goldstein M; Band 2; Macmillan Health Care Information, Florham Park, 1987 153-163, 293-304

51. Feriha O, Aytul M, Hasan M (2004): A case of camptocormia (bent spine) secondary to early motor neuron disease. Behav Neurol $\underline{15}, 51-54$

52. Fietzek UM, Schroeteler FE, Ceballos-Baumann AO (2009): Goal attainment after treatment of parkinsonian camptocormia with botulinum toxin. Mov Disord 24, 2027-2028

53. Finsterer J (2004): Dropped head syndrome in mitochondriopathy. Eur Spine J $\underline{13}$, 652-656

54. Finsterer J, Strobl W (2010): Presentation, Etiology, Diagnosis, and Management of Camptocormia. Eur Neurol $\underline{64}, 1-8$

55. Friden J, Lieber RL (2001): Eccentric exercise-induced injuries to contractile and cytoskeletal muscle fibre components. Acta Physiol Scand 171, 321-326

56. Friden J, Sjostrom M, Ekblom B (1983): Myofibrillar damage following intense eccentric exercise in man. Int J Sports Med $\underline{4}, 170-176$ 
57. Fujiwara H, Hasegawa M, Dohmae N, Kawashima A, Masliah E, Goldberg MS, Shen J, Takio K, Iwatsubo T (2002): Alpha-Synuclein is phosphorylated in synucleinopathy lesions. Nat Cell Biol $\underline{4}, 160-164$

58. Fukaya C, Otaka T, Obuchi T, Kano T, Nagaoka T, Kobayashi K, Oshima H, Yamamoto T, Katayama Y (2006): Pallidal high-frequency deep brain stimulation for camptocormia: an experience of three cases. Acta Neurochir Suppl 99, 25-28

59. Gamez J, Sierra-Marcos A, Gratacos M, Jorge L, Raguer N, Moncho-Rodriguez D, Jacas C, Conejero J, Badia M, Lorenzo-Bosquet C et al. (2010): Camptocormia Associated with an Expanded Allele in the TATA Box-Binding Protein Gene. Mov Disord 25, 1293-1295

60. Gdynia HJ, Sperfeld AD, Unrath A, Ludolph AC, Sabolek M, Storch A, Kassubek J (2009): Histopathological analysis of skeletal muscle in patients with Parkinson's disease and "dropped head"/"bent spine" syndrome. Parkinsonism Relat Disord 15, 633-639

61. Gelb DJ, Oliver E, Gilman S (1999): Diagnostic criteria for Parkinson disease. Arch Neurol 56, 33-39

62. Gerton BK, Theeler B, Samii A (2010): Backpack treatment for camptocormia. Mov Disord 30, 247-248

63. Godeiro-Junior C, Felicio AC, Barsottini OG, Aguiar PM, Silva SM, Borges V, Ferraz HB (2008): Clinical features of dystonia in atypical parkinsonism. Arq Neuropsiquiatr $\underline{66}, 800-804$

64. Goebel HH, Zeman W, Pilz H. (1975): Significance of Muscle Biopsies in Neuronal Ceroid-Lipofuscinoses. J Neurol Neurosurg Psychiatry $\underline{38}$, 985-993

65. Goldfarb LG, Gajdusek DC (1992): Viliuisk encephalomyelitis in the Yakut people of Siberia. Brain 115, 961-978

66. Goldfarb LG, Vladimirtsev VA, Platonov FA, Lee H-S, McLean CA, Masters CL (2009): Viliuisk encephalomyelitis in Eastern Siberia-analysis of 390 cases: In memory of D Carleton Gajdusek. Folia Neuropathol 47, 171-181

67. Gomez EA, Drooby AS (1987): Camptocormia in a case of manic-depressive disorder. Psychosomatics $\underline{28}, 592-595$

68. Gomez-Puerta JA, Peris P, Grau JM, Martinez MA, Guanabens N (2007): Camptocormia as a clinical manifestation of mitochondrial myopathy. Clin Rheumatol 26, 1017-1019

69. Hachulla E (2001): Dermatomyositis and polymyositis: clinical aspects and treatment. Ann Med Interne (Paris) 152, 455-464

70. Hansen L, Salmon D, Galasko D, Masliah E, Katzman R, DeTeresa BS, Thal L, Pay MM, Hofstetter R, Klauber M et al. (1990): The Lewy body variant of Alzheimer's disease : A clinical and pathological entity. Neurology $\underline{40}, 1-8$ 
71. Hawe A, Sutter M, Jiskoot W (2008): Extrinsic fluorescent dyes as tools for protein characterization. Pharm Res $\underline{25}$, 1487-1499

72. Hellmann MA, Djaldetti R, Israel Z, Melamed E (2006): Effect of deep brain subthalamic stimulation on camptocormia and postural abnormalities in idiopathic Parkinson's disease. Mov Disord 21, 2008-2010

73. Hilliquin P, Menkes CJ, Laoussadi S, Job-Deslandre C, Serratrice G (1992): Camptocormia in the elderly. A new entity by paravertebral muscle involvement? Rev Rhum Mal Osteoartic 푸, 169-175

74. Ho B, Prakash R, Morgan JC, Sethi KD (2007): A case of levodopa-responsive camptocormia associated with advanced Parkinson's disease. Nat Clin Pract Neurol $\underline{3}, 526-530$

75. Hoehn MM, Yahr MD (1967): Parkinsonism: Onset, progression, and mortality. Neurology $\underline{17}, 427-442$

76. Hoffman D, Gutmann L (1994): The Dropped Head Syndrome with Chronic Inflammatory Demyelinating Polyneuropathy. Muscle Nerve 17, 808-810

77. Hogan KA, Manning EL, Glaser JA (2006): Progressive cervical kyphosis associated with botulinum toxin injection. South Med J $\underline{99}, 888-891$

78. Holler I, Dirnberger G, Pirker W, Auff E, Gerschlager W (2003): Camptocormia in idiopathic Parkinson's disease: [(123)I]beta-CIT SPECT and clinical characteristics. Eur Neurol 50, 118-120

79. Hund E, Heckl R, Goebel HH, Meinck HM (1995): Inclusion-Body Myositis Presenting with Isolated Erector Spinae Paresis. Neurology 45, 993-994

80. Hurst AF (1918): The Bent Back of Soldiers. Br Med J 1918, 2, 621-623

81. Iwai A, Masliah E, Yoshimoto M, Ge N, Flanagan L, de Silva HA, Kittel A, Saitoh T (1995): The precursor protein of non-A beta component of Alzheimer's disease amyloid is a presynaptic protein of the central nervous system. Neuron $\underline{14}$, $467-475$

82. Jakes R, Spillantini MG, Goedert M (1994): Identification of two distinct synucleins from human brain. FEBS Lett $\underline{345}$, 27-32

83. Jankovic J (2010): Camptocormia, Head Drop and Other Bent Spine Syndromes: Heterogeneous Etiology and Pathogenesis of Parkinsonian Deformities. Mov Disord 25, 527-528

84. Ji H, Liu YE, Jia T, Wang M, Liu J, Xiao G, Joseph BK, Rosen C, Shi YE (1997): Identification of a breast cancer-specific gene, BCSG1, by direct differential cDNA sequencing. Cancer Res $\underline{57}, 759-764$

85. Jo E, Darabie AA, Han K, Tandon A, Fraser PE, McLaurin J (2004): alphaSynuclein-synaptosomal membrane interactions: implications for fibrillogenesis. Eur J Biochem 271, 3180-3189 
86. Johnson MA, Polgar J, Weightman D, Appleton D (1973): Data on the distribution of fibre types in thirty-six human muscles. An autopsy study. J Neurol Sci $\underline{18}, 111-129$

87. Kocaaga Z, Bal S, Turan Y, Gurgan A, Esmeli F (2008): Camptocormia and dropped head syndrome as a clinic picture of myotonic myopathy. Joint Bone Spine $\underline{75}, 730-733$

88. Kottlors M, Kress W, Meng G, Glocker FX (2010): Facioscapulohumeral Muscular Dystrophy Presenting with Isolated Axial Myopathy and Bent Spine Syndrome. Muscle Nerve 42, 273-275

89. Kramer ML, Schulz-Schaeffer WJ (2007): Presynaptic alpha-synuclein aggregates, not Lewy bodies, cause neurodegeneration in dementia with Lewy bodies. J Neurosci 27, 1405-1410

90. Lang AE, Lozano AM (1998): Parkinson's disease - First of two parts. N Engl J Med 339, 1044-1053

91. Lepoutre AC, Devos D, Blanchard-Dauphin A, Pardessus V, Maurage CA, Ferriby D, Hurtevent JF, Cotten A, Destee A, Defebvre L (2006): A specific clinical pattern of camptocormia in Parkinson's disease. J Neurol Neurosurg Psychiatry $\underline{77}, 1229-1234$

92. Lewy FH (1913): Zur pathologischen Anatomie der Paralysis agitans. Dtsch Z Nervenheilkd 50, 50-55

93. Lewy FH: Paralysis agitans; in: Handbuch der Neurologie, Spezielle Neurologie II; hrsg. Lewandowsky M; 3; Springer Verlag, Berlin 1912, 920-933

94. Lomen-Hoerth C, Simmons ML, Dearmond SJ, Layzer RB (1999): Adult-onset nemaline myopathy: Another cause of dropped head. Muscle Nerve 22, 11461150

95. Margraf NG, Wrede A, Rohr A, Schulz-Schaeffer WJ, Raethjen J, Eymess A, Volkmann J, Mehdorn MH, Jansen O, Deuschl G (2010): Camptocormia in idiopathic Parkinson's disease: A focal myopathy of the paravertebral muscles. Mov Disord 25, 542-551

96. Maroteaux L, Campanelli JT, Scheller RH (1988): Synuclein: a neuron-specific protein localized to the nucleus and presynaptic nerve terminal. J Neurosci $\underline{8}$, 2804-2815

97. McCann SJ, LeCouteur DG, Green AC, Brayne C, Johnson AG, Chan D, McManus ME, Pond SM (1998): The epidemiology of Parkinson's disease in an Australian population. Neuroepidemiology 17, 310-317

98. McKeith IG (2006): Consensus guidelines for the clinical and pathologic diagnosis of dementia with Lewy bodies (DLB): report of the Consortium on DLB International Workshop. J Alzheimers Dis $\underline{9}$, 417-423

99. McKeran RO, Slavin G, Andrews TM, Ward P, Mair WG (1975): Muscle fibre type changes in hypothyroid myopathy. J Clin Pathol 28, 659-663 
100. McKeran RO, Slavin G, Ward P, Paul E, Mair WG (1980): Hypothyroid myopathy. A clinical and pathologaical study. J Pathol 132, 35-54

101. Miake H, Mizusawa H, Iwatsubo T, Hasegawa M (2002): Biochemical characterization of the core structure of alpha-synuclein filaments. J Biol Chem 277, 19213-19219

102. Nagashima T, Chuma T, Mano Y, Goto Y, Hayashi YK, Minami N, Nishino I, Nonaka I, Takahashi T, Sawa H et al. (2004): Dysferlinopathy associated with „Rigid spine“-Syndrome. Neuropathology 24, 341-346

103. Neerunjun JS, Dubowitz V (1977): Concomitance of Basophilia, RibonucleicAcid and Acid-Phosphatase Activity in Regenerating Muscle-Fibers. J Neurol Sci $\underline{33}, 95-109$

104. Ozer F, Ozturk O, Meral H, Serdaroglu P, Yayla V (2007): Camptocormia in a patient with Parkinson disease and a myopathy with nemaline rods. Am J Phys Med Rehabil 6ㅜ 3-6

105. Parkinson J (2002): An essay on the shaking palsy. Reprint Originalartikel von 1817. J Neuropsychiatry Clin Neurosci 14, 223-236

106. Phillips RJ, Walter GC, Ringer BE, Higgs KM, Powley TL (2009): Alphasynuclein immunopositive aggregates in the myenteric plexus of the aging Fischer 344 rat. Exp Neurol 220, 109-119

107. Reichel G, Kirchhofer U, Stenner A (2001): Camptocormia-segmental dystonia. Proposal of a new definition for an old disease. Nervenarzt $\underline{72}, 281-285$

108. Roy S, Wolman L (1969): Ultrastructural observations in Parkinsonism. J Pathol $\underline{99}, 39-44$

109. Sakas DE, Boviatsis EJ, Stavrinou LC (2010): Backpack treatment for camptocormia. Mov Disord 25, 2254

110. Sako W, Nishio M, Maruo T, Shimazu H, Matsuzaki K, Tamura T, Mure H, Ushio Y, Nagahiro S, Kaji R et al. (2009): Subthalamic nucleus deep brain stimulation for camptocormia associated with Parkinson's disease. Mov Disord $\underline{24}, 1076-1079$

111. Sandmann-Keil D, Braak H (2005): Zur postmortalen Diagnose des idiopathischen Morbus Parkinson. Pathologe 26, 214-220

112. Scelsi R, Lotta S, Lommi G, Poggi P, Marchetti C (1984): Hemiplegic Atrophy: Morphological Findings in the Anterior Tibial Muscle of Patients with Cerebral Vascular Accidents. Acta Neuropathol 62, 324-331

113. Schröder JM: Pathologie der Muskulatur (Doerr W, Uehlinger E, Seifert G: Spezielle Pathologische Anatomie: Band 15), 1. Auflage; Springer Verlag, Berlin 1982

114. Schröder JM, Adams RD (1968): Ultrastructural Morphology of Muscle Fiber in Myotonic Dystrophy. Acta Neuropathol 10, 218-241 
115. Schulz-Schaeffer WJ, Tschoke S, Kranefuss N, Drose W, Hause-Reitner D, Giese A, Groschup MH, Kretzschmar HA (2000): The paraffin-embedded tissue blot detects PrPSC early in the incubation time in prion diseases. Am J Pathol 156, 5156

116. Seror P, Krahn M, Laforet P, Leturcq F, Maisonobe T (2008): Complete fatty degeneration of lumbar erector spinae muscles caused by a primary dysferlinopathy. Muscle Nerve $\underline{37}, 410-414$

117. Serratrice G (2007): Clinical semiology of neuromuscular diseases. Bent spine myopathy or syndrome. Acta Myol 26, 1-4

118. Shinjo SK, Torres SC, Radu AS (2008): Camptocormia: a rare axial myopathy disease. Clinics $\underline{63}, 416-417$

119. Souques A, Rosanoff-Saloff M (1915): La camptocormie. Incurvation du tronc consécutiveaux traumisme du dos et des lombes. Considérations morphologiques. Rev Neurol 30, 937-939

120. Spillantini MG, Divane A, Goedert M (1995): Assignment of human alphasynuclein (SNCA) and beta-synuclein ( $\mathrm{SNCB}$ ) genes to chromosomes $4 \mathrm{q} 21$ and 5q35. Genomics 27, 379-381

121. Spillantini MG, Schmidt ML, Lee VMY, Trojanowski JQ, Jakes R, Goedert M (1997): Alpha-synuclein in Lewy bodies. Nature $\underline{388}, 839-840$

122. Spillantini MG, Crowther RA, Jakes R, Hasegawa M, Goedert M (1998a): Alphasynuclein in filamentous inclusions of Lewy bodies from Parkinson's disease and dementia with Lewy bodies. Proc Natl Acad Sci USA 95, 6469-6473

123. Spillantini MG, Crowther RA, Jakes R, Cairns NJ, Lantos PL, Goedert M (1998b): Filamentous alpha-synuclein inclusions link multiple system atrophy with Parkinson's disease and dementia with Lewy bodies. Neurosci Lett 251, 205208

124. Spuler S, Krug H, Klein C, Medialdea IC, Jakob W, Ebersbach G, Gruber D, Hoffmann KT, Trottenberg T, Kupsch A (2009): Myopathy causing camptocormia in idiopathic Parkinson's disease: A multidisciplinary approach. Mov Disord 25, 552-559

125. Swash M (1998): „Dropped head“ and bent-spine syndromes; axial myopathies? Lancet $\underline{352}, 758$

126. Takeda A, Mallory M, Sundsmo M, Honer W, Hansen L, Masliah E (1998): Abnormal accumulation of NACP/alpha-synuclein in neurodegenerative disorders. Am J Pathol 152, 367-372

127. Takei A, Hamada S, Homma S, Hamada K, Tashiro K, Hamada T (2009): Amelioration of subacute camptocormia in multiple system atrophy by protirelin tartrate. Mov Disord 24, 2022-2023 
128. Terashima M, Kataoka H, Sugie K, Horikawa H, Ueno S (2009): Coexistence of chronic inflammatory demyelinating polyneuropathy and camptocormia. J Neurol Neurosurg Psychiatry $\underline{80}$, 1296-1297

129. Thomzig A, Schulz-Schaeffer W, Wrede A, Wemheuer W, Brenig B, Kratzel C, Lemmer K, Beekes M (2007): Accumulation of pathological prion protein PrPSc in the skin of animals with experimental and natural scrapie. PLoS Pathog $\underline{3}, 659-$ 667

130. Tiple D, Fabbrini G, Colosimo C, Ottaviani D, Camerota F, Defazio G, Berardelli A (2009): Camptocormia in Parkinson disease: an epidemiological and clinical study. J Neurol Neurosurg Psychiatry $\underline{80}$, 145-148

131. Tobe T, Nakajo S, Tanaka A, Mitoya A, Omata K, Nakaya K, Tomita M, Nakamura Y (1992): Cloning and characterization of the cDNA encoding a novel brain-specific 14-kDa protein. J Neurochem $\underline{59}$, 1624-1629

132. Tolosa E, Wenning G, Poewe W (2006): The diagnosis of Parkinson's disease. Lancet Neurology $\underline{5}, 75-86$

133. Tompkins MM, Hill WD (1997): Contribution of somal Lewy bodies to neuronal death. Brain Res $\underline{775}, 24-29$

134. Twelves D, Perkins KSM, Counsell C (2003): Systematic review of incidence studies of Parkinson's disease. Mov Disord $\underline{18}, 19-31$

135. Ueda K, Fukushima H, Masliah E, Xia Y, Iwai A, Yoshimoto M, Otero DA, Kondo J, Ihara Y, Saitoh T (1993): Molecular cloning of cDNA encoding an unrecognized component of amyloid in Alzheimer disease. Proc Natl Acad Sci USA $\underline{90}, 11282-11286$

136. Ueda K, Saitoh T, Mori H (1994): Tissue-dependent alternative splicing of mRNA for NACP, the precursor of non-A beta component of Alzheimer's disease amyloid. Biochem Biophys Res Commun 205, 1366-1372

137. Umapathi T, Chaudhry V, Cornblath D, Drachman D, Griffin J, Kuncl R (2002): Head drop and camptocormia. J Neurol Neurosurg Psychiatry $\underline{73}, 1-7$

138. Unal-Cevik I, Temucin CM (2009): Head Drop in an Elder Parkinson's Disease After Development of Myasthenia Gravis. Mov Disord 24, 2025-2026

139. Wakabayashi K, Tanji K, Mori F, Takahashi H (2007): The Lewy body in Parkinson's disease: molecules implicated in the formation and degradation of alpha-synuclein aggregates. Neuropathology 27, 494-506

140. Wemheuer WM, Benestad SL, Wrede A, Schulze-Sturm U, Wemheuer WE, Hahmann U, Gawinecka J, Schütz E, Zerr I, Brenig B, Bratberg B, Andréoletti O, Schulz-Schaeffer WJ (2009): Similarities between forms of sheep scrapie and Creutzfeldt-Jakob disease are encoded by distinct prion types. Am J Pathol $\underline{175}$, 2566-2273

141. Wilkinson KA, Henley JM (2010): Mechanisms, regulation and consequences of protein SUMOylation. Biochem J 428, 133-145 
142. Windpassinger C, Schoser B, Straub V, Hochmeister S, Noor A, Lohberger B, Farra N, Petek E, Schwarzbraun T, Ofner L et al. (2008): An X-linked myopathy with postural muscle atrophy and generalized hypertrophy, termed XMPMA, is

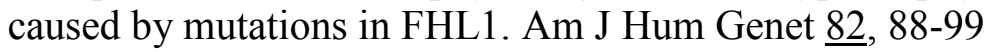

143. Yamawaki M, Kusumi M, Kowa H, Nakashima K (2009): Changes in Prevalence and Incidence of Parkinson's Disease in Japan during a Quarter of a Century. Neuroepidemiology $\underline{32}, 263-269$ 


\section{Veröffentlichung von Teilen dieser Dissertation}

Teile dieser Dissertation sind veröffentlicht worden in folgenden Arbeiten:

Margraf NG, Wrede A, Rohr A, Schulz-Schaeffer WJ, Raethjen J, Eymess A, Volkmann J, Mehdorn MH, Jansen O, Deuschl G (2010): Camptocormia in idiopathic Parkinson's disease: A focal myopathy of the paravertebral muscles. Mov Disord 25, 542-551

Poster: Wrede A, Margraf N, Raethjen J, Deuschl G, Schulz-Schaeffer WJ:

Camptocormia in Parkinson's disease - caused by a myopathy? AD/PD $9^{\text {th }}$ international Conference on Alzheimer's and Parkinson's Disease, 21. bis 25. März 2009 in Prag

Poster: Wrede A, Margraf N, Goebel HH, Deuschl G, Schulz-Schaeffer WJ: Camptocormia in PD is associated with a uniform lesion pattern in paraspinal muscles. Neurowoche 2010, 21. bis 25. September 2010 in Mannheim

\section{Einreichung zur Veröffentlichung}

Der derzeitige Stand der hier präsentierten Ergebnisse ist aktuell zur Veröffentlichung bei Acta Neuropathologica eingereicht:

Wrede A, Margraf NG, Goebel HH, Deuschl G, Schulz-Schaeffer WJ: Myofibrillar disorganization characterizes myopathy of camptocormia in Parkinson's disease. 


\section{Danksagung:}

Herrn Prof. Dr. Wolfgang Brück möchte ich für die sehr freundliche Aufnahme in seine Abteilung, die Ausbildung und die gute Unterstützung danken.

Walter Schulz-Schaeffer möchte ich ausgesprochen herzlich für die sehr gute Zusammenarbeit, die kritische Diskussion aller Daten, die Möglichkeit zur Mitarbeit in seiner Arbeitsgruppe und nicht zuletzt für die Vergabe des Themas und die Betreuung danken.

Unseren „Forschungs-TA's“ Tatjana Pfander, Kerstin Brekerbohm, Manuela Becker, Rita Spohr-Müller und Nadine Ruprecht möchte ich für die Unterstützung, Beratung und die wirklich schöne Zusammenarbeit danken.

Nicht vergessen möchte ich in diesem Zusammenhang auch unser „Routineteam“, bestehend aus Susanne Gloth, Brigitte Maruschak, Doris Bode, Margit Kollhoff, Dorothea HauseReitner und Monika Winkler, die mit vielen Tipps und Tatkraft immer zur Stelle waren.

Ein weiterer Dank geht an die Sektionsassistenten René Markus Müller, Marcel Krebs, Rolf Leuschner und Caroline Obergfell, ohne deren Mitarbeit manche Probe nicht hätte gewonnen werden können.

Nicht unerwähnt lassen möchte ich unser Sekretariat, Cynthia Bunker, Chris Croizier, Gisela Pach und Marion Thöne, die im Hintergrund immer möglich machen, dass Dienst und Forschung in einer Quadratur des Kreises Wirklichkeit werden können.

Unseren klinischen Partnern in Kiel, Herrn Prof. Dr.Günther Deuschl und Herrn Dr. Nils Margraf, die mit ihrer Frage quasi das Projekt initiiert haben, möchte ich für die wichtigen Diskussionen und die exzellente Zusammenarbeit danken.

Nicht zuletzt Herrn Prof. Dr. Hans-Hilmar Goebel möchte ich herzlich für die Diskussion der Befunde und die Faszination für die Muskelpathologie danken. 


\section{Lebenslauf}

Ich, Arne Wrede, wurde am 03.01.1976 in Göttingen als Sohn meiner Eltern Jutta WredeBaumbach, geborene Baumbach, und Erhard Wrede als erstes von zwei Geschwistern geboren.

Seit 1979 habe ich den Kindergarten in Göttingen Weende besucht.

Angeschlossen daran hat sich von 1981 bis 1986 meine Grundschulzeit in der

Leinebergschule, beginnend mit dem Besuch der Vorschule.

Von dort wechselte ich auf die Georg-Christoph-Lichtenberg Gesamtschule in Göttingen. Die

Schulzeit habe ich dort 1995 mit dem Abitur abgeschlossen.

Daran anschließend habe ich meinen Zivildienst in der Abteilung Neurochirurgie, Station 4011, des Universitätsklinikums Göttingen geleistet.

1996 habe ich dann mein Studium der Humanmedizin in Göttingen aufgenommen. Dieses habe ich 2003 mit dem Staatsexamen erfolgreich abgeschlossen. Während des Studiums konnte ich Erfahrungen in Allgemeinarztpraxen in Sattenhausen und Osnabrück sammeln. Weitere Erfahrungen konnte ich im Rahmen einer Auslandsfamulatur in Schweden, Neurologie des Huddinge Universitetssjukhus Stockholm, sammeln. Zwei meiner PJ-Tertiale habe ich in der chirurgischen und der internistischen Abteilung des St. MartiniKrankenhauses in Duderstadt gearbeitet. Während des dritten Tertials war ich im Zentrum Pathologie des Universitätsklinikums in Göttingen bei Herrn Prof. Dr. Füzesi und Herrn Prof. Dr. Radzun tätig.

Nach neun Monaten in Tätigkeit als Arzt im Praktikum in der Neuropathologie des Universitätsklinikums Göttingen wurde mir am 1.10.2004 die Approbation erteilt. Seither bin ich als Assistenzarzt in der Weiterbildung zum Facharzt für Neuropathologie in der Abteilung Neuropathologie der Universitätsmedizin Göttingen, Leitung Prof. Dr. Wolfgang Brück, am Schwerpunkt Prion- und Demenzforschung bei Herrn PD. Dr. Walter Schulz-Schaeffer tätig. Mein besonderes Interesse gilt hierbei der Myopathologie. 